\title{
Modal Analysis of Multiterminal High Voltage Direct Current Transmission
}

\author{
J. E. Dagle
}

December 1993

Prepared for the Bonneville Power Administration under a Related Services Agreement with the U.S. Department of Energy Contract DE-AC06-76RLO 1830

Pacific Northwest Laboratory Richland, Washington 99352

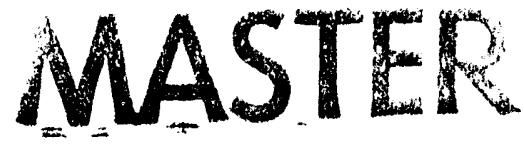




\section{Foreword}

The Pacific HVnC Intertie (PDCI), stretching 846 miles from the Columbia River to Los Angeles, California, has long been a premiere resource in the western North American power system. It was commissioned in 1970 as a $\pm 400-\mathrm{kV}, 1440-\mathrm{MW}$ bipole based upon mercury arc valve technology. Other series groups, added in 1985, used silicon-controlled rectifier (SCR) technology to bring the rating to $\pm 500 \mathrm{kV}$ and $2000 \mathrm{MW}$. Parallel SCR terminals added in 1989 produced its present rating of $\pm 500 \mathrm{kV}$ and $3100 \mathrm{MW}$. Consequently, the PDCI involves three generations of valve technology and a rather complex multiterminal HVDC (MTDC) architecture.

PDCI interactions with the embedding alternating current (ac) system are also complex. This complexity is a natural consequence of the high response speed necessary to HVDC control and of the many dynamic processes linked together by the PDCI itself. It is compounded by the wide range of ac and dc operating conditions. (a) The PDCI itself is very useful for testing these dynamics, and it is by far the most powerful actuator for stability control in the western system. The knowledge base and general infrastructure necessary to safe use of these capabilities are still under development, however. The existing shortage of model-based analysis capabilities is a major impediment in this respect.

Only one computer model now represents the PDCI within the framework of overall western system dynamics. This is the transient stability model coded by Control Technologies, Inc. (CTI) for use in the Electric Power Research Institute (EPRI) Extended Transient-Midterm Stability Package (ETMSP). The Bonneville Power Administration (BPA) is now drawing upon the Pacific Northwest Laboratory for assistance in applying the CTI model to analysis of ac/dc interactions involving the PDCI. The general thrust of effort is that CTI's model be interfaced to and tested against all tools provided by EPRI's Power System Analysis Package (PSAPAC), and that these tools then be used to investigate options for PDCI use in testing and control of western system dynamics. It is expected that this will require some adjustments to the tools, the CTI model, and the data used in western system stability models.

Dr. John F. Hauer

Principal Engineer for Power System Dynamics

Bonneville Power Administration

(a) Hauer, J. F. 1987. "Reactive Power Control As a Means for Enhanced Interarea Damping in the Western U.S. Power System - A Frequency Domain Perspective Considering Robustness Needs." In Application of Static Var Systems for System Dynamic Performance, pp. 79-92. IEEE Publication 87THO187-5-PWR, Institute of Electrical and Electronics Engineers, Inc., New York. 


\section{Summary}

This report describes a first phase of effort in providing the Bonneville Power Administration (BPA) with comprehensive tools for model-based analysis of interactions between the Pacific HVDC Intertie (PDCI) and the alternating current (ac) system that contains it. The work builds upon the transient stability model coded by Control Technologies, Inc. (CTI) for use in the Electric Power Research Institute (EPR) Extended Transient-Midterm Stability Package (ETMSP). The general thrust of effort is that CTI's model be interfaced to and tested against all tools provided by EPRI's Power System Analysis Package (PSAPAC), and that these tools then be used to investigate options for PDCI use in testing and control of western system dynamics. The BPA anticipates that this will require refinements to the tools, the model, and western system case data.

The PSAPAC tool for eigenanalysis is the Small Signal Stability Package (SSSP), useful for performing modal analysis of the multiterminal HVDC (MTDC) system. Such analyses are necessary to design and test an expanded role of the PDCI for power system control. This study focused on testing the application of the MTDC with SSSP. Modifications were made to enable SSSP to read the MTDC model, and the model was adjusted slightly to be consistent with SSSP requirements. The PSAPAC and SSSP tools and the MTDC model were evaluated for accuracy and consistency using several modal analysis techniques, including Prony analysis on ETMSP-generated data.

The results indicate that although SSSP appears to be useful in analyzing the PDCI modes, certain inconsistencies limit the overall usefulness of that approach. The modal frequencies and damping identified by SSSP are inconsistent, indicating that SSSP has difficulty properly analyzing the MTDC representation of the dc systems. This difficulty may stem from problems with the model or with SSSP itself. The Prony analysis performed on the ETMSP results was very useful for crosschecking those results. It also represents a useful modal analysis technique, particularly in conjunction with the SSSP tools.

Additional work is needed to verify that the SSSP tools function properly, particularly with the conversion of BPA power flow format data into that used by the SSSP. Further analysis of the MTDC model is recommended, to verify SSSP operation and to determine which portions of the model are causing the inconsistencies. Specifically, the creation of a simplified MTDC model is recommended, in which SSSP yields consistent results with time-domain simulation. This work will provide an enlanced eigenanalysis modeling capability. In addition, the differences between the new and existing models can be used to identify the particular modeling issues associated with SSSP which are presently resulting in inconsistent results. 


\section{Acknowledgments}

I want to thank Dr. John Hauer, Bonneville Power Administration, for the insightful guidance he provided for this work. My thanks go also to Dennis McNulty and Gary Keenan of BPA, who were instrumental in collecting the files and programs necessary to perform the analysis and offerred their assistance throughout the project as needed. In addition, Dennis' work on the initialization aspects of the model was a great benefit to this study. Their help and support are appreciated.

I am indebted to Dr. Daniel Trudnowski for his technical guidance and for performing the Prony analysis, which was a cornerstone for this effort. Dr. Matthew Donnelly also deserves thanks for his assistance in helping me understand the model.

My appreciation is extended to Graham Rogers of Ontario Hydro for providing his thoughtful comments at the conclusion of the project and for the excellent seminar on the applications of SSSP he hosted earlier this year. 


\section{Contents}

Foreword $\quad \ldots \ldots \ldots \ldots \ldots \ldots \ldots \ldots \ldots \ldots \ldots \ldots \ldots \ldots \ldots$ iii

Summary $\quad \ldots \ldots \ldots \ldots \ldots \ldots \ldots \ldots \ldots \ldots \ldots \ldots \ldots \ldots$

Acknowledgments $\ldots \ldots \ldots \ldots \ldots \ldots \ldots \ldots \ldots \ldots \ldots \ldots \ldots \ldots \ldots \ldots$

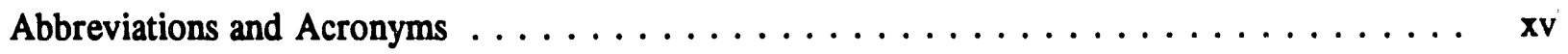

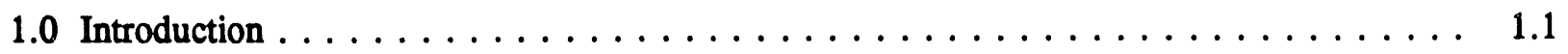

2.0 Multiterminal Direct Current Model $\ldots \ldots \ldots \ldots \ldots \ldots \ldots \ldots \ldots \ldots \ldots \ldots \ldots \ldots \ldots$

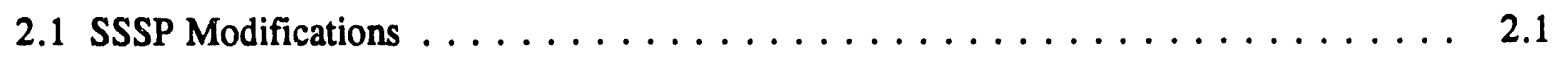

2.2 Equal Eigenvalues $\ldots \ldots \ldots \ldots \ldots \ldots \ldots \ldots \ldots \ldots \ldots \ldots \ldots$

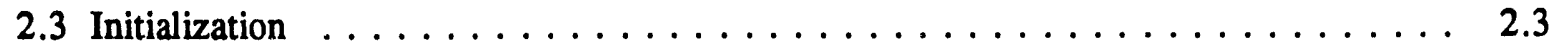

3.0 Modal Analysis on Reduced-Order Model $\ldots \ldots \ldots \ldots \ldots \ldots \ldots$

3.1 Initial Results $\quad \ldots \ldots \ldots \ldots \ldots \ldots \ldots \ldots \ldots \ldots \ldots \ldots \ldots \ldots \ldots \ldots$

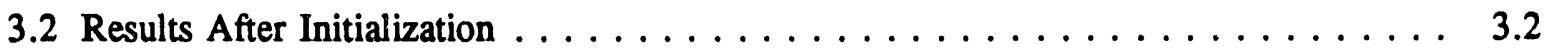

3.3 Mode Shapes $\quad \ldots \ldots \ldots \ldots \ldots \ldots \ldots \ldots \ldots \ldots \ldots \ldots \ldots \ldots$

4.0 Modal Analysis on Western System Model $\ldots \ldots \ldots \ldots \ldots \ldots \ldots$

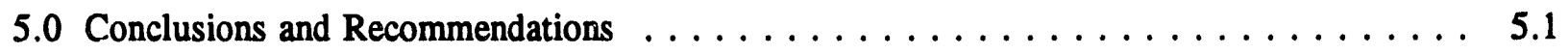

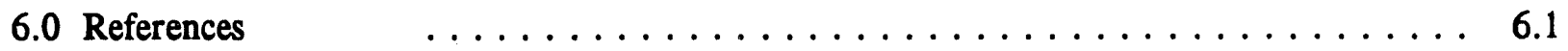

Appendix A - Control Block Diagrams $\ldots \ldots \ldots \ldots \ldots \ldots \ldots \ldots \ldots \ldots \ldots \ldots \ldots$ A.1

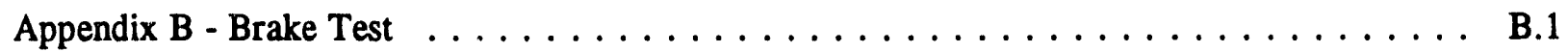

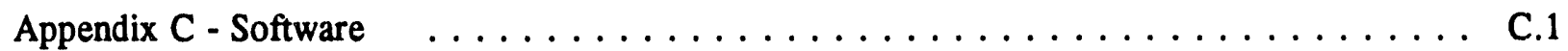




\section{Figures}

2.1 One-Line Diagram of Reduced-Order Model $\ldots \ldots \ldots \ldots \ldots \ldots \ldots$

2.2 Simplified Diagram of Celilo Control Structure $\ldots \ldots \ldots \ldots \ldots \ldots$

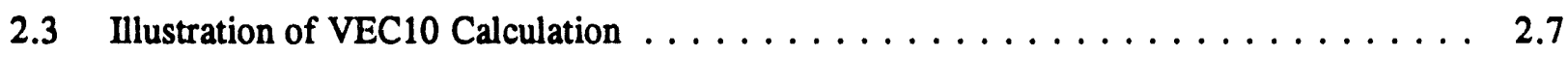

2.4 Celilo Expansion Converter Firing Angle with No Disturbance $\ldots \ldots \ldots \ldots \ldots$

2.5 Celilo Original Converter Firing Angle with No Disturbance $\ldots \ldots \ldots \ldots \ldots$

2.6 Sylmar Expansion Converter Firing Angle with No Disturbance $\ldots \ldots \ldots \ldots$

2.7 Sylmar Original Converter Firing Angle with No Disturbance $\ldots \ldots \ldots \ldots \ldots$

2.8 Intermountain Converter Firing Angle with No Disturbance $\ldots \ldots \ldots \ldots \ldots$

2.9 Adelanto Converter Firing Angle with No Disturbance $\ldots \ldots \ldots \ldots \ldots \ldots$

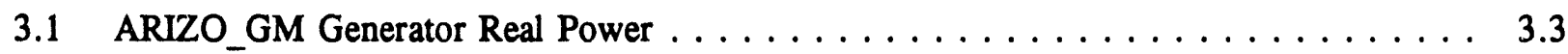

3.2 CANAD_GM Generator Real Power $\ldots \ldots \ldots \ldots \ldots \ldots \ldots \ldots \ldots \ldots$

3.3 NOCAL_GM Generator Real Power $\ldots \ldots \ldots \ldots \ldots \ldots \ldots \ldots$

3.4 NORTH_GM Generator Real Power $\ldots \ldots \ldots \ldots \ldots \ldots \ldots \ldots \ldots$

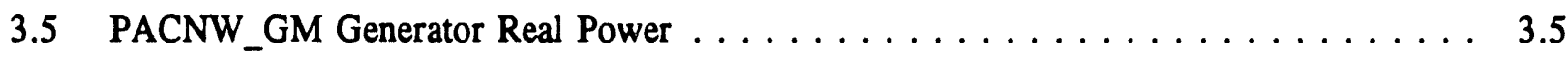

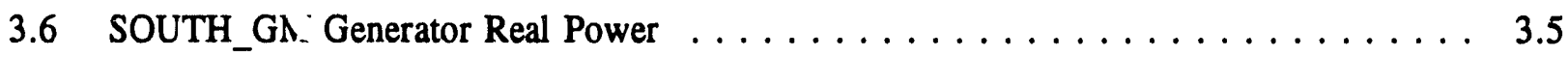

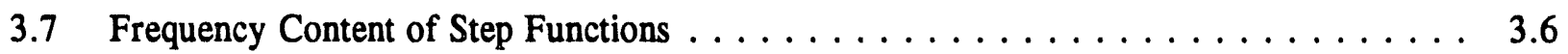

3.8 MASS and PEALS Mode Shape with No DC (0.3449 Hz, 0.0492 Damping) $\ldots \ldots$. . 3.9

3.9 Aesops Mode Shape (Probe @ ARIZO_G1, 0.4079 Hz, 0.2436 Damping) . . . . . . . 3.10

3.10 Aesops Mode Shape (Probe @ SOUTH_G1, 0.4084 Hz, 0.2430 Damping) . . . . . 3.10

3.11 Aesops Mode Shape (Probe @ MONTA_G1, 0.4087 Hz, 0.2461 Damping) . . . . . . . 3.11

3.12 Aesops Mode Shape (Probe @ BUTAH_G1, $0.5961 \mathrm{~Hz}, 0.0313$ Damping) $\ldots \ldots \ldots 3.11$

3.13 Aesops Mode Shape (Probe @ CANAD_G1, 0.7081 Hz, 0.0529 Damping) . . . . . . 3.12 
3.14 Aesops Mode Shape (Probe @ NOCAL_G1, 0.7977 Hz, 0.0106 Damping) . . . . . . 3.12

3.15 Aesops Mode Shape (Probe @ PACNW_G1, $1.3772 \mathrm{~Hz}, 0.0172$ Damping) . . . . . . 3.13

3.16 Aesops Mode Shape (Probe @ NORTH_G1, $1.4131 \mathrm{~Hz}, 0.0180$ Damping) $\ldots \ldots \ldots 3.13$

3.17 Prony Mode Shape $(0.34 \mathrm{~Hz}, 0.039$ Damping $) \ldots \ldots \ldots \ldots \ldots \ldots$

3.18 Prony Mode Shape $(0.70 \mathrm{~Hz}, 0.016$ Damping $) \ldots \ldots \ldots \ldots \ldots \ldots$

3.19 Prony Mode Shape $(0.81 \mathrm{~Hz}, 0.013$ Damping $) \ldots \ldots \ldots \ldots \ldots \ldots$

3.20 Prony Mode Shape $(0.96 \mathrm{~Hz}, 0.019$ Damping $) \ldots \ldots \ldots \ldots \ldots$

3.21 Prony Mode Shape $(1.17 \mathrm{~Hz},-0.014$ Damping - Unstable $) \ldots \ldots \ldots \ldots$

3.22 PEALS (Arnoldi) Mode Shape $(0.799 \mathrm{~Hz}, 0.011$ Damping) $\ldots \ldots \ldots \ldots \ldots . \ldots . \ldots$

4.1 92LW Model Mode Shape without MTDC (0.8305 Hz, 0.0646 Damping $) \ldots \ldots . \ldots .4$

4.2 92LW Model Mode Shape with MTDC Modelled (0.8315 Hz, 0.0666 Damping) $\ldots$. . 4.4

4.3 Unit GEYSER D Response to Palo Verde - Devers Line Outage . . . . . . . . . . . 4.6

4.4 Unit COLSTP 4 Response to Palo Verde - Devers Line Outage . . . . . . . . . . 4.6

4.5 Unit COMANCHE Response to Palo Verde - Devers Line Outage $\ldots \ldots \ldots$. . . . . 4.7

4.6 Unit CORONAD2 Response to Palo Verde - Devers Line Outage . . . . . . . . . . . 4.7

4.7 Unit OMAR G Response to Palo Verde - Devers Line Outage $\ldots \ldots \ldots \ldots \ldots$

4.8 Unit NEWMN4G1 Response to Palo Verde - Devers Line Outage . . . . . . . . . 4.8

4.9 Line PALOVRDE -DEVEers Response to Palo Verde - Devers Line Outage . . . . . . 4.9

4.10 Line LOSTCANY - CURECANT Response to Palo Verde - Devers Line Outage _ . . 4.9

4.11 Line BEARS - BONANZA Response to Palo Verde - Devers Line Outage $\ldots \ldots$. . . 4.10

4.12 Line TAFT - DWORSHAK Response to Palo Verde - Devers Line Outage . . . . . . 4.10

4.13 Line MALIN - ROUND MT Response to Palo Verde - Devers Line Outage . . . . . 4.11

4.14 Line HUNTNGTN - PINTO Response to Palo Verde - Devers Line Outage . . . . . . . 4.11 
A.1 Celilo Converter Control Block Diagram $\ldots \ldots \ldots \ldots \ldots \ldots \ldots \ldots \ldots$

A.2 Sylmar Converter Control Block Diagram $\ldots \ldots \ldots \ldots \ldots \ldots \ldots \ldots \ldots \ldots$

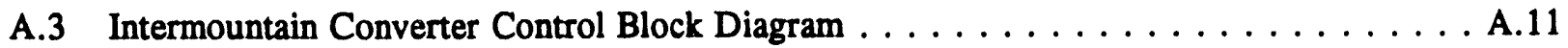

A.4 Adelanto Converter Control Block Diagram $\ldots \ldots \ldots \ldots \ldots \ldots \ldots \ldots \ldots$. . . . . . . . .

B.1 Case 92LW1T010: Malin - Round Mountain Line Real Power . . . . . . . . . . . B.3

B.2 Case 92LW1T012: Malin - Round Mountain Line Real Power . . . . . . . . . . B.3

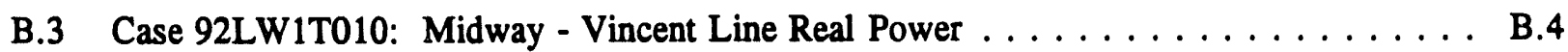

B.4 Case 92LW1T012: Midway - Vincent Line Real Power $\ldots \ldots \ldots \ldots \ldots \ldots$

B.5 Case 92LW1T010: Nelway - Boundary Line Real Power $\ldots \ldots \ldots \ldots \ldots \ldots$. . . . B.5

B.6 Case 92LW1T012: Nelway - Boundary Line Real Power $\ldots \ldots \ldots \ldots \ldots$. . . . B.5

B.7 Case 92LW1T010: Chief Joseph Bus Voltage $\ldots \ldots \ldots \ldots \ldots \ldots \ldots \ldots$

B.8 Case 92LW1T012: Chief Joseph Bus Voltage $\ldots \ldots \ldots \ldots \ldots \ldots \ldots \ldots \ldots$

B.9 Case 92LW1T010: Malin Bus Voltage $\ldots \ldots \ldots \ldots \ldots \ldots \ldots \ldots \ldots \ldots$

B.10 Case 92LW1T012: Malin Bus Voltage $\ldots \ldots \ldots \ldots \ldots \ldots \ldots \ldots \ldots$

B.11 Trapezoidal: Langdon Voltage Angle $\ldots \ldots \ldots \ldots \ldots \ldots \ldots \ldots \ldots \ldots$

B.12 Runge-Kutta Fourth Order: Langdon Voltage Angle $\ldots \ldots \ldots \ldots \ldots \ldots \ldots$

B.13 Trapezoidal: Cranbrook Voltage Angle $\ldots \ldots \ldots \ldots \ldots \ldots \ldots \ldots \ldots$

B.14 Runge-Kutta Fourth Order: Cranbrook Voltage Angle . . . . . . . . . . . . . B.9

B.15 Trapezoidal: Chief Joseph Voltage Angle $\ldots \ldots \ldots \ldots \ldots \ldots \ldots$. . . . . . . . . .

B.16 Runge-Kutta Fourth Order: Chief Joseph Voltage Angle $\ldots \ldots \ldots \ldots \ldots \ldots$

B.17 Trapezoidal: Malin Voltage Angle $\ldots \ldots \ldots \ldots \ldots \ldots \ldots \ldots \ldots \ldots \ldots$

B.18 Runge-Kutta Fourth Order: Malin Voltage Angle $\ldots \ldots \ldots \ldots \ldots \ldots \ldots$

B.19 Frequency Response of Sundance PSS $\ldots \ldots \ldots \ldots \ldots \ldots \ldots \ldots \ldots \ldots$

B.20 Frequency Response of Mica PSS $\ldots \ldots \ldots \ldots \ldots \ldots \ldots \ldots \ldots \ldots \ldots$ 


\section{Tables}

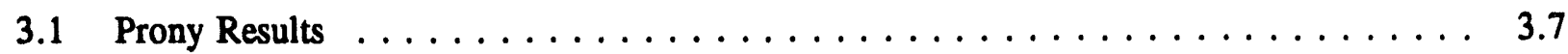

3.2 Aesops Results $\ldots \ldots \ldots \ldots \ldots \ldots \ldots \ldots \ldots \ldots \ldots \ldots \ldots \ldots$

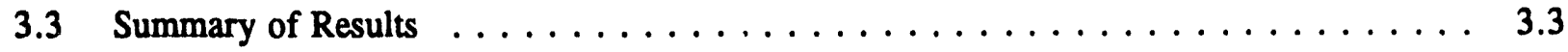

4.1 Eigenvalues in $92 \mathrm{LW}$ Model Without MTDC $(0.1$ to $1.5 \mathrm{~Hz}) \ldots \ldots \ldots \ldots . \ldots$

4.2 Eigenvalues in 92LW Model with MTDC Included $(0.1$ to $1.5 \mathrm{~Hz}) \ldots \ldots \ldots$

4.3 Prony Results for $92 \mathrm{LW}$ Model $\ldots \ldots \ldots \ldots \ldots \ldots \ldots \ldots \ldots \ldots$

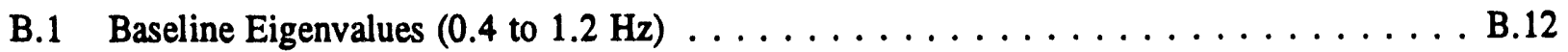

B.2 Eigenvalues with MICA PSS Removed $(0.4$ to $1.2 \mathrm{~Hz}) \ldots \ldots \ldots \ldots \ldots \ldots$ 


\title{
Abbreviations and Acronyms
}

\author{
ABB Asea Brown Boveri \\ ac alternating current \\ BPA Bonneville Power Administration \\ CTI Control Technologies, Inc. \\ dB decibel(s) \\ dc direct current \\ ECA2 Existing Converter Adaptation 2 \\ EMTP Electromagnetic Transients Program \\ EPRI Electric Power Research Institute \\ ETMSP Extended Transient-Midterm Stability Package \\ $\mathrm{Hz} \quad$ hertz \\ ICMC Inverter Current Margin Compensation \\ IPP Intermountain Power Project \\ LADWP Los Angeles Department of Water and Power \\ MASS Multi-Area Small Signal Stability \\ MTDC multiterminal HVDC \\ PCMC Pole Current Margin Compensation \\ PDCI Pacific HVDC Intertie \\ PEALS Program for Eigenvalue Analysis of Large Systems \\ PNL Pacific Northwest Laboratory \\ PSAPAC Power System Analysis Package \\ PSS Power System Stabilizer \\ SCR silicon-controlled rectifier \\ SSSP Small Signal Stability Package \\ W watt(s) \\ WSCC Western Systems Coordinating Council
}




\subsection{Introduction}

The interconnected power system in the western United States and Canada has two dc lines that transmit power for long distances across the system. The first, the Pacific HVDC Intertie (PDCI), transmits power between the Bonneville Power Administration (BPA) in northern Oregon and the Los Angeles Department of Water and Power (LADWP) in southern California. The second is the Internountain Power Project (IPP) dc transmission system, providing east-to-west power transmission from Utah to southern California.

The existing ac system has some limitations on power transfers because of power system oscillations at the higher power transfer levels. Use of the dc transmission systems as a control actuator to mitigate these oscillations has been tried in the past and is proposed for the future iviartin et al. 1992). However, significant problems associated with adverse modal interaction are a concern. To alleviate that concern, accurate modeling of the controls and interactions of the dc line with the rest of the system is necessary.

Although "real-world" frequency-domain measurements are needed for the final design of HVDC modulation, careful use of analytic tools to model the characteristics of the devices is also of paramount importance to the design and implementation of dc modulation. These tools include both time-domain simulation and eigenanalysis. The Power Systems Analysis Package (PSAPAC), developed by the Electric Power Research Institute (EPRI), includes a time-domain simulation tool called the Extended Transient-Midterm Stability Package (ETMSP) and an eigenanalysis tool called the Small Signal Stability Package (SSSP).

In this report, the analysis of detailed HVDC transmission control models using these tools is documented, and cross-validation among the tools to verify their accuracy is described. Shortcomings are identified and, if possible within the scope of this work, have been circumvented.

Recommendations for improving the analysis tools or model are provided.

In Section 2, the Multiterminal Direct Current model is described. Section 3 documents the analysis of the reduced-order model. Modal analysis of the western system model is presented in Section 4, followed by the conclusions and recommendations in Section 5. Appendixes A through C provide additional information and the software used to do the analyses. 


\subsection{Multiterminal Direct Current Model}

The multiterminal direct current (MTDC) model used in this project simulates both the PDCI from Celilo, Oregon, to Sylmar, California, and the IPP 'ine from Delta, Utah, to Adelanto, California.

The PDCI was energizad in 1970 , with both terminals rated at $\pm 400 \mathrm{kV}$ and $1800 \mathrm{~A}$. Valve technology of the time-6-pulse mercury arc converters-was used in the terminals. The converters' rating was raised to $2000 \mathrm{~A}$ in 1979 . In 1985 , the terminals were upgraded to $\pm 500 \mathrm{kV}$ with the addition of 6-pulse solid-state converters in series to each pole. The latest expansion occurred in 1989; with the addition of 12-pulse thyristor converters in parallel with the old terminals. The new bipole converters were then rated at $\pm 500 \mathrm{kV}$ and $1100 \mathrm{~A}$ (Hammad et al. 1993).

The IPP HVDC line, energized in 1986, uses the newer 12-pulse thyristor converter technology, rated at $\pm 500 \mathrm{kV}$ and $1600 \mathrm{MW}$ continuous rating, with a 2.0 per unit rating for up to 1 second upon the loss of a pole and 1.5 per unit continuous single-pole rating, or $1200 \mathrm{MW}$ (Martin et al. 1992).

The capability to model MTDC systems is particularly important for the PDCI, as it contains two separate converter stations in parallel at either end of the dc line. In addition, accurate modeling of the unique controls (the new converter controls replaced much of the existing converter controls, although many of the control aspects of the existing converters remain in a hybrid scheme) is important for accurate representation of this system in planning models. The MTDC models have been developed for each, based on previous Electromagnetic Transients Program (EMTP) studies, by Control Technologies, Inc. (CTI), created to be used with ETMSP (Smith et al. 1992).

The MTDC model is included in a reduced-order model, also provided by CTI, which is useful for checking the operation of the MTDC model without the complexities associated with running a large model. This reduced-order model, fashioned after the western United States power system, includes 19 machines in eight separate areas representative of the equivalent inertias in the actual system. A one-line diagram of the MTDC transmission lines in the reduced-order model is given in Figure 2.1.

The control block diagrams, from the document prepared by CTI (Smith et al. 1992), are given in Appendix A for reference.

\subsection{SSSP Modifications}

It was necessary to modify the FLODA5 module in both SSSP programs MASS ${ }^{(a)}$ and PEALS. ${ }^{(b)}$ MASS is an eigenanalysis tool useful for finding all of the modes associated with all states of a relatively small system. PEALS, on the other hand, is designed to find only specific

(a) Multi-Area Small Signal Stability

(b) Program for Eigenvalue Analysis of Large Systems 


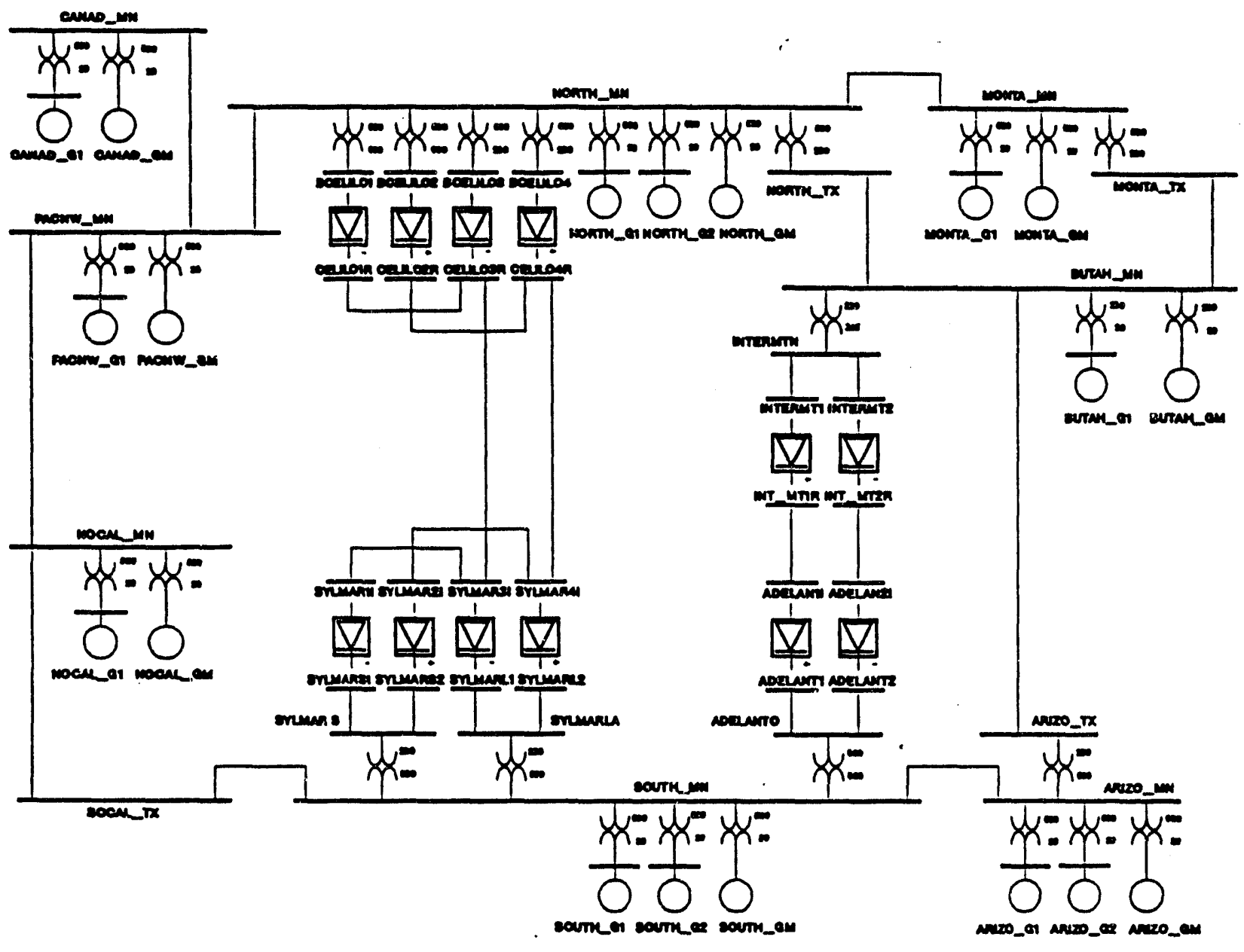

Figure 2.1. One-Line Diagram of Reduced-Order Model

modes of states corresponding to generator speed. The PEALS is useful for performing modal analysis on large power system models. The FLODA5 module is used to read BPA binary power flow output data. In its original state, it is not equipped to read MTDC data, which is in a different format. The capability of the BPA POWERFLOW program to accept MTDC data requires a variant of the standard program. Consequently, variations are required to the FLODA5 module. Both MASS and PEALS, without this needed modification, terminate execution with error messages indicating that the converter data present in the dynamic data file were not found in the load flow.

Using the previously modified FLODA5 module for ETMSP as a guide (performed by BPA and CTI staff to read the BPA MTDC data into ETMSP), the FLODA5 modules in both MASS and PEALS were modified in a similar manner, thus enabling these programs to read BPA MTDC data. Successful implementation of these changes was indicated when MASS and PEALS executed for the reduced-order model without error messages.

One way to independently verify that the changes to FLODA5 were properly made would be to run an identical case using IPFLOW. IPFLOW is a load flow program companion to ETMSP, with 
similar data formats (eliminating the need to convert data from one program format to another). A comparison was made of the BPA power flow and the IPFLOW results for the reduced-order model without the dc line data; the results were similar. Some problems were encountered while running ETMSP with the MTDC line data reading IPFLOW power flow data. The error messages are similar to those encountered when reading BPA POWERFLOW data without modifications made to the FLODA5 module. Thus, there is suspicion that modifications might be needed to FLOPSF (similar to FLODA5, except it is responsible for reading IPFLOW output data) to fix this problem, but this was not confirmed.

The modified SSSP programs are attached in Appendix C.

\subsection{Equal Eigenvalues}

When PEALS was run with the MTDC model, an error message indicated that equal eigenvalues were found. Because PEALS formulates an upper Hessenberg matrix to be used in the QR algorithm, the program is unable to diagonalize the matrix if there are equal eigenvalues (Ontario Hydro 1993). These equal eigenvalues had time constants of $T=0$ and $T=\infty$.

Because of the time constants involved, it was apparent that they were not related to the dynamics of the HVDC controls. The impedances of the short ac lines connecting the converters from the ac commutating buses to intermediate ac buses were increased. Both the line resistance and reactance were changed from $10^{-5}$ to $10^{-4}$ per unit, making them higher than the zero-impedance threshold default of the program. These impedances appear to have been arbitrarily chosen as very small impedances, the actual magnitude being determined qualitatively rather than quantitatively. Thus, this change does not represent a significant departure from modeling accuracy. Increasing the impedances solved the equal eigenvalue error at $\mathrm{T}=0$.

The second fix to the model was to change the impedance of the short dc lines connecting the existing and expansion converters at Celilo and Sylmar. While keeping the inductances of these short lines the same at $620 \mathrm{mH}$, the resistance was changed from 0.06 to $1.00 \Omega$. The magnitude of these short lines compared to that of the long lines connecting Celilo and Sylmar is very small, so this change does not represent a dramatic change in the model response. The resistance change fixed the equal eigenvalue error at $\mathrm{T}=\infty$.

\subsection{Initialization}

The HVDC model requires initialization to set the controls to provide output consistent with the steady-state load flow solution when the simulation starts. This is accomplished by reading key parameters, such as alpha, from the load flow data and back-calculating to derive key variables that will provide the desired output from strategic points in the control architecture (such as at an integrator output). Some difficulties were encountered with the initialization of the controls in the original MTDC model. In conjunction with work performed by BPA staff, these initialization problems were analyzed, and appropriate modeling changes were made, addressing these problems. 
The modeling changes included the following:

- The initial value for the integrator in the Celilo Pole Current Margin Compensation (PCMC) control and the Sylmar Inverter Current Margin Compensation (ICMC) control was derived by back-calculating from the desired alpha from the old converter (from the load flow) to determine the value at the integrator output that gives this desired result. This computation did not take into account the new converter, which is also controlled from the PCMC and ICMC.

- A slack variable to properly initialize the old converters (based on the load flow alpha) was added to the model, based on an Asea Brown Boveri (ABB) diagram. This replaces the initialization of the PCMC and ICMC integrators (above). The new converters have integrators that are similarly initialized.

- The variable vec10 in the Existing Converter Adaptation 2 (ECA2) blocks was changed from a high-speed feedback to a proportional plus high-gain integral control to eliminate mismatches in the calculations for the variables vec10 and vcae at $t=0$.

The first two changes are interrelated and must be made together. An integrator block given by the transfer function $1 / \mathrm{s}$ must have an input of zero at $t=0$, with the initial output determined by the user, which can be nonzero. In the Celilo and Sylmar controls, an integrator is associated with the firing angle control for the expansion converters, with the initial condition determined by backcalculating the desired firing angle (from the load flow solution) to determine the appropriate initial value for the integrator. The older converters do not have an integrator associated with the firing angle control, so the desired firing angle for $t=0$ (from the load flow solution) for these converters was used to determine the initial value of the integrator in the PCMC and ICMC controls. This was inappropriate, because the PCMC and ICMC control the current order that is fed to both the old and new converter controls. As a result, the initial value of the integrator in the PCMC and ICMC does not have enough degrees of freedom to be explicitly specified to arrive at the correct value of the old converter firing angle.

A slack variable, which is essentially a constant offset, was added into the converter control for the older converters, its placement determined by ABB drawings. The constant offset provides the same function as specifying an initial value of an integrator.

In implementing these changes, the initial value of the integrator in the PCMC and ICMC was set to zero (the output of this integrator representing current error). The slack variable was inserted into the converter controllers for the older converters, deriving its value from the desired firing angle, and back-calculating to the point of insertion the desired value to result in the appropriate firing angle. This represented a total of eight changes to the model: two changes each for the positive and negative poles of the Celilo and Sylmar controls. These changes are illustrated for the Celilo converters in Figure 2.2, which is similar to the basic function of the Sylmar converters as well.

The anal initialization change to the model was associated with the existing converter voltage control (at both Celilo and Sylmar), which provides a correction to the firing angle based on voltage deviation. This control utilized a high-speed feedback with which ETMSP had difficulty; in one instance, the output was different from the input through a block with unity gain, no dynamics, and 


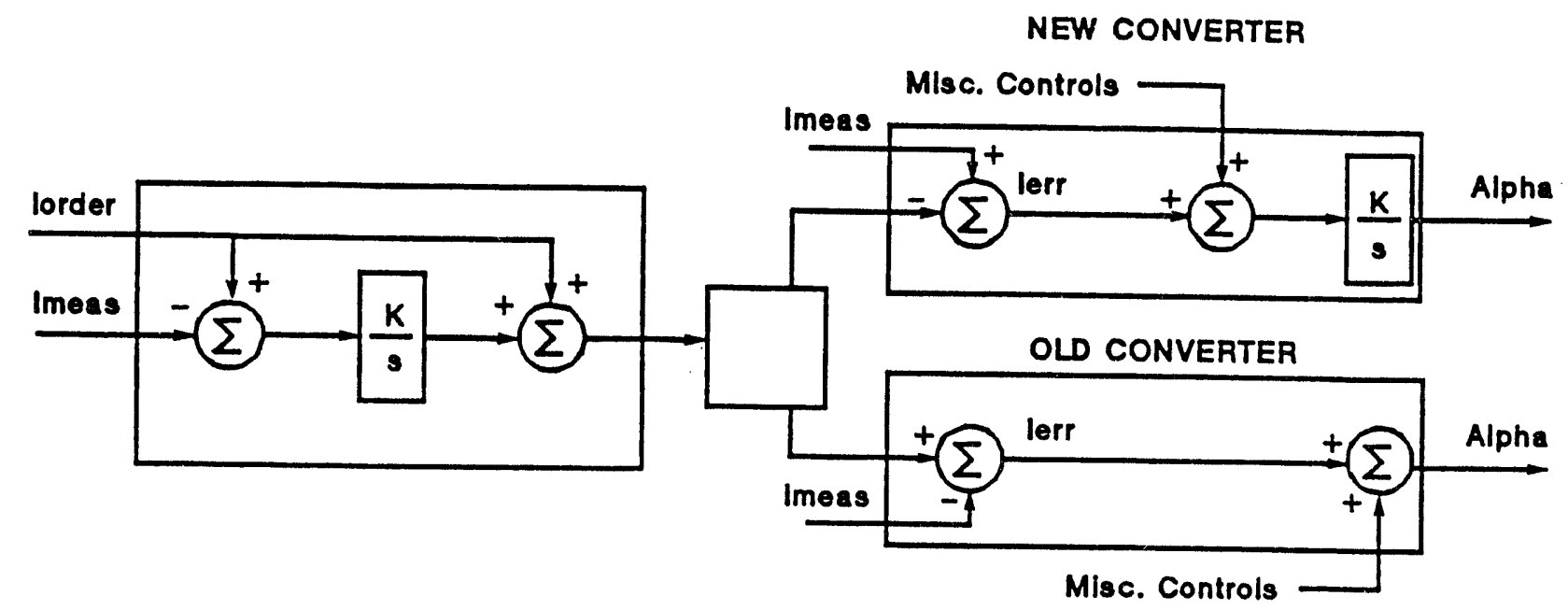

(a) Initial Model

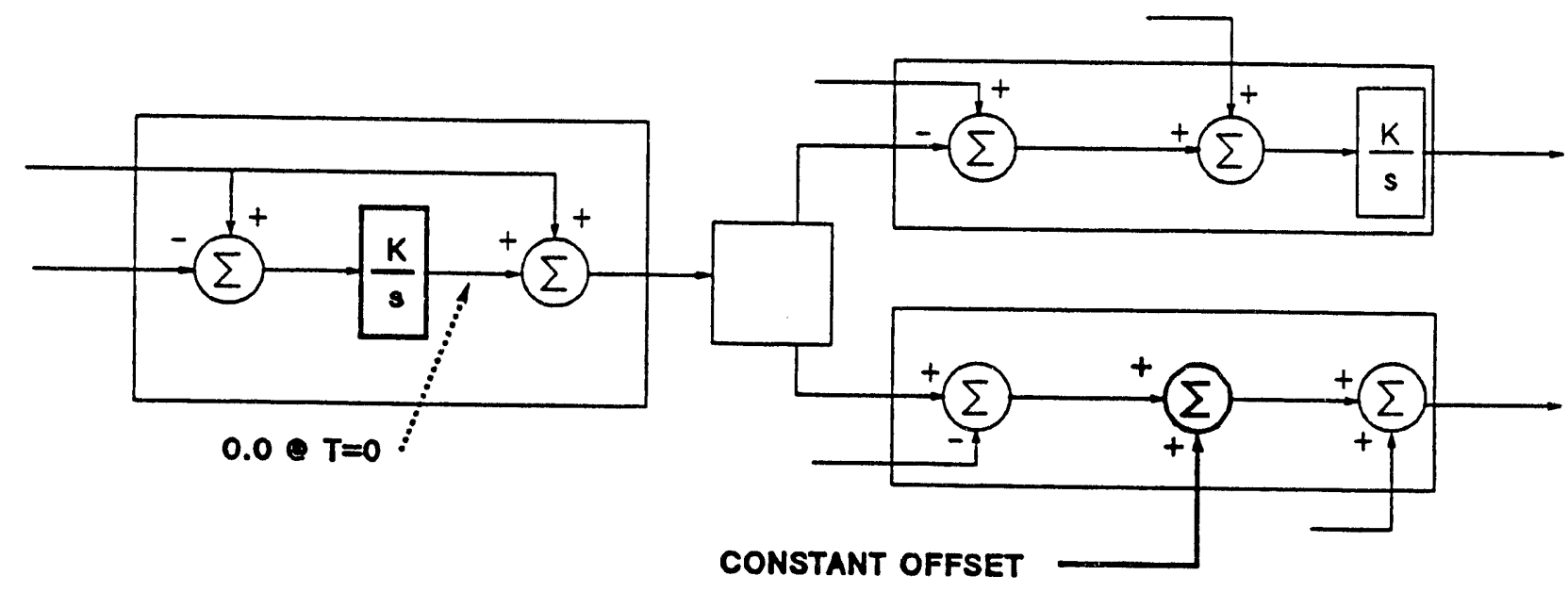

(b) Initialization Change

Figure 2.2. Simplified Diagram of Celilo Control Structure

no limit violations. This problem (a difficulty in the numerics of ETMSP rather than a modeling error) was corrected by replacing the high-speed feedback with a proportional plus high-gain integral control. This is shown in Figure 2.3. 


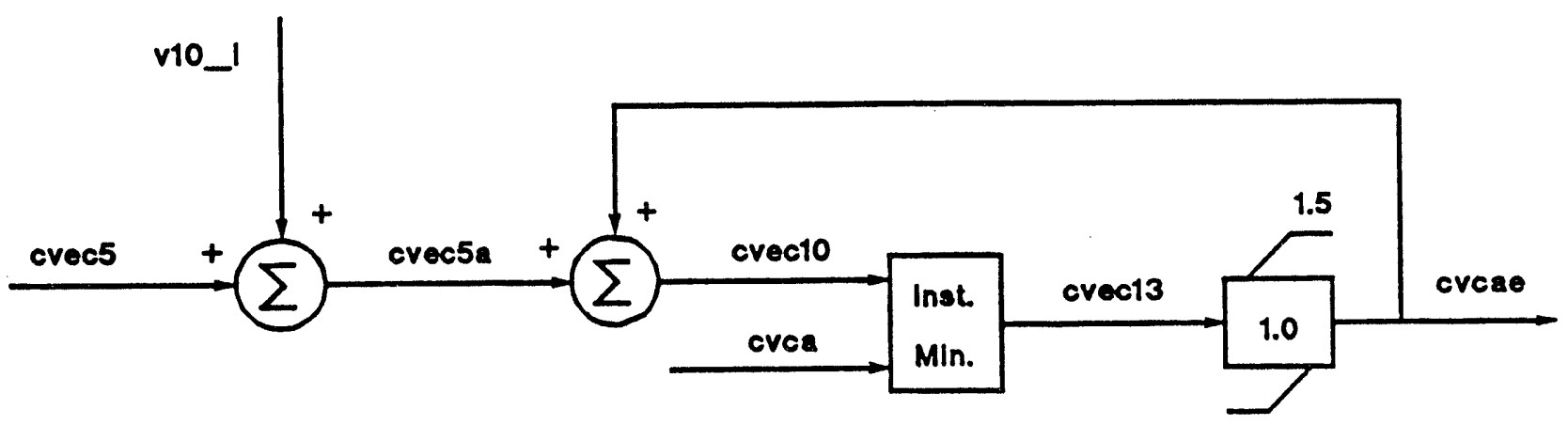

0.0

(a) Celilo Initially

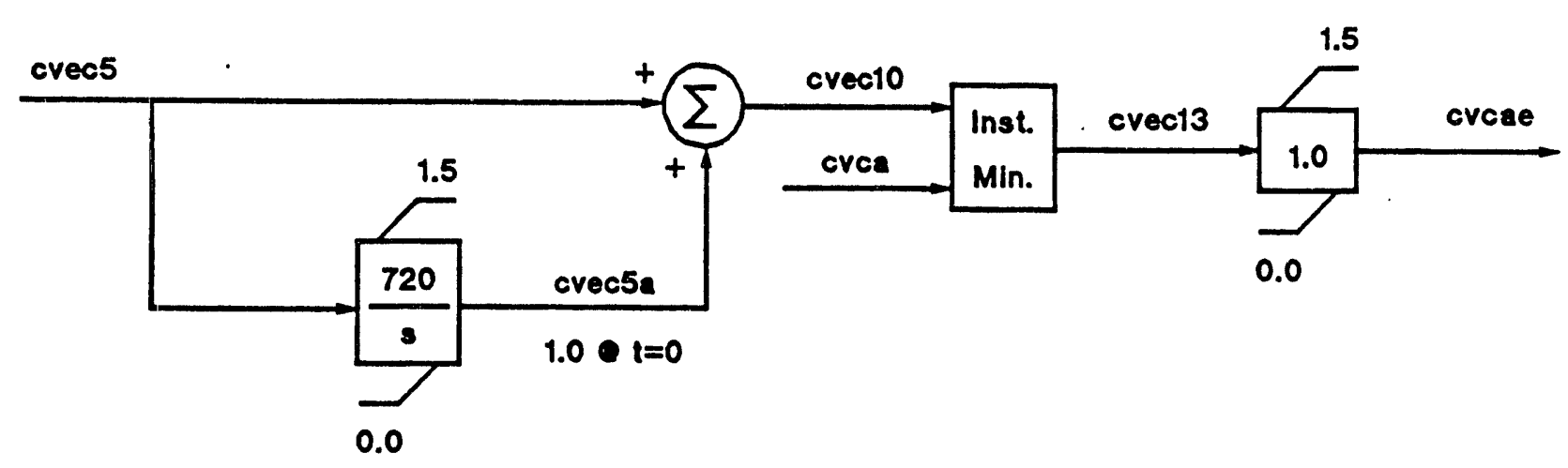

(b) Celilo Modified

Figure 2.3. Illustration of VEC10 Calculation

Significant differences were found between the MTDC model PNL obtained from CTI (dated 3/20/92) and the version BPA used to perform the initialization corrections, also obtained from CTI (dated 7/07/92). For example, in the earlier version of the model, the ICMC integrator initial value (described above) was already set to zero. Many other changes were apparent between these two versions of the model, which were not explored in detail. Future analysis should be centered on a single model for consistency among organizations.

The initialization corrections described above were implemented and tested using a nodisturbance ETMSP simulation. There was a marked improvement in the stability of the variables, with the new model showing only slight variations in key variables (such as alpha) over several seconds of simulation (compared to dramatic changes in the noninitialized model over fractions of seconds). The converter firing angles (alpha) are illustrated in Figures 2.4 through 2.9 for one pole of each converter, showing the response after the initialization changes were incorporated compared to the response without any initialization changes. 


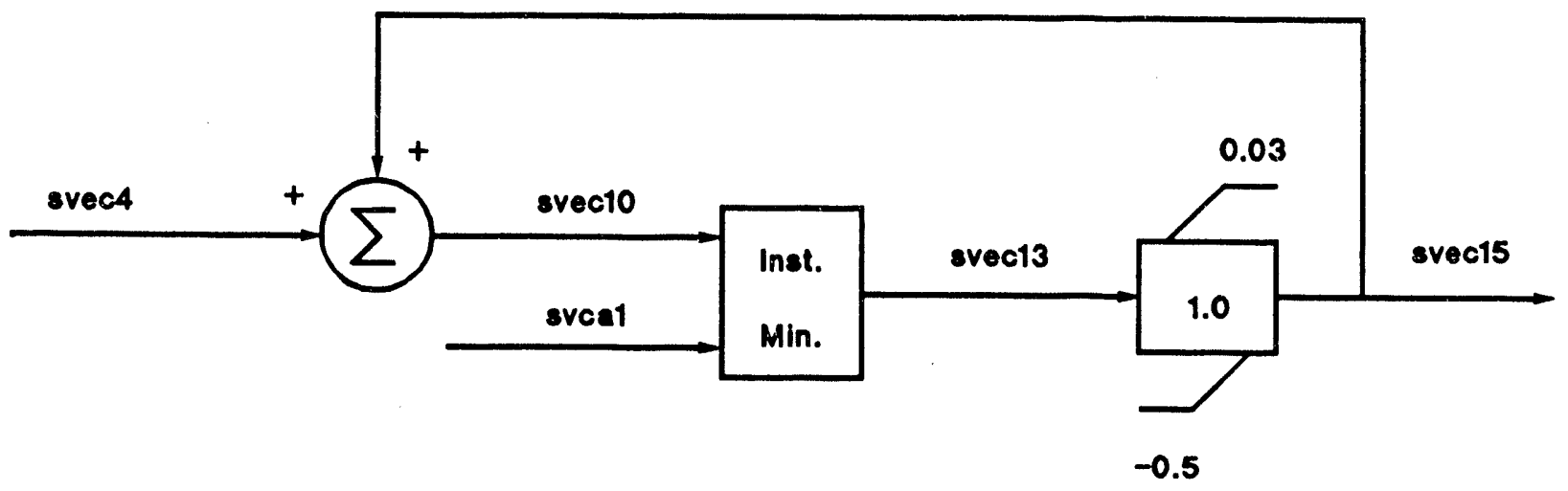

(c) Sylmar Initially

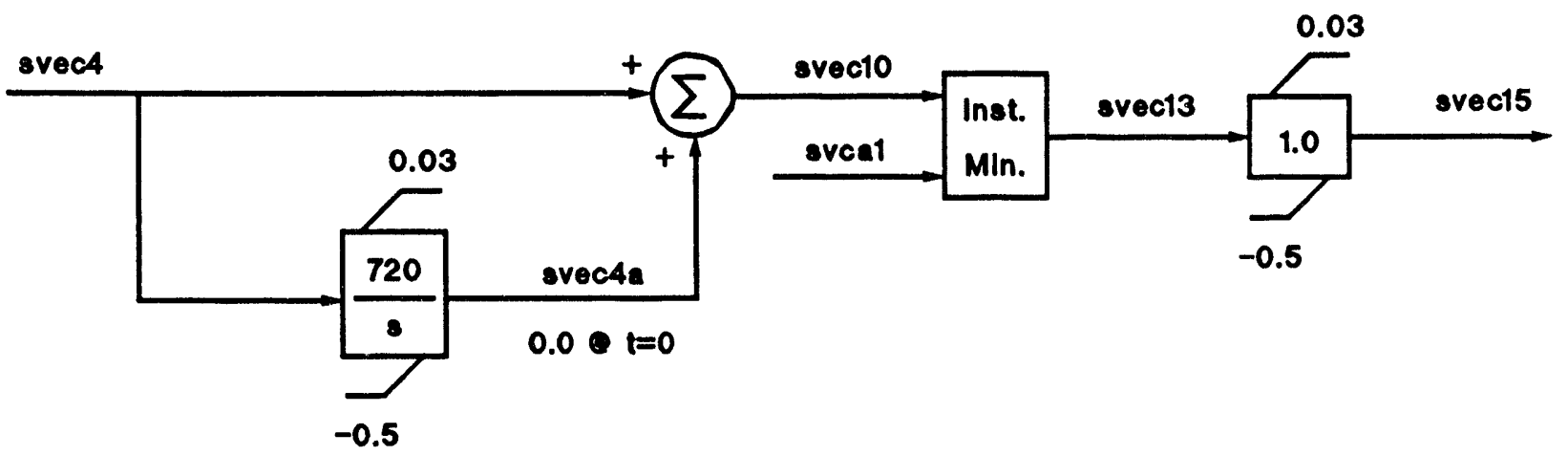

(d) Sylmar Modified

Figure 2.3. (contd)

The MTDC models, with the equal eigenvalue problem corrected and the initialization changes performed, are attached in Appendix C. 


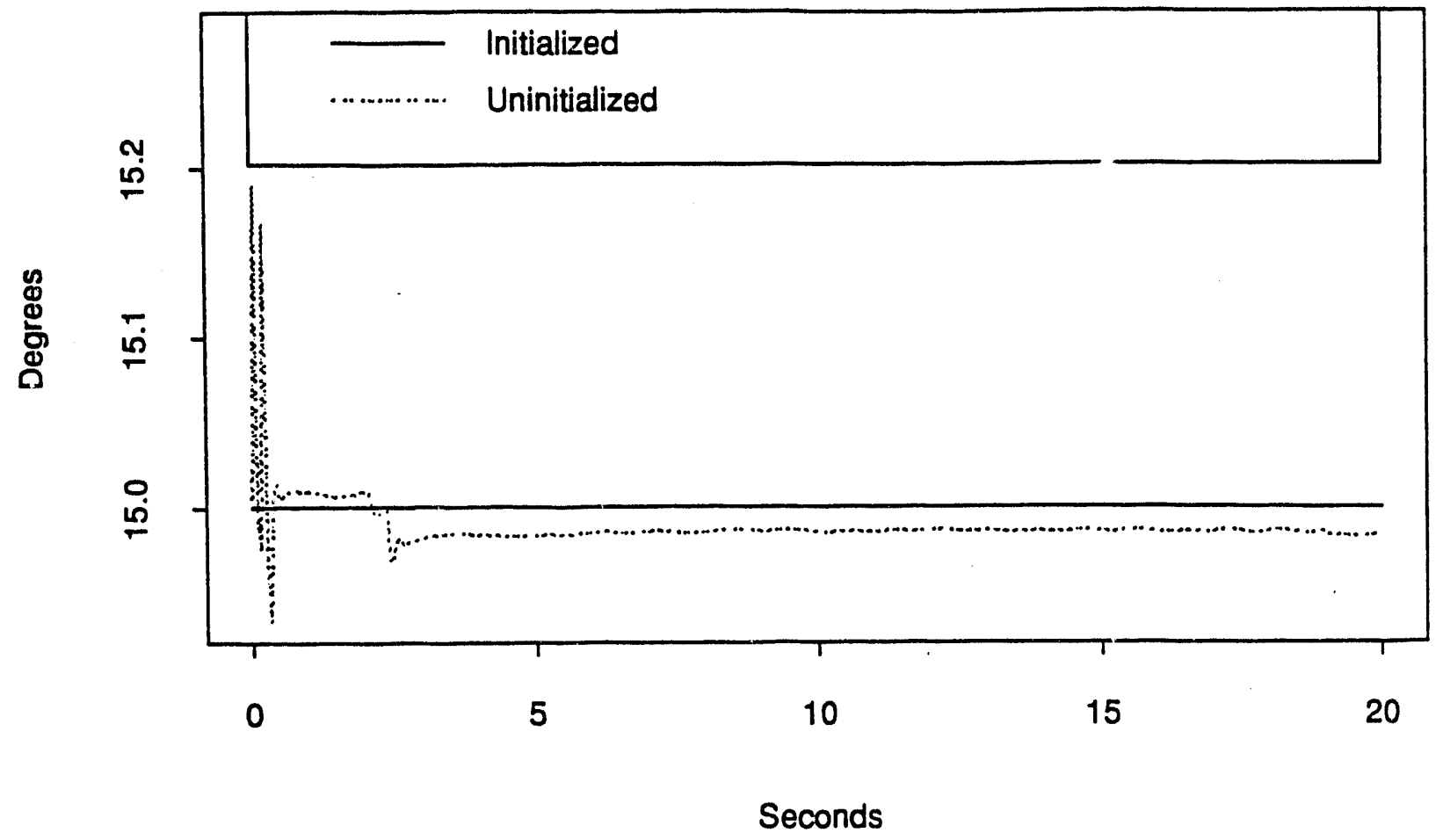

Figure 2.4. Celilo Expansion Converter Firing Angle with No Disturbance

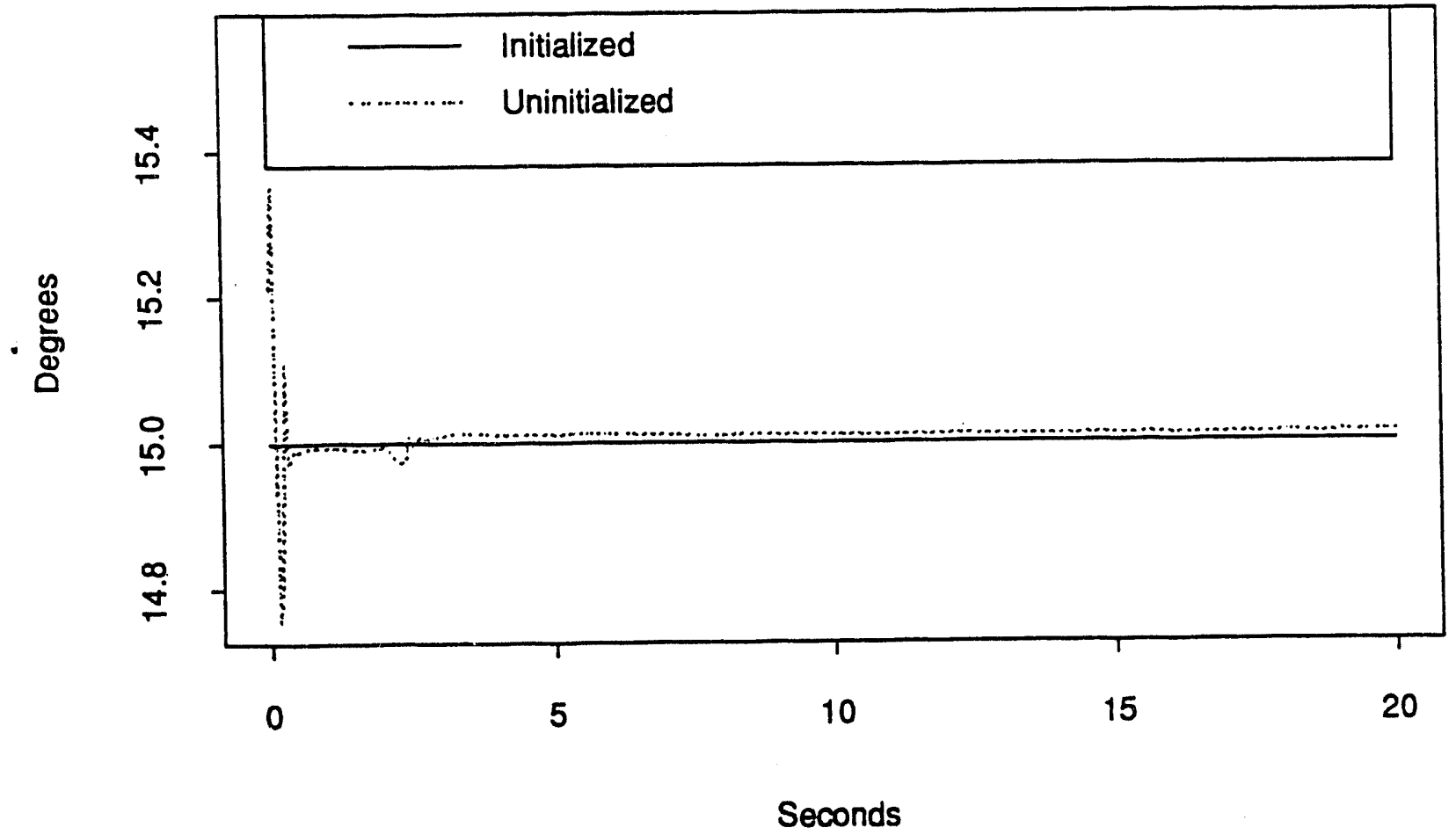

Figure 2.5. Celilo Original Converter Firing Angle with No Disturbance 


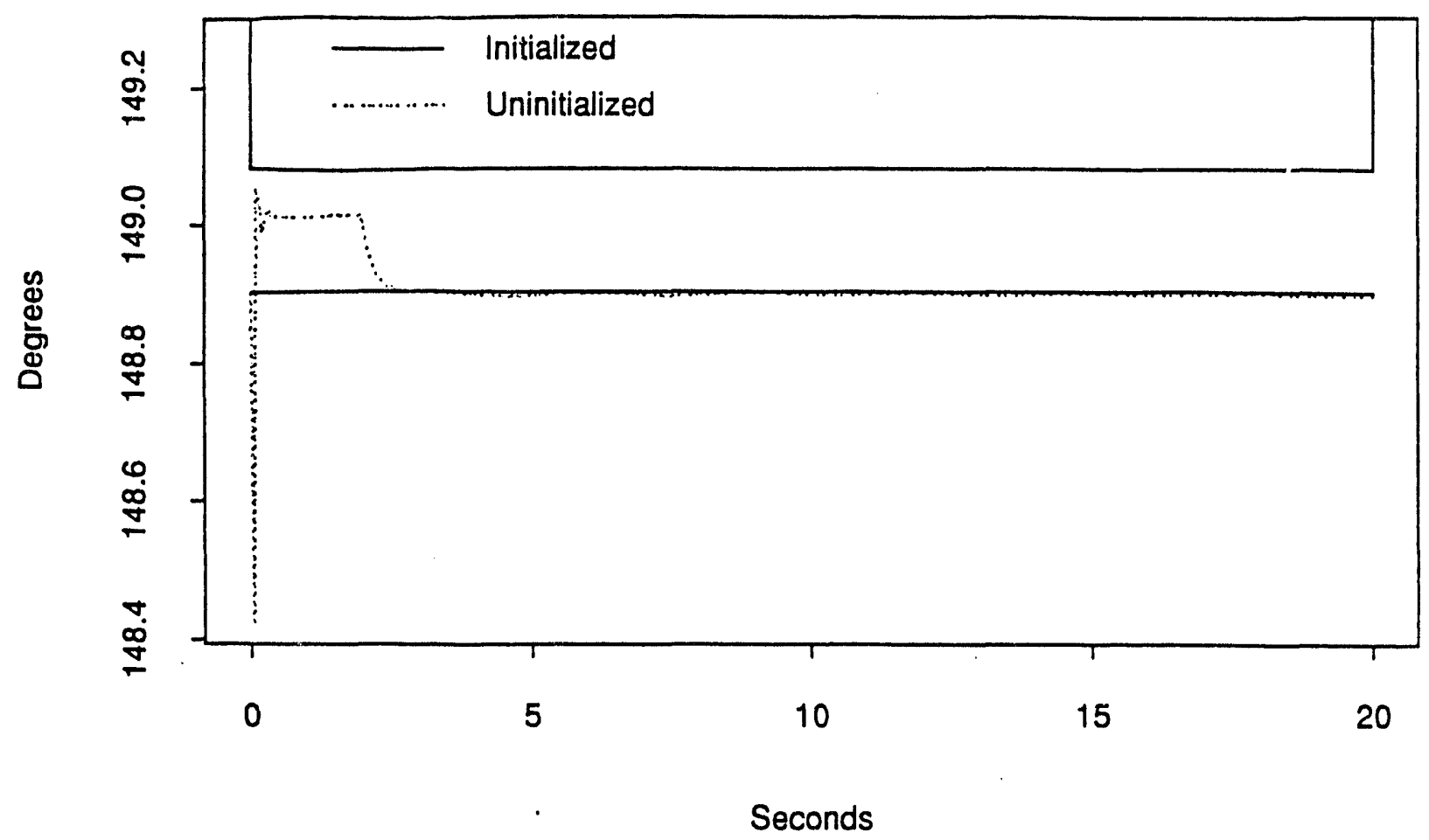

Figure 2.6. Sylmar Expansion Converter Firing Angle with No Disturbance

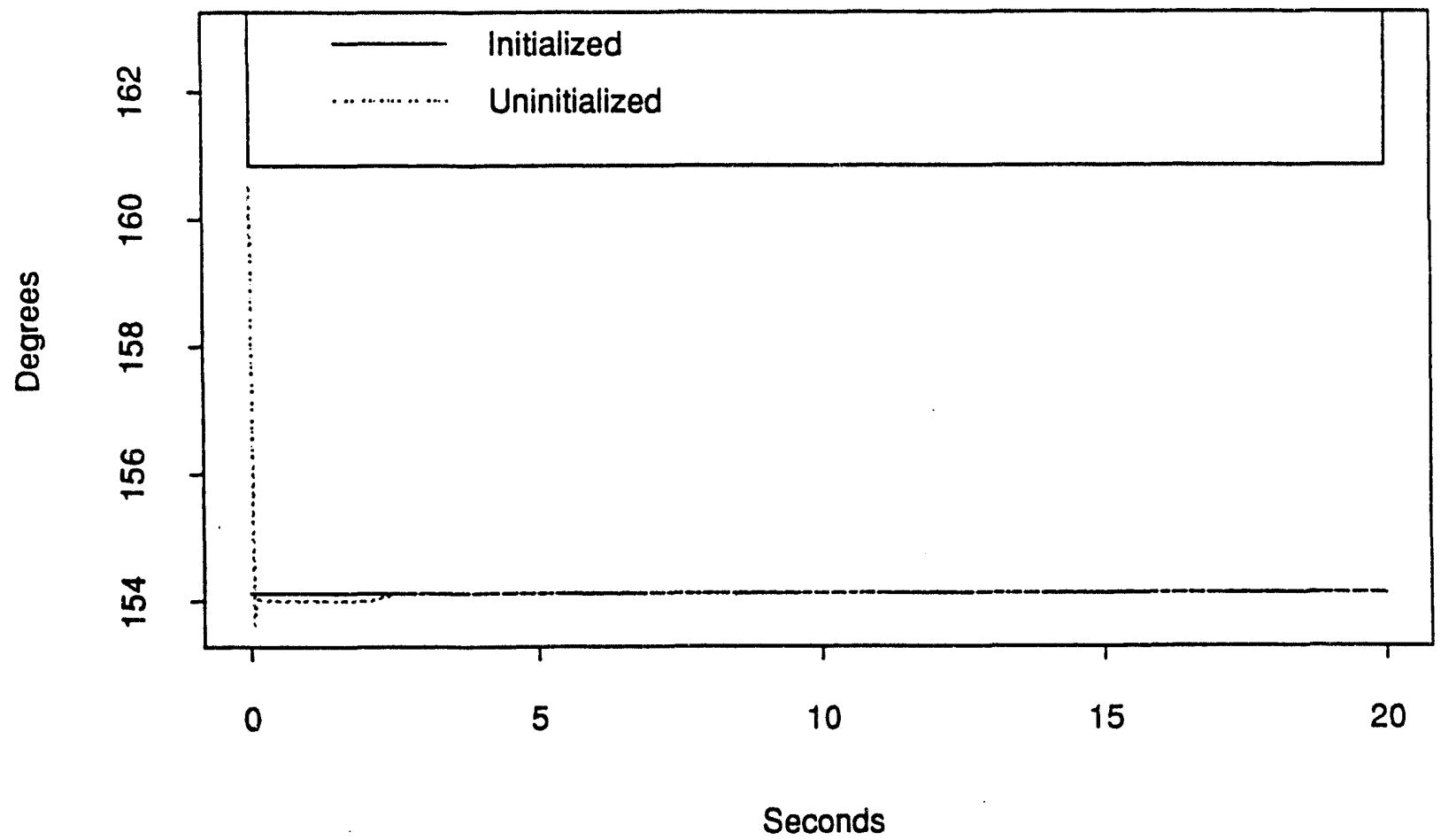

Figure 2.7. Sylmar Original Converter Firing Angle with No Disturbance 


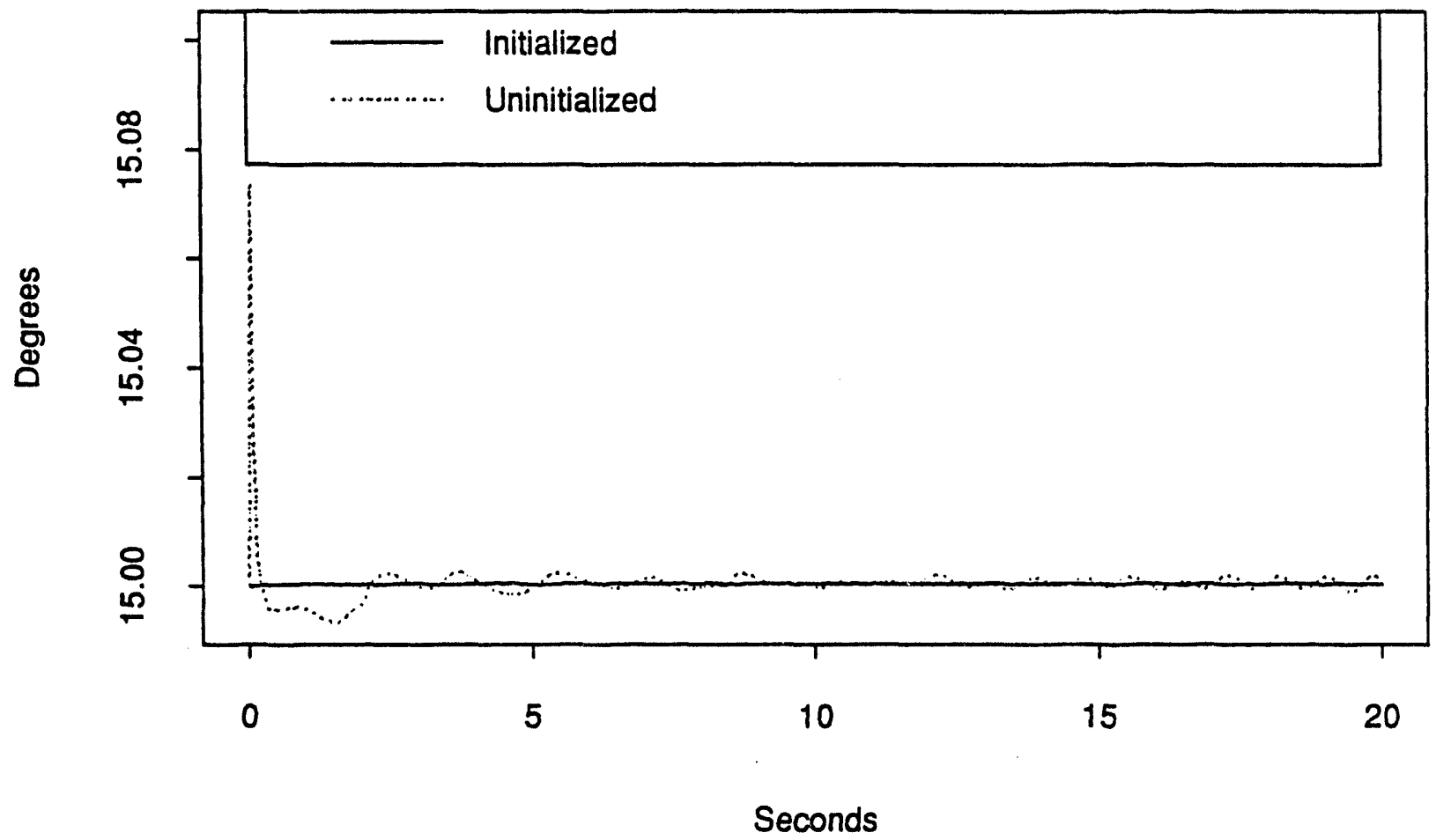

Figure 2.8. Intermountain Converter Firing Angle with No Disturbance

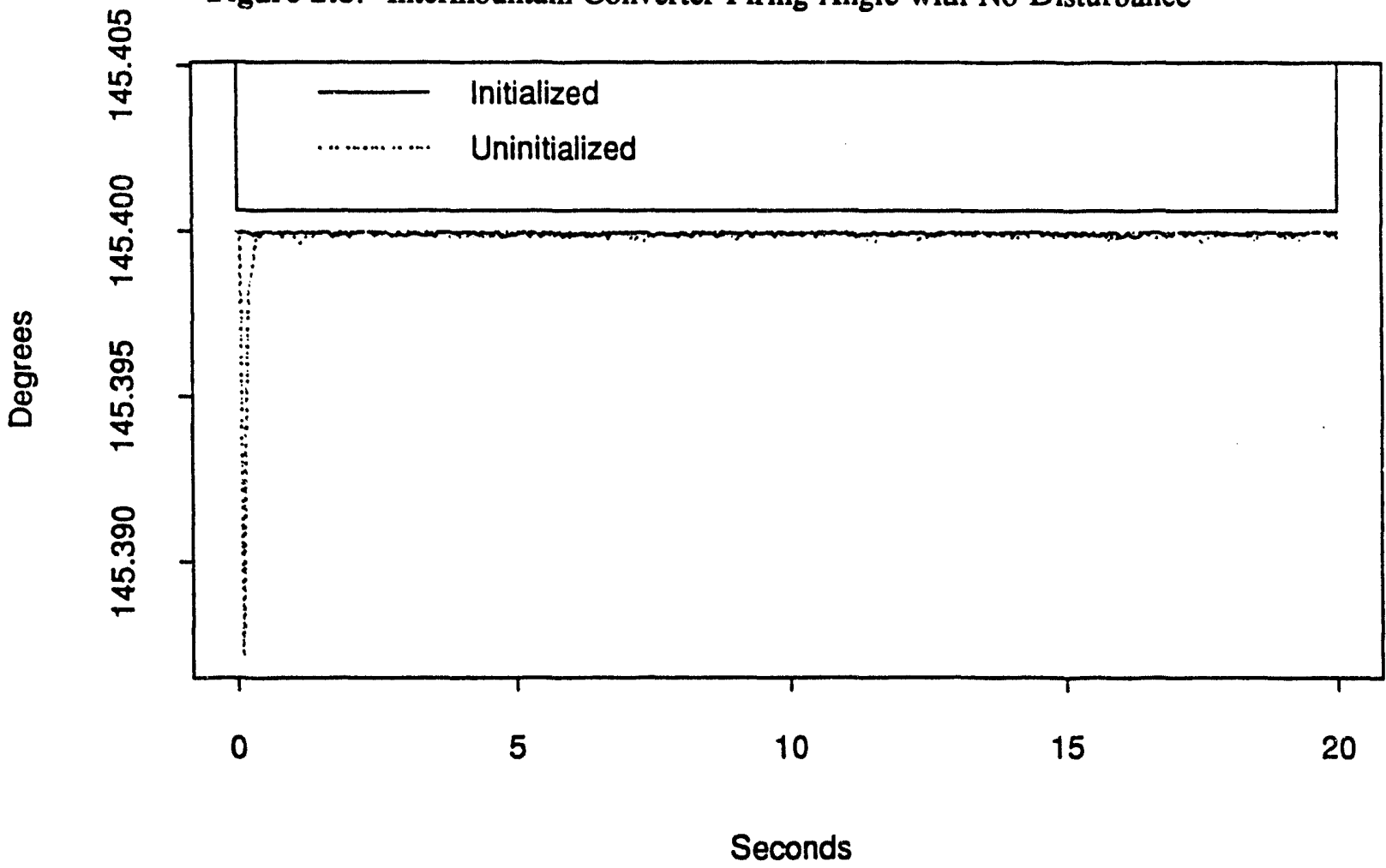

Figure 2.9. Adelanto Converter Firing Angle with No Disturbance 


\subsection{Modal Analysis on Reduced-Order Model}

To compare the modal characteristics of the MTDC model, several analysis tools were used to analyze the reduced-order model. These tools include both MASS and PEALS in SSSP and modal composition of time-domain simulation data generated by ETMSP using Prony analysis to derive the modal characteristics (the BPA/PNL program IPRONYID was used).

To demonstrate the comparison results, focus is placed on a single mode. This mode is an interarea mode, and with the dc line netted out as load, has a frequency of oscillation of $0.3449 \mathrm{~Hz}$ with a damping ratio ${ }^{(a)}$ of 0.0492 . This mode is a north-south mode, and resembles the $0.35-\mathrm{Hz}$ mode observed in the actual power system.

All of the tools described above produced consistent results for this mode to at least three significant digits with no dc modeling. However, when the MTDC model is included, the results are not as consistent between the various tools, which is described in detail in this section.

\subsection{Initial Results}

The first priority was to check the SSSP tools (MASS and PEALS) for consistency with the MTDC model included. The check was performed using versions of MASS and PEALS modified to accept BPA POWERFLOW data with the MTDC model after the equal eigenvalue error was fixed (see Section 2.2) but before the initialization modifications were made (as described in Section 2.3).

Both MASS and PEALS gave consistent results. MASS found this mode at $0.3431 \mathrm{~Hz}$, with a damping ratio of -0.0474 (negative damping ratios indicate an unstable mode). PEALS reported this mode at $0.3439 \mathrm{~Hz}$ with a damping ratio of -0.0490 . This is excellent agreement: the frequencies are nearly identical, and the damping ratios differ by only approximately $3 \%$ (tolerances within expected numerical error).

Although the agreement between the MASS and PEALS results is encouraging, these results themselves were disturbing. They indicated an unstable mode at $0.34 \mathrm{~Hz}$, but the time-domain simulation gave no indication of instability. This instability was confirmed through Prony analysis on the time-domain data, which found this mode with a frequency of $0.340 \mathrm{~Hz}$ and a damping ratio of 0.038 (a stable mode of oscillation).

This discrepancy between the results of the time-domain simulation and those of the eigenanalysis tools can be explained, to some extent, by improper initialization of the dc model. Because eigenanalysis tools linearize the system at its initial operating point (which does not account

(a) As used in this report, damping ratio is defined as

$$
\zeta=\frac{-\sigma}{\sqrt{\sigma^{2}+\omega^{2}}}
$$


for nonlinear behavior such as limiters) and is valid for only small perturbations at this point (hence the name Small-Signal Stability), significant error can be introduced if the initial operating point is not determined correctly.

\subsection{Results After Initialization}

After the changes described in Section 2.3 were made to the model, the MASS results indicated that this mode changed to have a frequency at $0.3201 \mathrm{~Hz}$ with a damping ratio of 0.0602 . The PEALS program was unable to properly find this mode. The mode identified for this region (PEALS is designed to find specific modes, with the user giving the initial search point) has a frequency of $0.3757 \mathrm{~Hz}$ and a damping ratio of 0.2524 , and was a control mode rather than an electromechanical mode of oscillation. Furthermore, when the initial search point was altered (the second run with an initial search point corresponding exactly with the mode identified by MASS), the result was a mode with an $0.4026-\mathrm{Hz}$ frequency and a damping ratio of 0.2488 , again a control mode. These appear to be the same mode (based on the dominant participation factors and right eigenvector entries), but have significant error (the frequency different by about 7\%), especially considering that everything between these cases is identical except the initial search point. Consequently, the PEALS program was not used in these comparisons.

The Prony fits were performed on the real power and speed deviations of certain classical generators (the large machines in the reduced-order model, which are representative of virtually the entire area modeled as a single machine) for different disturbances. After the data were experimented with, real power variations gave better results for the interarea modes, so they were used in the remainder of the analysis.

Four disturbances were used for the 20-second ETMSP simulations. The first two were a 5\% step on a generator reference voltage for 0.5 second (starting 1.0 second into the simulation) on two of the detailed machines, CANAD_G1 and NORTH_G1. These machines were chosen to provide views of the effects of a perturbation distant from the dc line and those of one close, to see if the interaction of the dc line appreciably affected the modal composition of the data. The third disturbance was the removal of the PACNW_MN - NOCAL_MN line for 0.1 second (again at 1.0 second into the simulation). The fourth disturbance was a $1 \overline{\%}$ pulse on the dc line (at the modulation input, called Cdampsig in the UDC model) for 0.5 second at 1.0 second into the simulation. This Cdampsig has a limit of $\pm 2 \%$. To verify that minimum nonlinearities were introduced by the $1 \%$ pulse, a test case was performed with a $0.5 \%$ pulse, which matched the $1 \%$ pulse (with $1 / 2$ magnitude) extremely closely, indicating that the $1 \%$ pulse was free of nonlinearities.

The four disturbances are shown in Figures 3.1 through 3.6 for six of the key classical generators in the reduced-order model. The classical generators represent an equivalent inertia of many machines within that area and, thus, how an entire area swings with respect to the rest of the system. This representativeness is helpful in demonstrating an interarea mode of oscillation. 


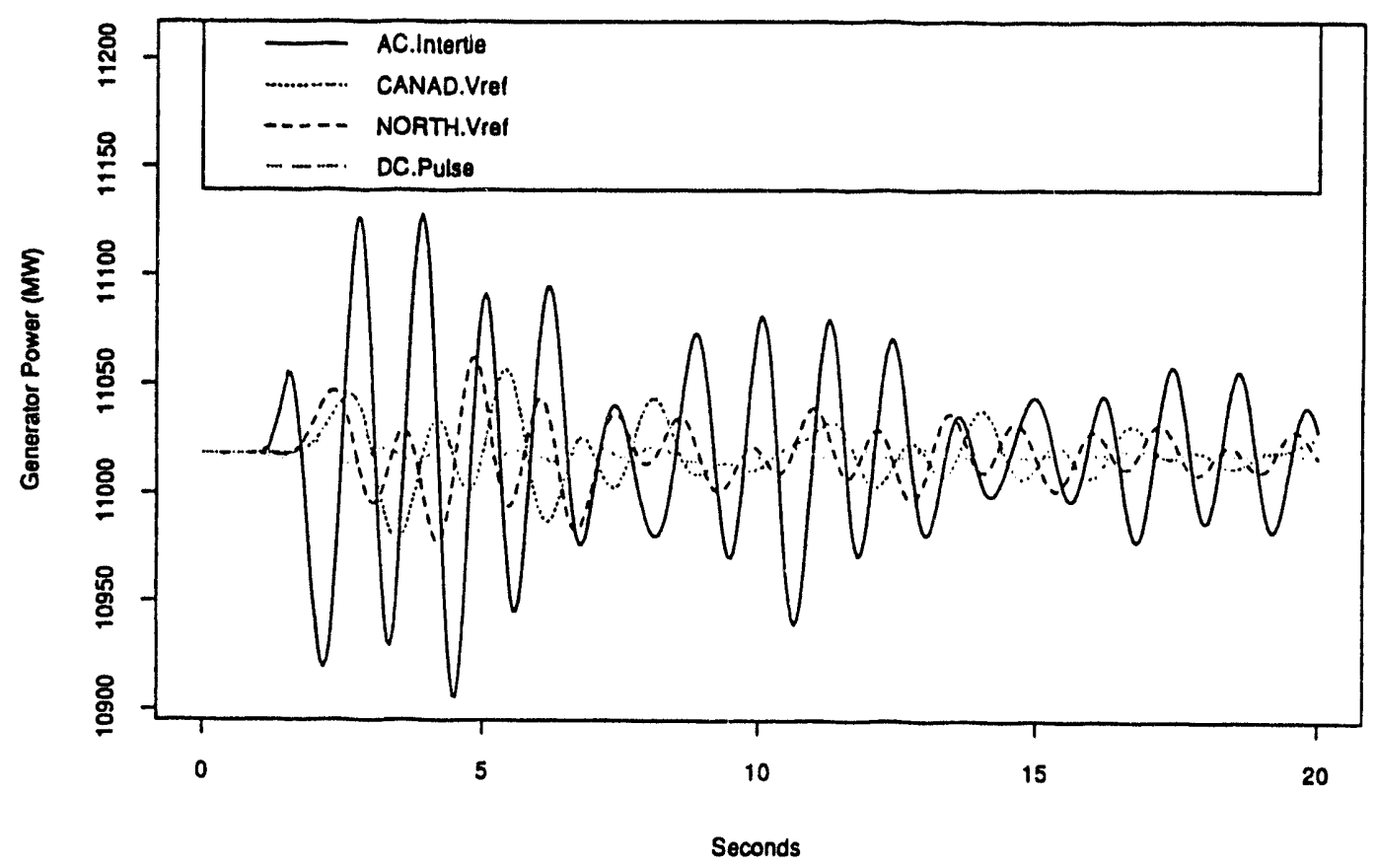

Figure 3.1. ARIZO_GM Generator Real Power

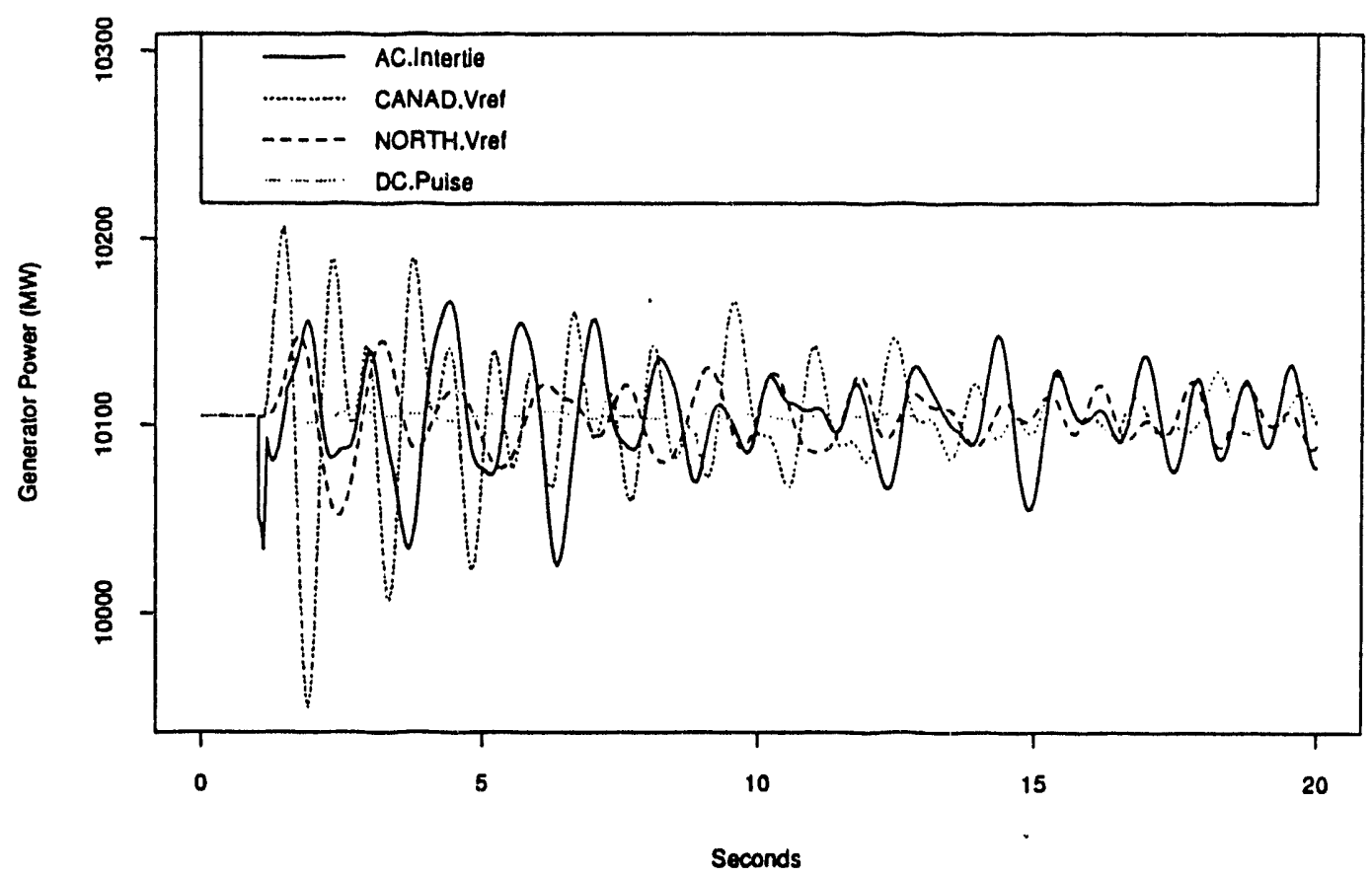

Figure 3.2. CANAD_GM Generator Real Power 


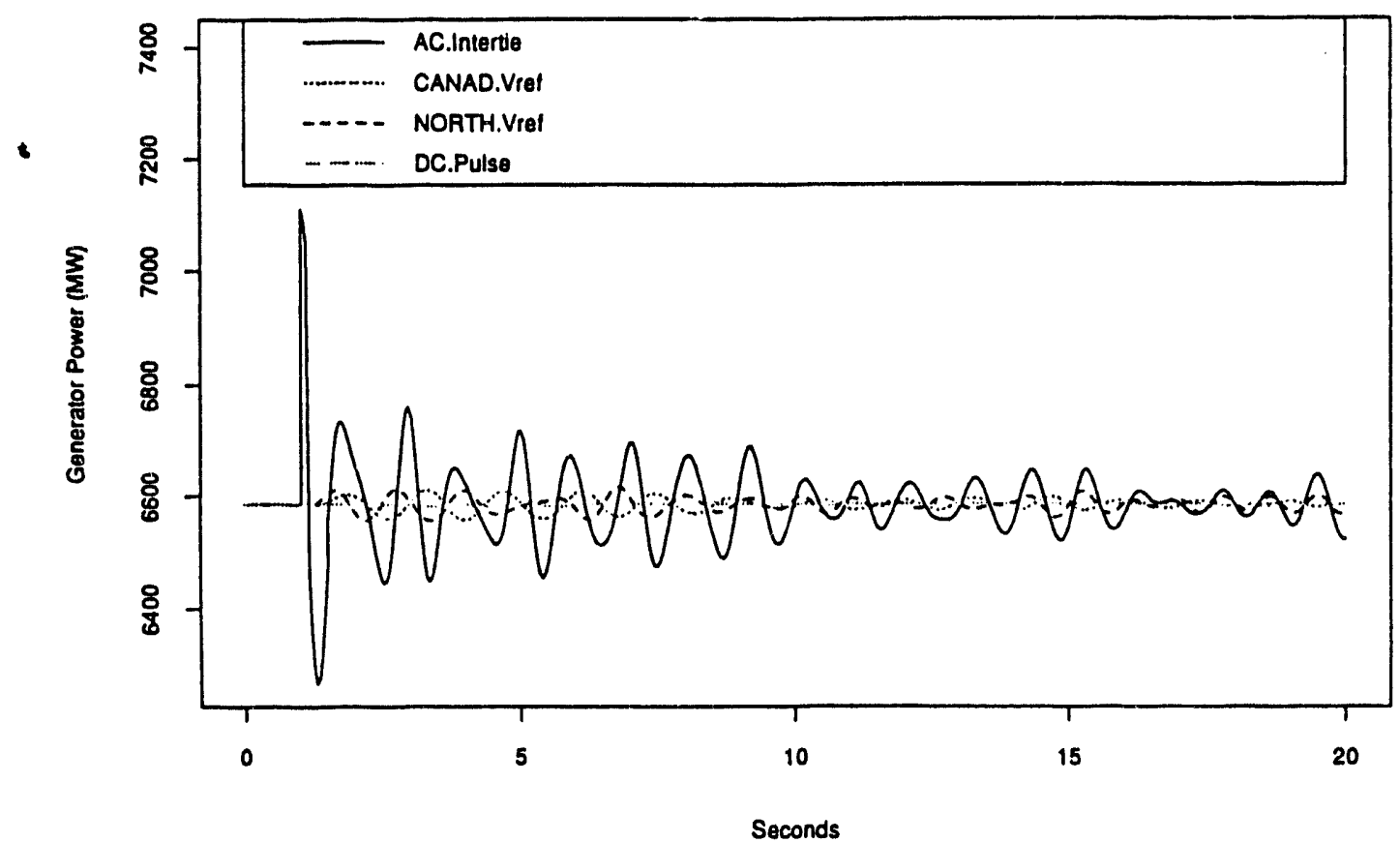

Figure 3.3. NOCAL_GM Generator Real Power

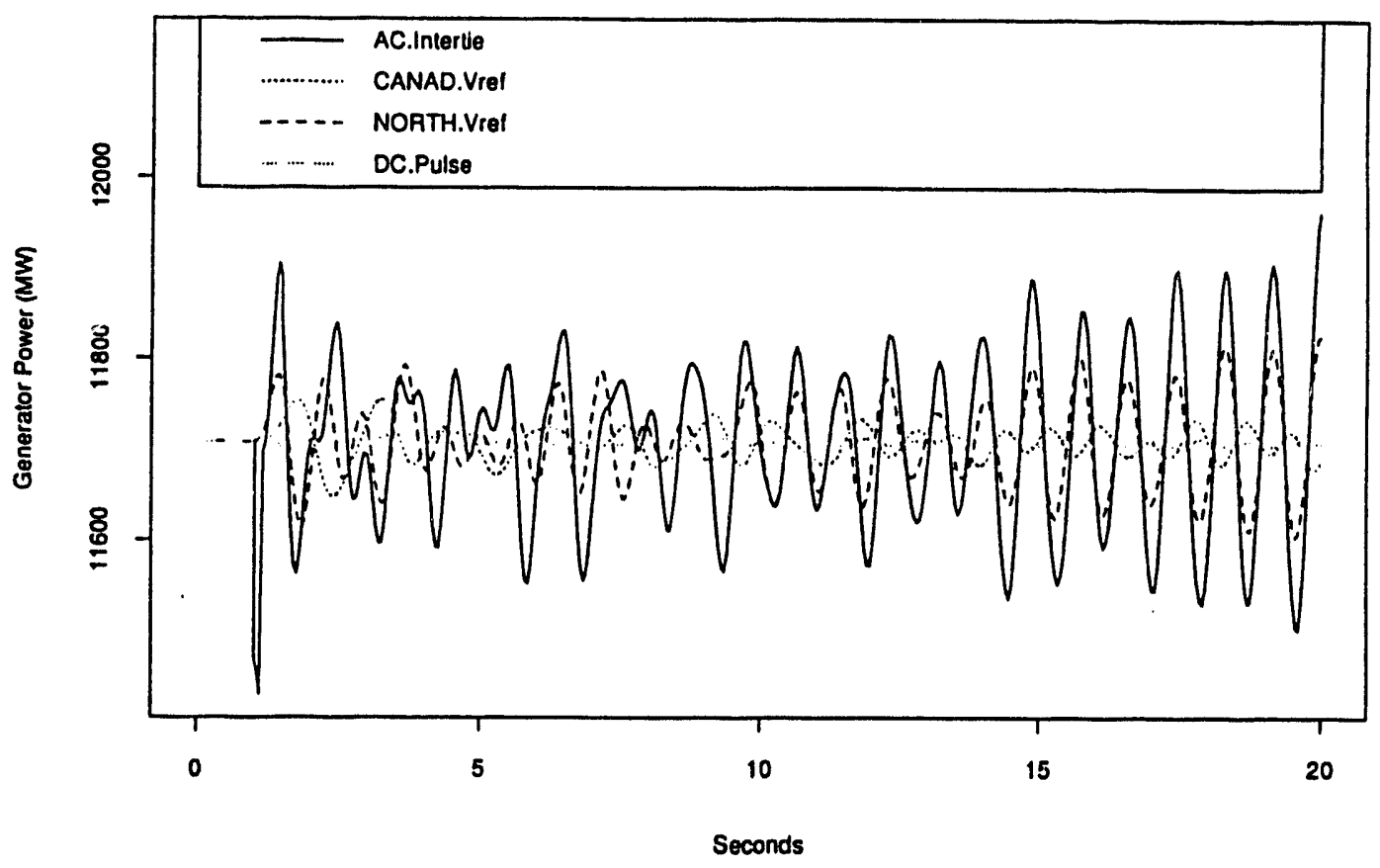

Figure 3.4. NORTH_GM Generator Real Power 


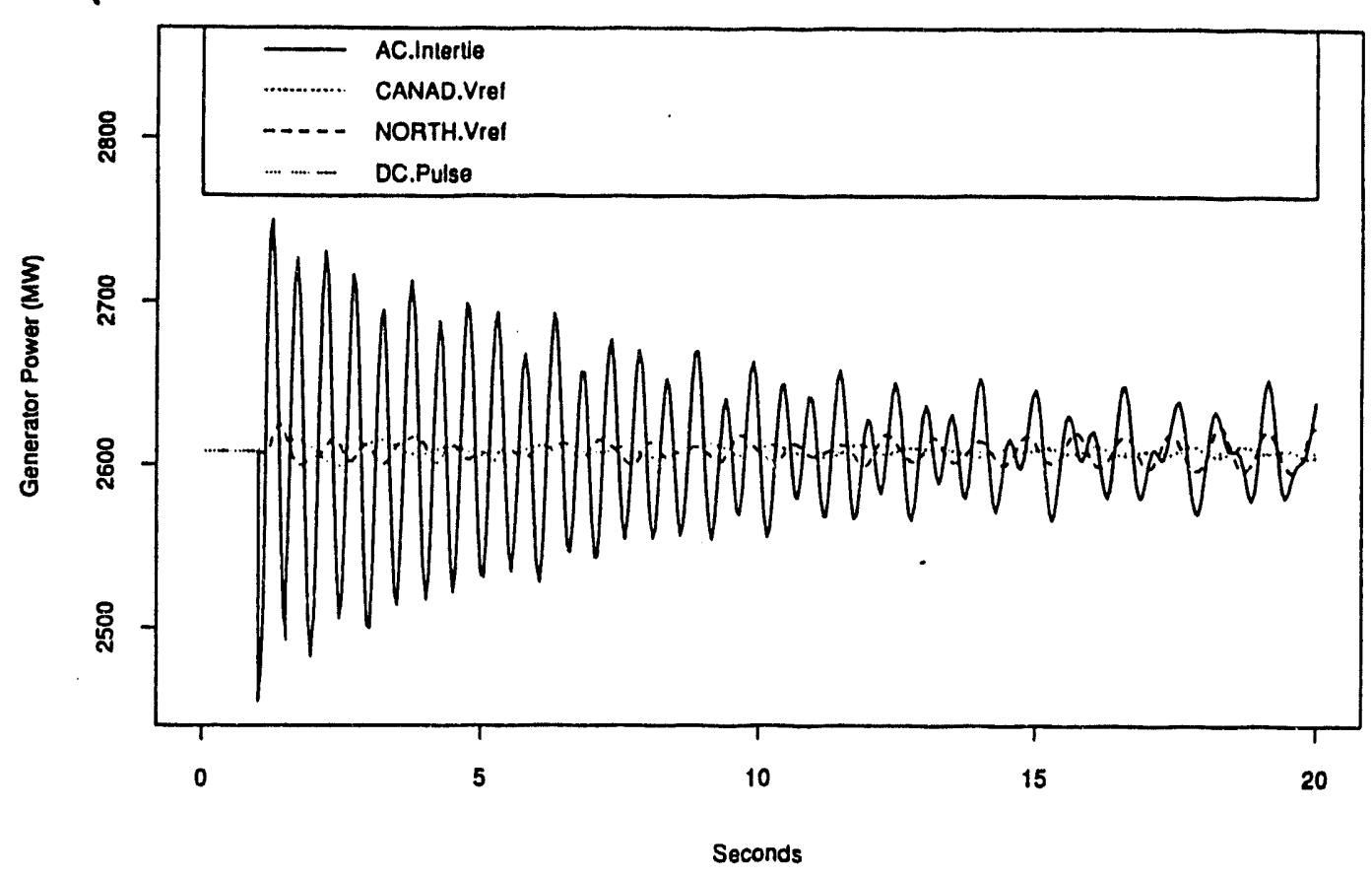

Figure 3.5. PACNW_GM Generator Real Power

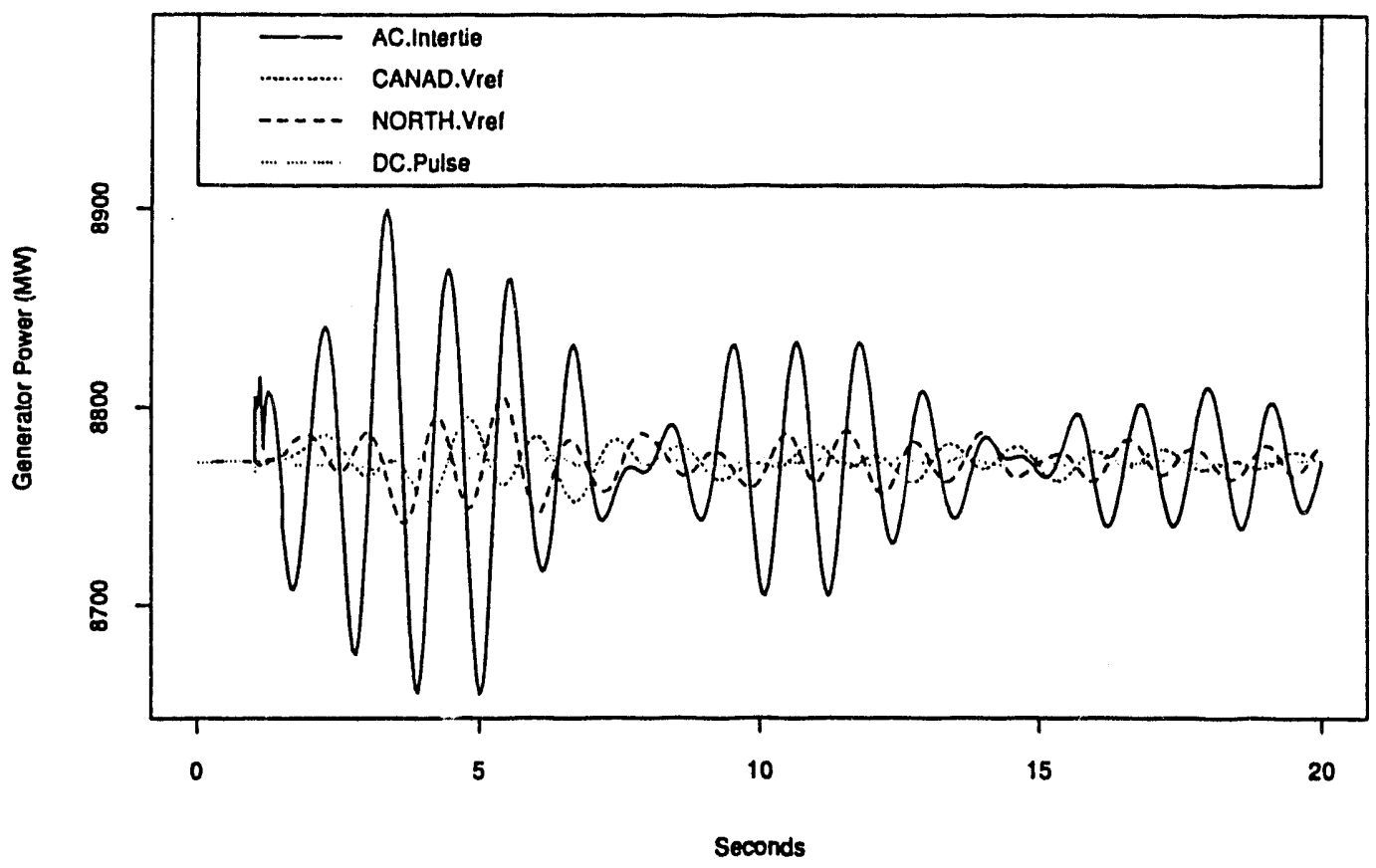

Figure 3.6. SOUTH_GM Generator Real Power 
All of the pulses were chosen as 0.5 second to excite low-frequency modes. This duration applies to all of the disturbances except the loss of the PACNW_MN - NOCAL_M. The pulse will maximize the excitation of the modes of interest $(0.3$ to $1.5 \mathrm{~Hz})$ without strongly biasing one mode over another within this range. See Figure 3.7 for the frequency contents of these two types of step functions: a single square wave and a single pulse. The single pulse was used to excite the system with which the Prony analysis was performed.

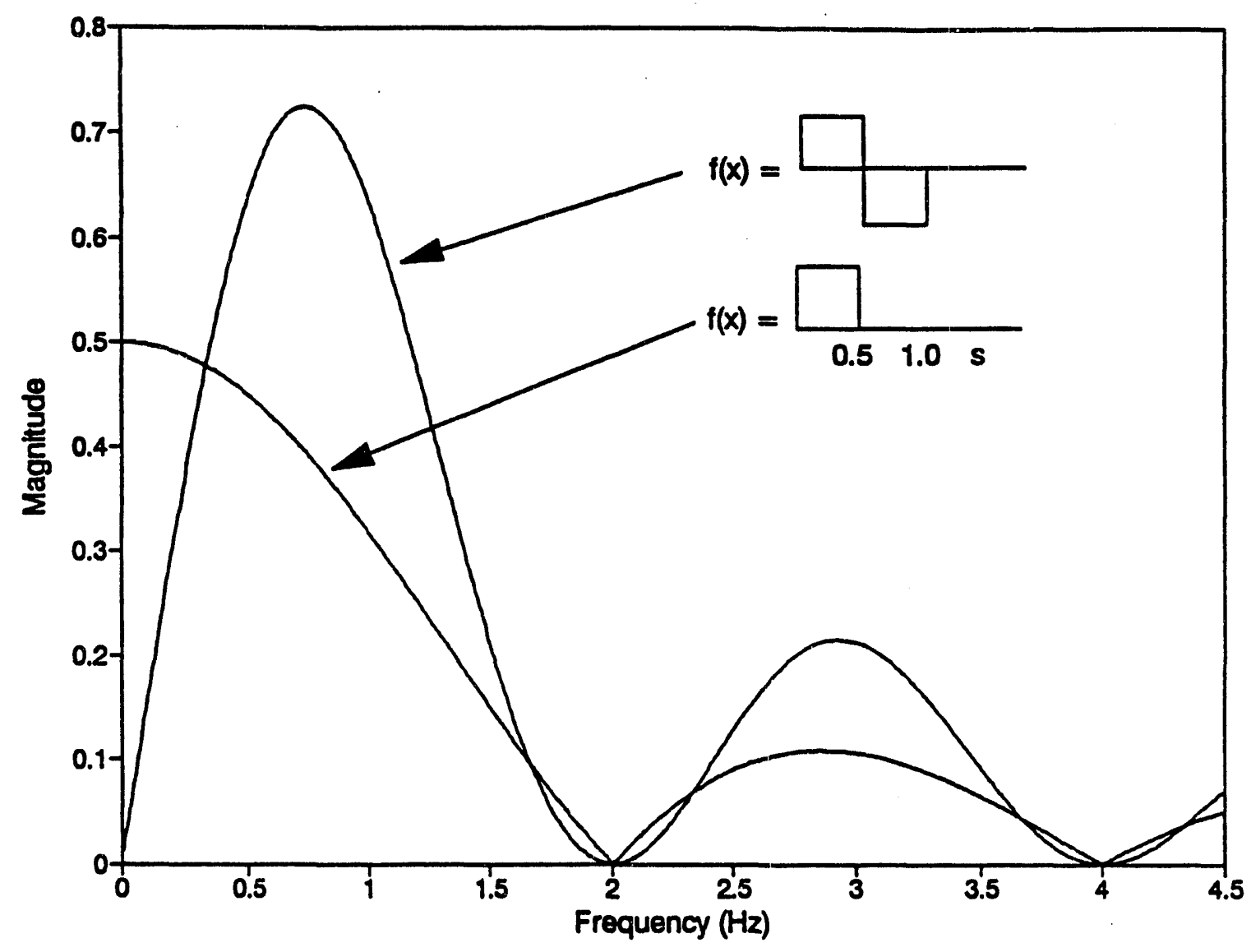

Figure 3.7. Frequency Content of Step Functions

The Prony analysis results are given in Table 3.1. The results are highly consistent, regardless of which machine data are used or which disturbance is applied. Therefore, there a high degree of confidence is placed in the Prony results because of to this consistency. Of course, if there is a modeling error or some problem in ETMSP itself, these errors would be propagated throughout the analysis and would still yield consistent results, but these problems were not considered germane to the cross-validation performed as part of this work. 
Table 3.1. Prony Results

\begin{tabular}{lrrrrrr} 
Signal Used: & \multicolumn{2}{c}{ ARIZO_GM Power } & \multicolumn{2}{c}{ CANAD_GM Power } & \multicolumn{2}{c}{ NORTH_GM Power } \\
Disturbance & Frequency & \%Damping & Frequency & \%Damping & Erequency & \%Damping \\
S\% Vref Pulse at: & & & & & & \\
5ANAD_G1 & 0.3401 & 0.0401 & 0.3401 & 0.0399 & 0.3401 & 0.0397 \\
NORTH_G1 & 0.3403 & 0.0400 & 0.3402 & 0.0399 & 0.3402 & 0.0398 \\
AC Intertie Outage & 0.3403 & 0.0406 & 0.3402 & 0.0404 & 0.3401 & 0.0407 \\
1\% Pulse on DC & 0.3403 & 0.0395 & 0.3403 & 0.0393 & 0.3403 & 0.0393
\end{tabular}
Average Frequency
$0.3402 \pm 0.0001$
Average Damping
$0.0399 \pm 0.0005$

A fourth method was used to further investigate the discrepancies between the SSSP results and the Prony analysis results. The PEALS program is equipped with an alternative algorithm called Aesops, which is completely different from the Arnoldi algorithm, the standard PEALS approach to eigenanalysis. Both MASS and the Arnoldi approach use the $Q R$ algorithm to find the eigenvalues (and right and left eigenvectors) of the A matrix. The primary difference between MASS and Arnoldi is that while MASS finds all eigenvalues of the full state matrix, the Arnoldi approach applies a recursive algorithm to a small upper Hessenberg matrix, which is then solved by the QR algorithm. The Aesops approach differs significantly in that the rotor angle mode eigenvalues are found one at a time via a search algorithm. Aesops will find only rotor angle modes associated with the disturbed generator. Although using this tool properly can be tricky (it has a tendency to give false results if the user is not careful picking the proper generator to disturb when exciting a particular mode, which can be difficult when analyzing interarea modes of oscillation), it is a distinctively different approach in that it does not formulate a state matrix or use the $Q R$ algorithm (and thus it is a handy tool for independent verification of SSSP results).

The results of the Aesops analysis are given in Table 3.2. The initial shift point was 0.318 $\mathrm{Hz}$, with probing disturbances applied at detailed machines at each of the main buses in the reducedorder model. When the probing disturbance was applied at ARIZO_G1, SOUTH_G1, and MONTA_G1, the solution converged to the same mode, with an average frequency of $0.4083 \mathrm{~Hz}$ with a $0 . \overline{2} 442$ damping ratio (very consistently). This is the mode of interest, albeit at a different frequency and damping ratio than identified by the other analysis techniques.

The solutions found with the probing disturbance applied at the other main buses are not the same mode, but are equally valid. This is an expected characteristic of the Aesops algorithm. These solutions converged to local modes that dominate the response to a perturbation in the frequency range of interest. Once exception in which the mode was not a dominant local mode is the $0.8-\mathrm{Hz}$ mode found with the probing signal applied at NOCAL_G1. This is an interarea mode, but this machine has very small participation in the $0.35-\mathrm{Hz}$ north-south oscillation (this machine acts as a pivot for this mode), so the $0.8-\mathrm{Hz}$ modal interaction dominates the $0.35-\mathrm{Hz}$ response, causing the algorithm to converge to the mode with dramatically higher participation. This is illustrated in Section 3.3. 
Table 3.2. Aesops Results

Initial Shift Point: $s=0+j 2$

Probing Disturbance
ARIZO_G1
SOUTH_G1
MONTA_G1
BUTAH_G1
CANAD_G1
NOCAL_G1
PACNW_G1
NORTH_G1

\begin{tabular}{c} 
Erequency (Hz) \\
\hline 0.4079 \\
0.4084 \\
0.4087 \\
0.5961 \\
0.7081 \\
0.7977 \\
1.3772 \\
1.4131
\end{tabular}

Damping Ratio

0.2436

0.2430

0.2461

0.0313

0.0529

0.0106

Although the Aesops results are internally consistent, they are strikingly different from the results obtained from MASS and Prony analysis. To explore if there is a dependency on the initial starting point, different initial shift points were analyzed with the probing disturbance applied at ARIZO G1. Several initial starting points were tried, mapping out a region around the expected value of the pole in the complex plane. Each of these cases converged to the same result (within numerical tolerances), and indicates that the Aesops results are independent of the initial shift point specified. This diminishes the likelihood that the results are indicative of a "saddle point," to which this algorithm is especially prone to inadvertently converting, and the solutions are relatively independent of the machine used for the probing disturbance (except in instances where other modes, particularly local modes, are much more prevalent, causing the algorithm to converge to these other modes).

The results of all analytic methods of modal analysis performed on this case are summarized in Table 3.3. The ETMSP results using Prony analysis to obtain the modal characteristics of the time-domain data are most likely to be correct. This assertion is based on the excellent consistency among the various cases analyzed using this approach.

Table 3.3. Summary of Results

$\begin{array}{lcc}\text { Analysis Tool } & \text { Erequency }(\mathrm{Hz}) & \text { Damping Ratio } \\ \text { MASS } & 0.3201 & 0.0602 \\ \text { PEALS (Arnoldi) } & & \text { Failed to Converge } \\ \text { PEALS (Aesops) } & 0.4083 & 0.2442 \\ \text { ETMSP (using Prony) } & 0.3402 & 0.0399\end{array}$

The MASS results are relatively close and could be considered close enough to be useful, although they still differ by a significant enough margin to suggest a problem somewhere. The PEALS program performs dismally with this model: the Arnoldi algorithm fails to accurately find this mode, and Aesops finds the mode but with significant error. Therefore, the results of the study indicate that further modifications to the MTDC model and/or to SSSP are needed before reliable analytic methods of performing modal analysis on complex HVDC systems are realizable. 


\subsection{Mode Shapes}

The programs' ability to ascertain proper mode shapes was also analyzed. Calculating accurate mode shape information may be just as valuable as correctly identifying the frequency and damping ratio in assessing the modal characteristics for the design of HVDC modulation schemes and tests. Figures 3.8 through 3.22 show mode shapes of this mode $(0.35 \mathrm{~Hz})$, as well as other key modes of interest, which are described following the figures.

The SSSP-derived mode shapes (Figures 3.8 through 3.16) are normalized based on gentrator speed. With no dc models included, MASS and PEALS provide exactly the same results. With the MTDC model, however, MASS is unable to provide mode shape information. Although participation matrix information is available, the corresponding right eigenvector entries for the states of interest (generator speeds of the classical machines) are not correct. For example, the right eigenvector entries for the classical generators' speed corresponding to the $0.3201-\mathrm{Hz}$ mode are all zero (an exciter mode was so large that it caused the remaining right eigenvector entries to become zero with normalization). Similarly, for some of the other modes, which should be clearly electromechanical modes (supported by the participation matrix results), key right eigenvector results for the classical generator speeds do not exhibit electromechanical modal characteristics. Therefore, mode shape information for the MTDC model (using SSSP) relied upon using Aesops.

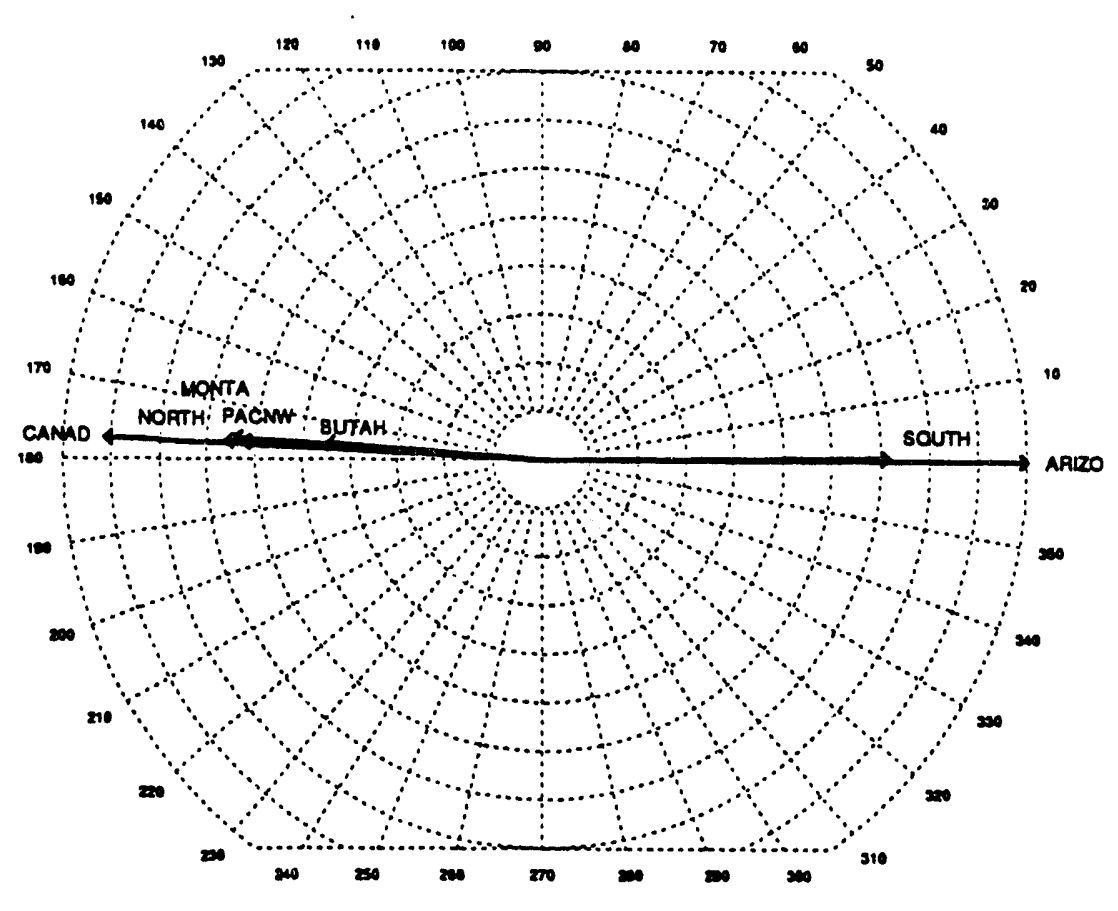

Figure 3.8. MASS and PEALS Mode Shape with No DC (0.3449 Hz, 0.0492 Damping) 


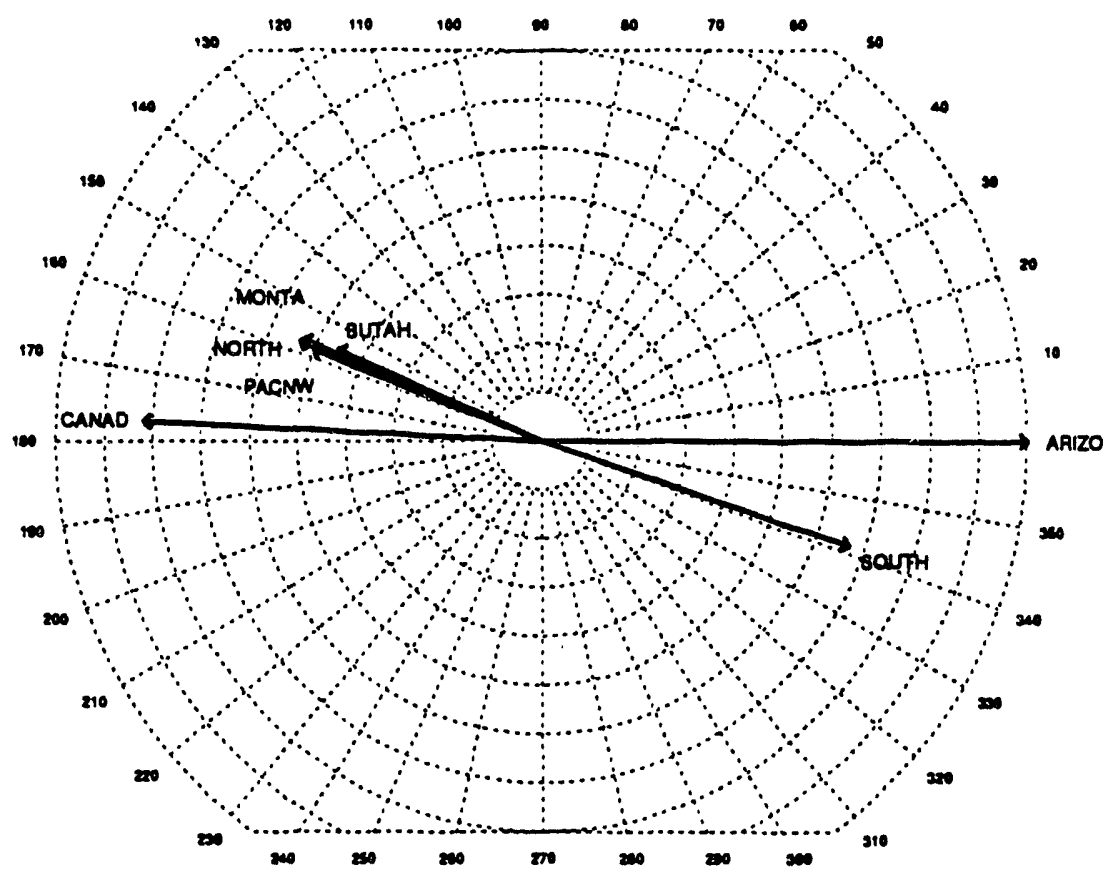

Figure 3.9. Aesops Mode Shape with DC (Probe @ ARIZO_G1, $0.4079 \mathrm{~Hz}, 0.2436$ Damping)

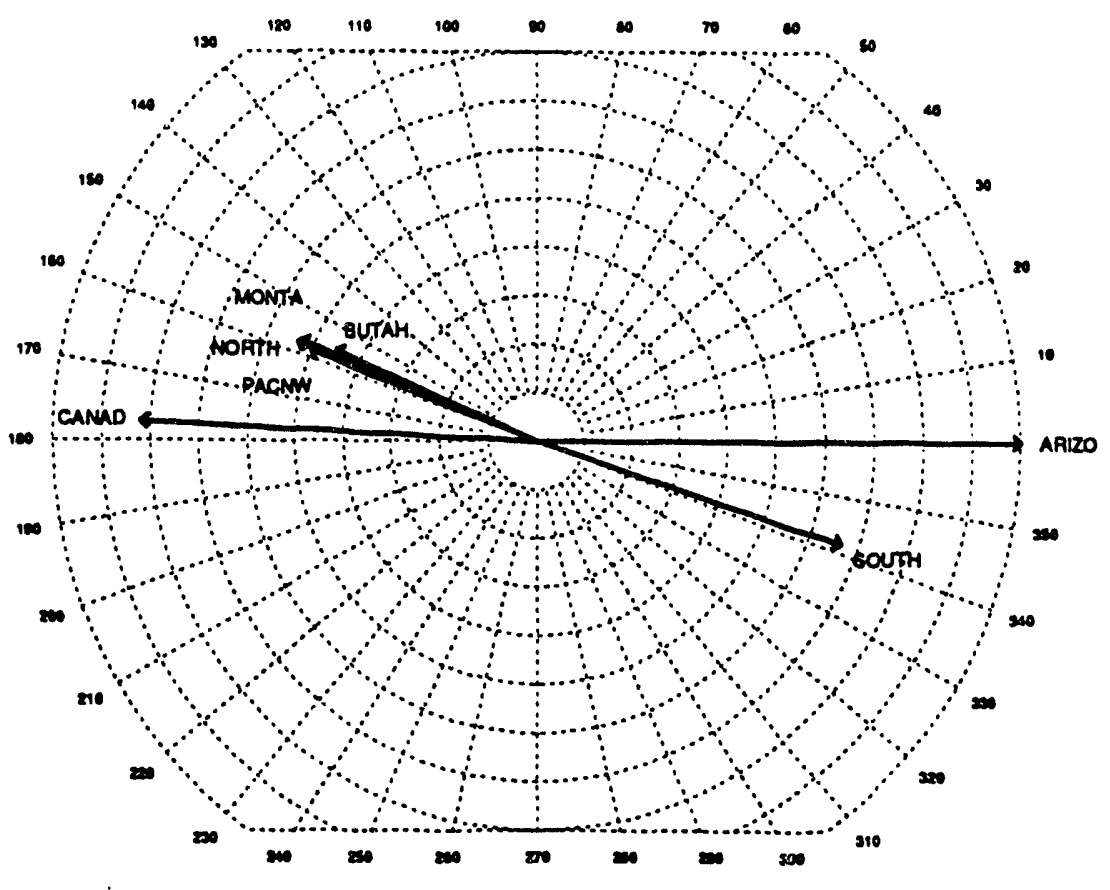

Figure 3.10. Aesops Mode Shape with DC (Probe @ SOUTH_G1, 0.4084 Hz, 0.2430 Damping) 


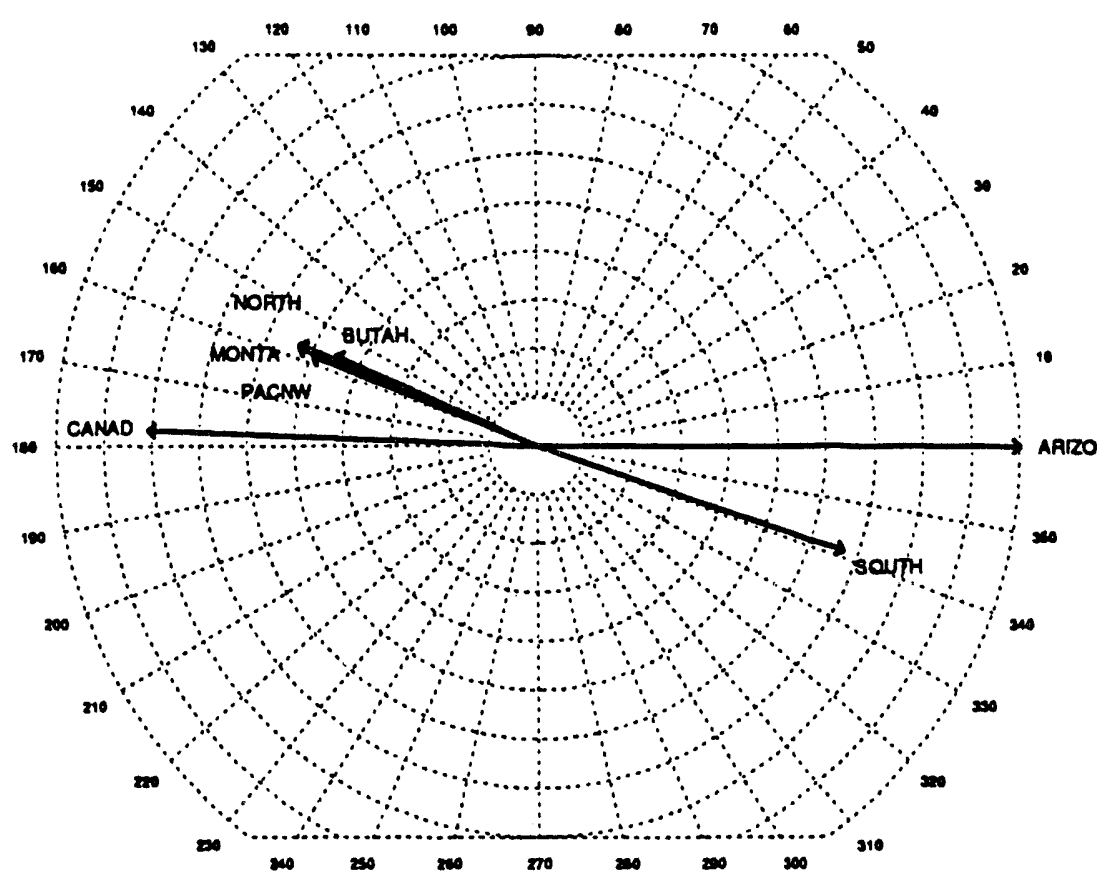

Figure 3.11. Aesops Mode Shape with DC (Probe @ MONTA_G1, $0.4087 \mathrm{~Hz}, 0.2461$ Damping)

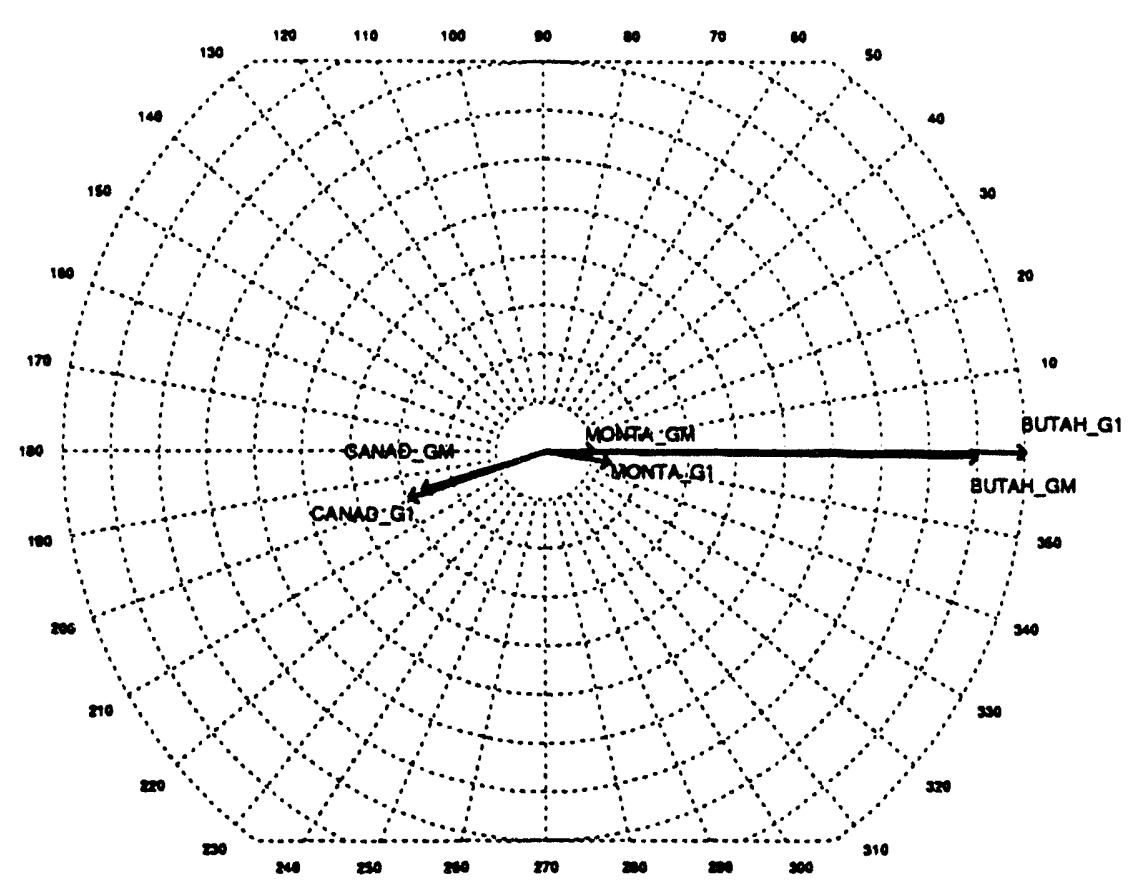

Figure 3.12. Aesops Mode Shape with DC (Probe @ BUTAH_G1, 0.5961 Hz, 0.0313 Damping) 


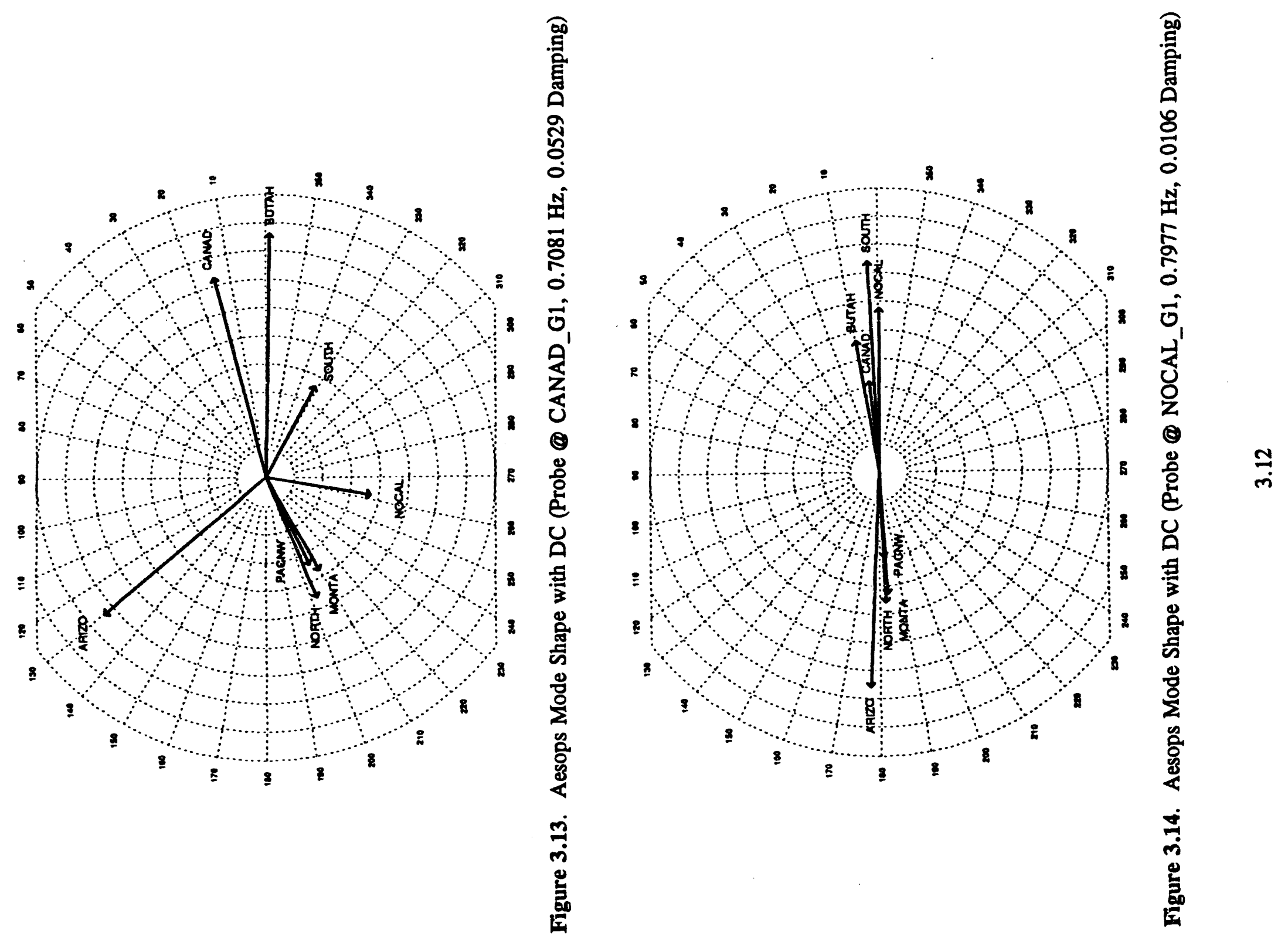




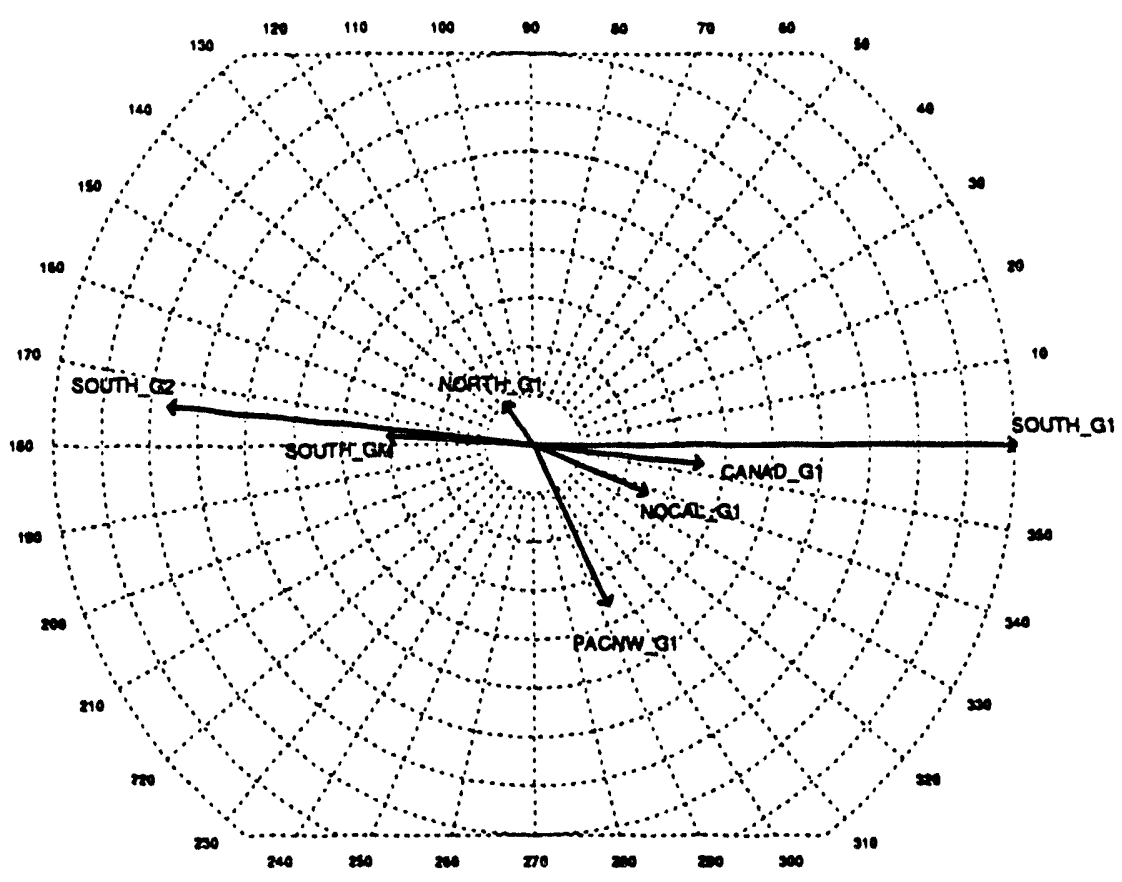

Figure 3.15. Aesops Mode Shape with DC (Probe @ PACNW_G1, 1.3772 Hz, 0.0172 Damping)

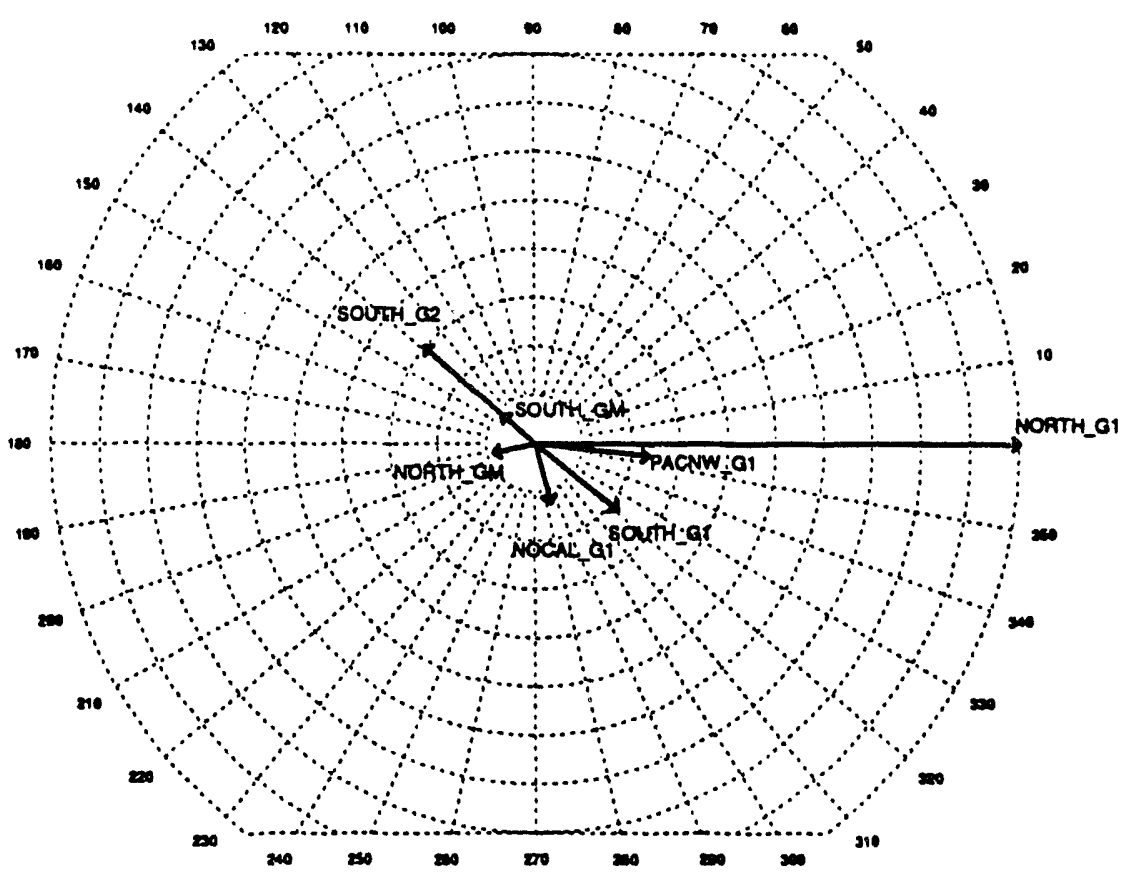

Figure 3.16. Aesops Mode Shape with DC (Probe @ NORTH_G1, $1.4131 \mathrm{~Hz}, 0.0180$ Damping) 


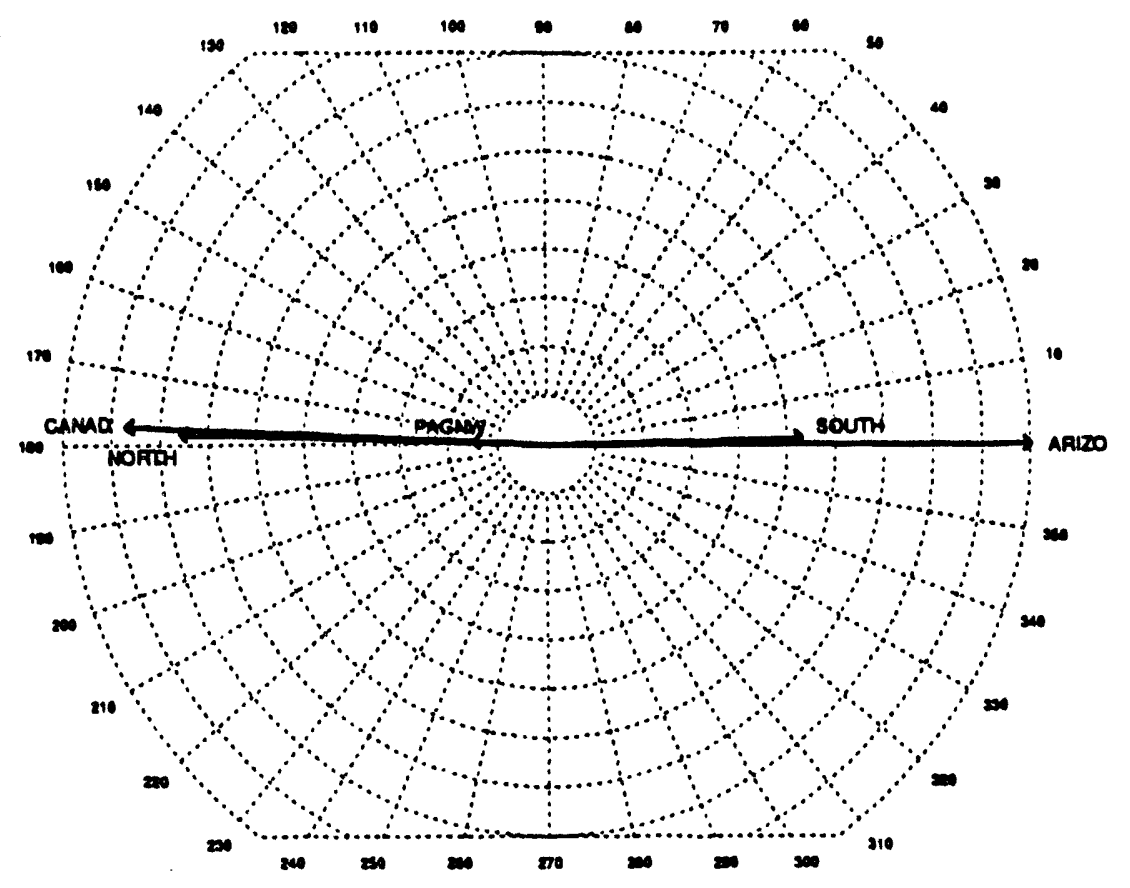

Figure 3.17. Prony Mode Shape with DC ( $0.34 \mathrm{~Hz}, 0.039$ Damping)

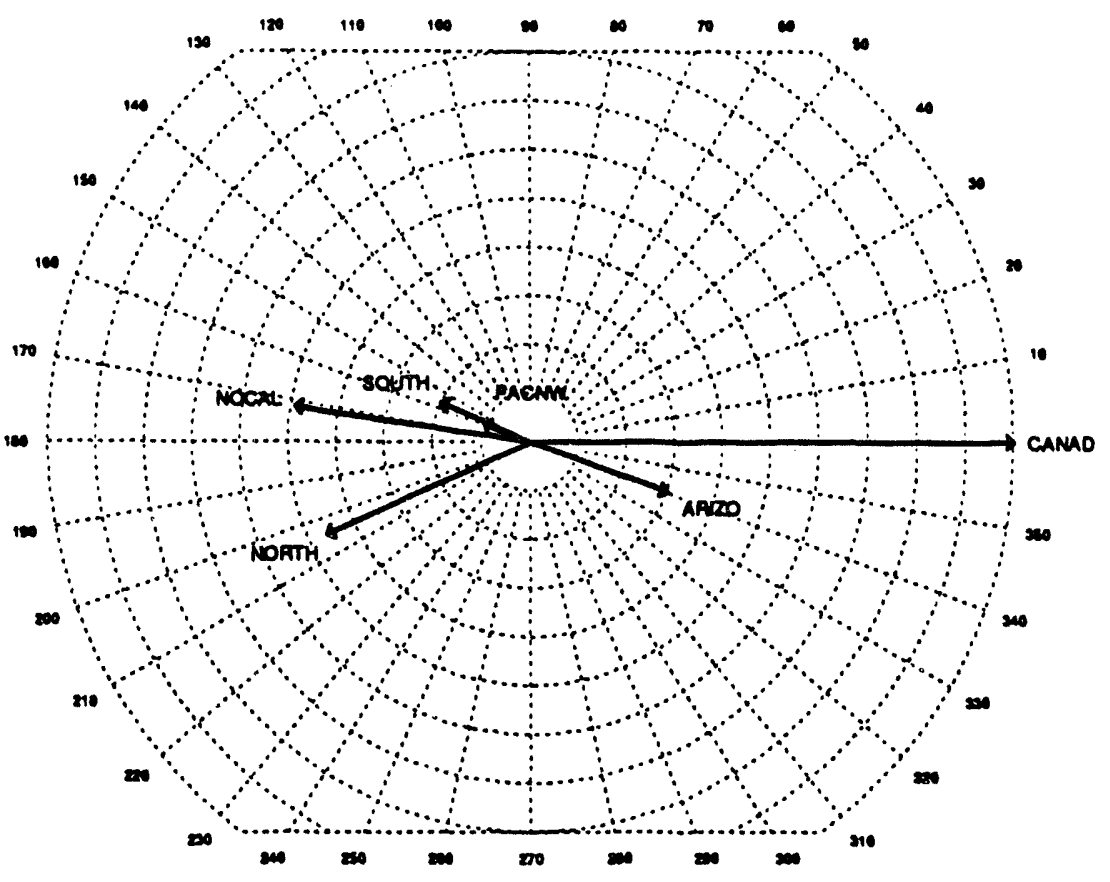

Figure 3.18. Prony Mode Shape with $D C(0.70 \mathrm{~Hz}, 0.016$ Damping) 


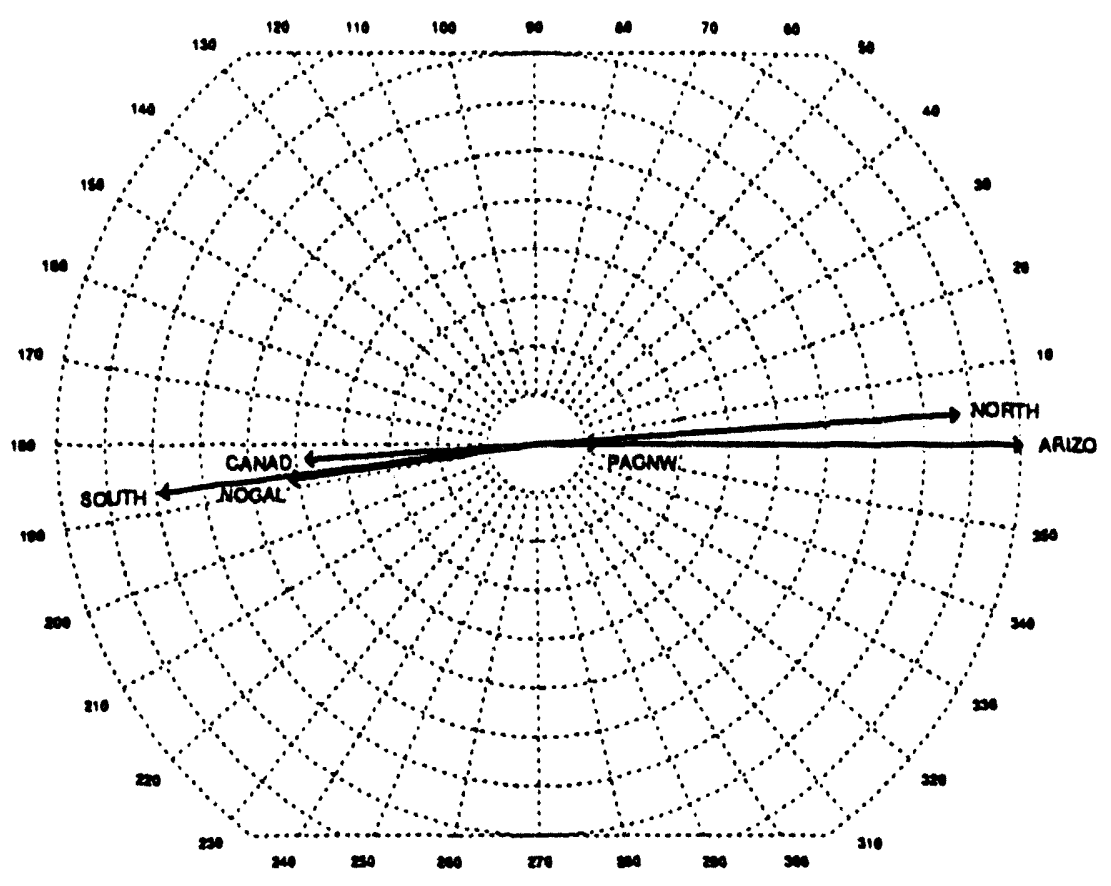

Figure 3.19. Prony Mode Shape with $D C(0.81 \mathrm{~Hz}, 0.013$ Damping)

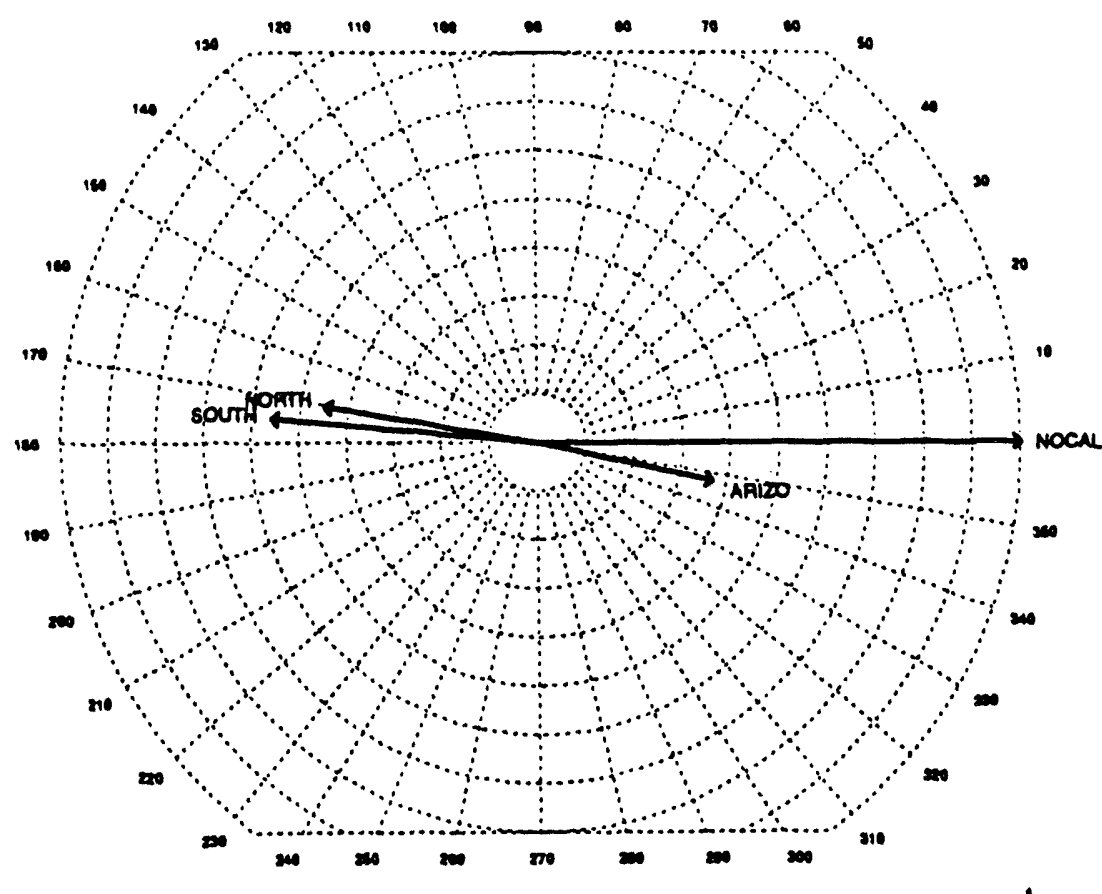

Figure 3.20. Prony Mode Shape with DC (0.96 Hz, 0.019 Damping) 
(8)

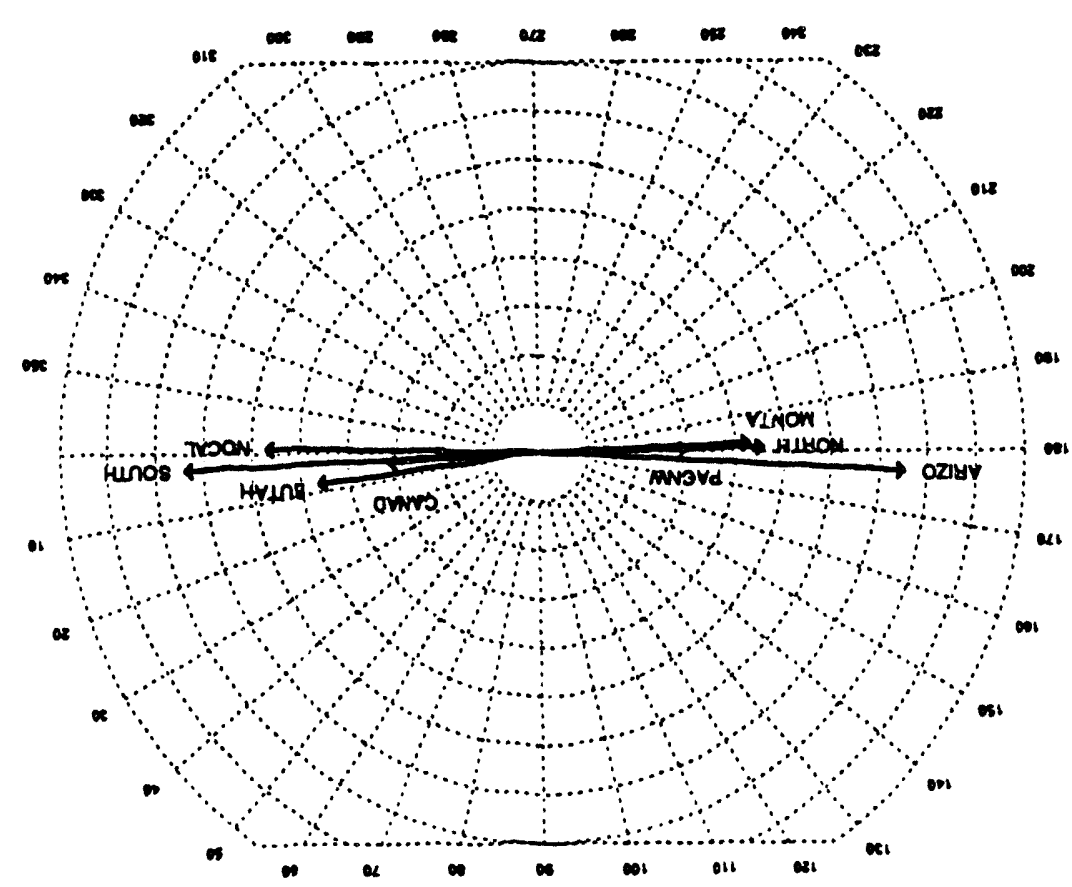

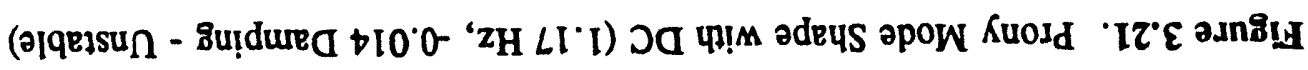

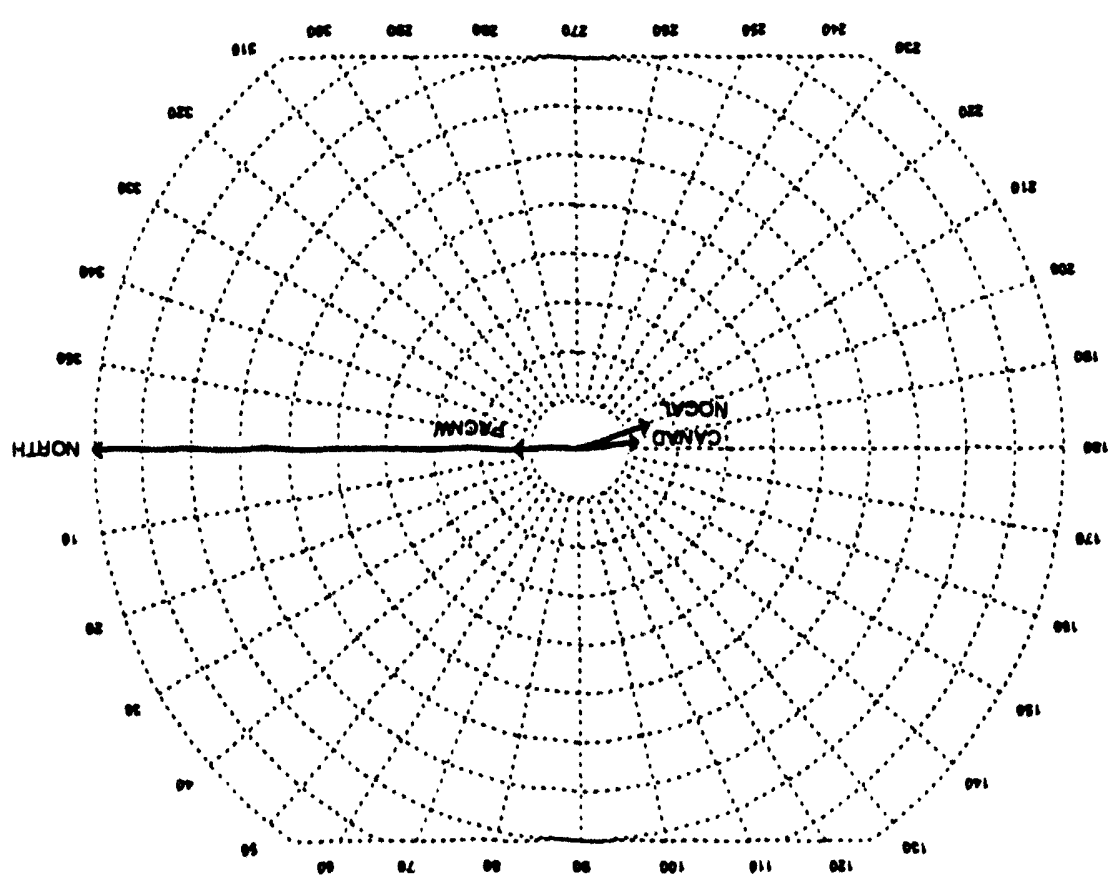


The Prony-derived mode shapes (Figures 3.17 through 3.21) were determined by using the transfer function residues. The generator real power for the key machines (shown in Figures 3.1 though 3.6), with a $1 \%$ pulse on the PDCI providing the disturbance to excite the modes of interest, were analyzed using Prony methods to determine the modal characteristics of each of the generator responses. Then the modes were analyzed, with the normalized transfer function residue for each generator providing the mode shape. The mode shapes given by the Prony analysis correspond to the SSSP mode shapes fairly well, although the phase relationships seem to be inverted (mirror images of each other).

Based on experience working with a larger system model (discussed in Section 4), PEALS using the Arnoldi approach was used to find the interarea electromechanical mode identified by MASS at $0.7768 \mathrm{~Hz}, 0.0216$ damping ratio, and identified by the PEALS Aesops routine at $0.7977 \mathrm{~Hz}$, 0.0106 damping ratio, and the Prony analysis at $0.81 \mathrm{~Hz}, 0.013$ damping ratio. The PEALS Arnoldi routine found this mode at $0.7990 \mathrm{~Hz}$ with a 0.0100 damping ratin, and the mode shape is shown in Figure 3.22.

The accurate location of the $0.8-\mathrm{Hz}$ mode using PEALS is somewhat encouraging, as it tends to indicate that the problem is rooted with interactions between the analytic tools and the model with the lower frequency modes. This result also suggests that PEALS can be applied effectively when finding higher frequency modes. This behavior was observed also when analyzing the larger system model (Section 4), in which PEALS was unable to locate any modes with frequencies less that 0.5 $\mathrm{Hz}$, but did not have any difficulty locating many of the higher frequency modes accurately.

The SSSP results do not appear to provide accurate results with the MTDC modeled (based on the large numerical differences between the various tools). However, the mode shape information that it can provide may be extremely useful for designing HVDC modulation tests: the mode shapes are relatively easy to determine using these methods as opposed to using Prony analysis, which requires substantial time-domain data from which to correlate modal information. An efficient approach for modal analysis (if the tools and models are not fixed to resolve the problems identified) would be to use the SSSP tools to determine rough orders of magnitudes of modes, which can also readily determine the relative participation (both controllability from the participation matrix and observability from the right eigenvector matrix) from which mode shape and modal characteristics can be easily extracted. This information can then provide enough insight into designing a reasonable approach to performing time-domain simulation with which Prony analysis methods can be performed. The disturbances (to isolate and excite only the modes of particular interest), and the data collected, need to be selected in such a way so that the Prony analysis can properly determine the modal characteristics. 


\subsection{Modal Analysis on Western System Model}

The next step in addressing the design of HVDC modulation is implementing the MTDC model in the full model representation of the western United States power system. Developed by utility members of the Western Systems Coordinating Council (WSCC), the model provided by BPA to perform this analysis was a 1992 light winter case, consisting of 2428 buses, 3673 lines, 990 transformers, 314 detailed machines, and 74 classical machines representing the interconnected power system of the western United States, and hereby referred to as the 92LW Model. Bonneville Power Administration personnel have expressed considerable concern over the accuracy of this model, even without the MTDC model. These issues were investigated under this project and are discussed in detail in Appendix B.

The modes identified by SSSP (PEALS) are shown in Table 4.1. MASS cannot be used for analysis with this larger model because it contains too many states. These eigenvalues indicate that all modes with frequencies near $0.35 \mathrm{~Hz}$ are extremely damped. Thus, eigenanalysis using the $92 \mathrm{LW}$ Model will focus on another mode. An interarea mode with a frequency of oscillation of $0.8305 \mathrm{~Hz}$ and a 0.0646 damping ratio (eigenvalue number 16 ) was chosen for this analysis.

The same frequency scan as above was used to find all the modes (between 0.1 and $1.5 \mathrm{~Hz}$ ) in the 92LW Model with the MTDC model included. These results are shown in Table 4.2. The PEALS program using the Arnoldi approach did not find any modes with frequencies less than 0.54 $\mathrm{Hz}$, which is quite unusual because there are a lot of modes in this range without the MTDC model. Therefore, some interaction between the program and the MTDC modeling must be causing the program to not work properly for these lower-frequency modes.

Detailed modal analysis of the $0.83-\mathrm{Hz}$ mode was performed using PEALS. Both the participation factors and right eigenvector entries corresponding to generator speed were analyzed. The participation factor, which is a cross product between the right and left eigenvectors, is an indication of controllability. This is useful for designing control systems and determining such issues as optimal placement of various actuator devices. The right eigenvector entry is associated with observability, and is an indication of how the particular machine swings with respect to the other machines in the system. Thus, the right eigenvector entries for the various machines define the mode shape, while the participation factors define how the mode could be optimally controlled.

Because the focus of this analysis is on the $0.83-\mathrm{Hz}$ interarea mode, generators throughout the 92LW Model were selected for tracking. The right eigenvector entries of these selected key generators are plotted in Figures 4.1 and 4.2, for the cases without and with the MTDC model included, respectively. Units were selected to include a large geographical dispersal throughout the system, located at strategic nodes of the transmission network. Furthermore, key generators were chosen, typically a large unit from the largest plant in a particular area. For interarea modes of oscillation, units at a given plant (or a small well-connected geographical area) will tend to swing together and, hence, have similar right eigenvector entries. Thus, the mode shape figures illustrate only select generators that demonstrate the interactions between the various areas for this mode. 
Table 4.1. Eigenvalues in 92LW Model Without MTDC $(0.1$ to $1.5 \mathrm{~Hz})$

Eigenvalue No.

1
2
3
4
5
6
7
8

2

3

4

5

6

7

8

10

11

12

13
Eigenvalues

-0.193578
-0.309314
-0.327173

$-0.346022$

$-0.350131$

$-0.538189$

$-0.575607$

$-0.587972$

$-0.482860$

$-0.699612$

$-0.813556$

$-0.564875$

$-0.566608$

$-0.919132$

$-0.514367$

$-0.337707$

$-0.304649$

$-0.735106$

$-0.358805$

$-0.456516$

$-0.107360$

$-0.217175$

$-0.513236$

$-0.227792$

$-0.434920$

$-0.401578$

$-0.237067$

$-0.345965$

$-0.140495$

$-0.219260$

$-0.198358$

$-0.180032$

$-0.258105$

$-0.398769$

$-0.388692$

$-0.337102$

$-0.270061$

$-0.399265$

$-0.195900$

$-0.011860$

$-0.049819$

$-0.164815$

$-0.199541$
0.747551

0.799774

0.868620

0.947027

0.948482

1.488002

1.614921

1.721245

2.090324

2.098813

2.220843

2.298099

3.572101

3.583416

4.531871

5.218447

5.527895

5.660519

5.914367

6.113287

6.288425

6.424511

6.508926

6.611739

6.662100

7.017793

7.038061

7.133780

7.182787

7.259583

7.330081

7.498230

7.750571

7.806112

7.929868

7.965631

8.084966

8.094153

8.235353

8.372635

8.508387

8.661058

8.696908
Erequency (Hz) Damping Ratio

0.1190

0.2507

0.1273

0.3607

0.1382

0.3525

0.1507

0.3432

0.1510

0.3463

0.2368

0.3401

0.2570

0.3357

0.2739

0.3327

0.3233

0.2251

0.3340

0.3535

0.3658

0.5685

0.5703

0.7213

0.8305

0.8798

0.9009

0.9413

0.9730

1.0008

1.0225

1.0359

1.0523

1.0603

1.1169

1.1201

1.1354

1.1432

1.1554

1.1666

1.1934

1.2335

1.2424

1.2621

1.2678

1.2868

1.2882

1.3107

1.3325

1.3542

1.3785

1.3842
0.3162

0.3440

0.2387

0.1567

0.2485

0.1128

0.0646

0.0550

0.1288

0.0606

0.0745

0.0171

0.0338

0.0786

0.0344

0.0651

0.0571

0.0337

0.0484

0.0196

0.0302

0.0271

0.0240

0.0333

0.0510

0.0490

0.0423

0.0334

0.0493

0.0238

0.0014

0.0059

0.0190

0.0229 
Table 4.1. (contd)

Eigenvalue No.

Eigenvalues

Erequency (Hz)

Damping Ratio

$\begin{array}{lll}44 & -0.193977 & 8.868014 \\ 45 & -0.375957 & 8.972172 \\ 46 & -0.040432 & 9.022776 \\ 47 & -0.367158 & 9.110851 \\ 48 & -0.179496 & 9.140314 \\ 49 & -0.237173 & 9.331198 \\ 50 & -0.120631 & 9.404383\end{array}$

1.4114

0.0219

1.4280

0.0419

1.4360

0.0045

1.4500

0.0403

1.4547

0.0196

1.4851

0.0254

1.4968

0.0128

Table 4.2. Eigenvalues in 92LW Model with MTDC Included $(0.1$ to $1.5 \mathrm{~Hz})$

Eigenvalue No.

1

2

3

4

5

6

7

8

9

10

11

12

13

14

15

16

17

18

19

20

21

22

23

24

25

26

27

28

29
Eigenvalues

-0.490732
-0.492198
-0.919432
-0.489955
-0.349108
-0.280587
-0.280879
-0.574795
-0.363491
-0.435596
-0.435400

$-0.107037$

$-0.107048$

$-0.216724$

$-0.522068$

$-0.234951$

$-0.235018$

$-0.419969$

$-0.402495$

$-0.237420$

$-0.237420$

$-0.140880$

$-0.140879$

$-0.218330$

$-0.218332$

$-0.197686$

$-0.197684$

$-0.179901$

$-0.254393$
3.430932

3.431377

3.584424

4.560416

5.224364

5.521218

5.521284

5.677850

5.891507

6.173919

6.174098

6.293573

6.293575

6.424790

6.515671

6.608564

6.608586

6.687434

7.016449

7.038350

7.038352

7.182848

7.182849

7.262222

7.262224

7.332467

7.332468

7.498017

7.756691
Frequency (Hz)

0.5460

0.5461

0.5705

0.7258

0.8315

0.8787

0.8787

0.9037

0.9377

0.9826

0.9826

1.0017

1.0017

1.0225

1.0370

1.0518

1.0518

1.0643

1.1167

1.1202

1.1202

1.1432

1.1432

1.1558

1.1558

1.1670

1.1670

1.1933

1.2345
Damping Ratio

0.1416

0.1420

0.2485

0.1068

0.0667

0.0508

0.0508

0.1007

0.0616

0.0704

0.0703

0.0170

0.0170

0.0337

0.0799

0.0355

0.0355

0.0627

0.0573

0.0337

0.0337

0.0196

0.0196

0.0301

0.0301

0.0270

0.0270

0.0240

0.0328 


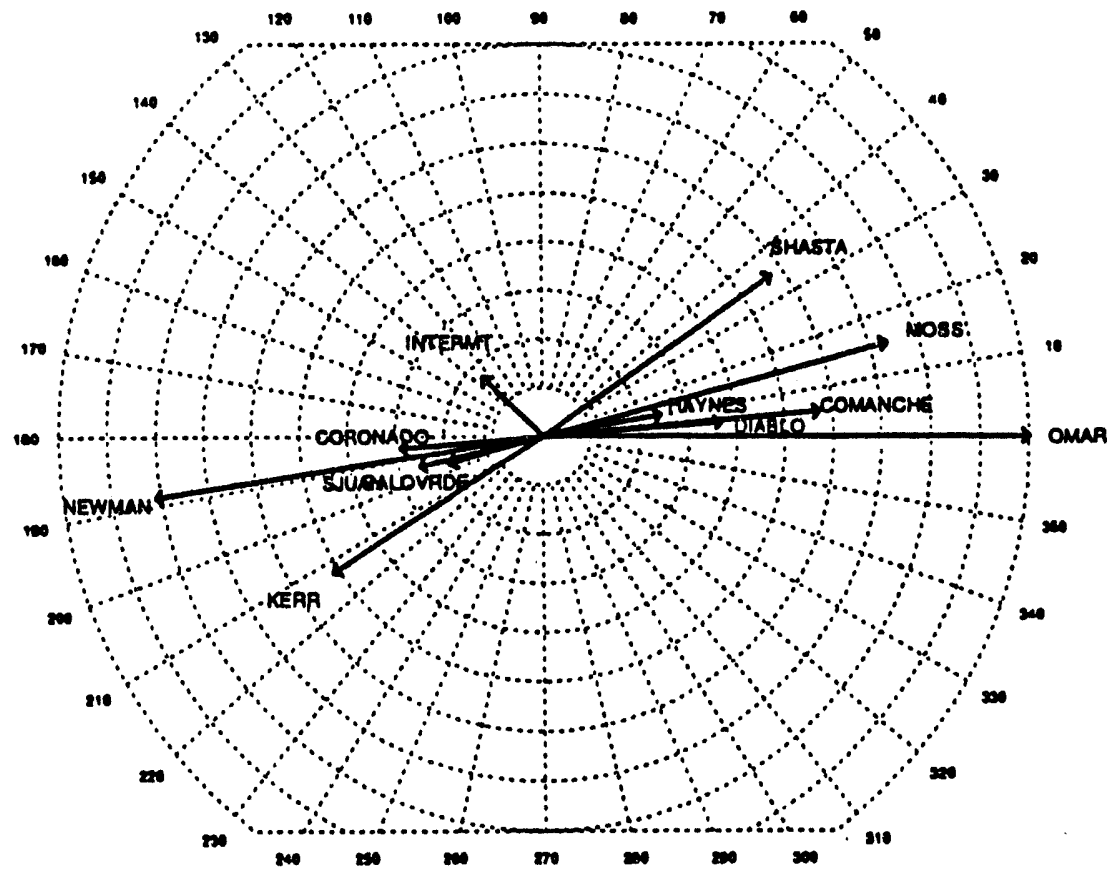

Figure 4.1. 92LW Model Mode Shape without MTDC using PEALS/Arnoldi (0.8305 Hz, 0.0646 Damping)

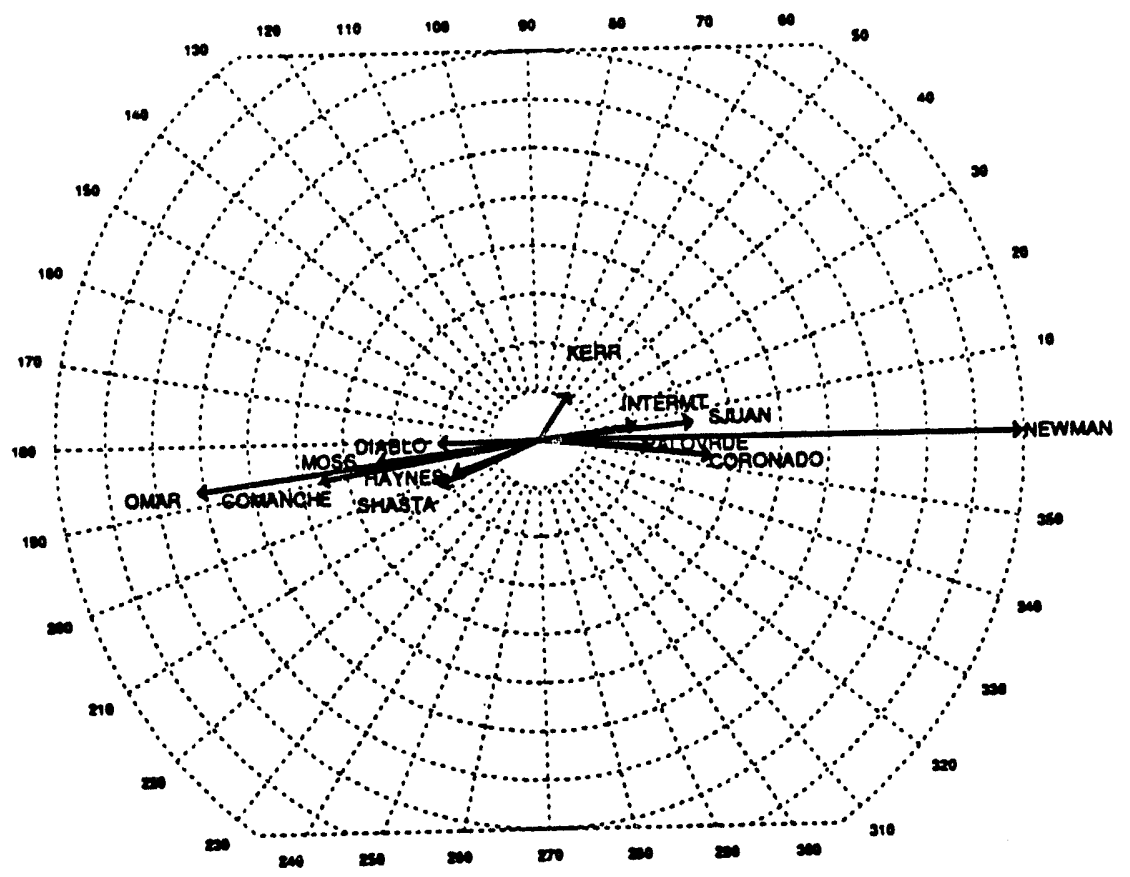

Figure 4.2. 92LW Model Mode Shape with MTDC Modeled using PEALS/Arnoldi (0.8315 Hz, 0.0666 Damping) 
The $0.83-\mathrm{Hz}$ mode exhibits an east-west mode of oscillation with a very strong boundary between Arizona and Southern California. This mode was excited by removing the Palo Verde to Devers transmission line for 0.625 second twice (with 0.625 second between the events), thus creating a double pulse at the frequency of interest (designed to excite modes with frequencies near $0.8 \mathrm{~Hz}$ ).

The simulation responses were selected to maximize the observed effects of this mode. Thus, generators with a high degree of participation in the mode were selected, and mode boundaries (where a group of machines oscillated against another group of machines) were investigated in detail. The simulation results, given in Figures 4.3 through 4.14 , were carefully selected to maximize demonstrating this particular mode.

Prony analysis was performed on the simulation results. There was an extreme amount of difficulty extracting consistent results for various disturbances (other disturbances than the one described above were tried) and monitoring location. The inclusion of the MTDC model did not seem to have much effect on the results or on the consistency of the results. It is believed that problems with the 92LW Model itself, described in Appendix B, is causing problems with being able to perform Prony analysis (and may also be causing problems with the SSSP eigenanalysis routines). These problems are evident in the no-disturbance (or predisturbance) data, which have a considerable amount of activity (they should remain steady until a perturbation is applied).

Because of these modeling problems (even without the MTDC model included), no further investigations on this model were performed. Considerable attention was devoted to addressing some of these issues, including integration step size and type sensitivities, and the identification and a proposed correction for an unstable mode associated with the Alberta system, discussed in Appendix B. Further modifications to the 92LW Model were beyond the scope of this project.

Prony analysis was performed on the time-domain simulations shown in Figures 4.3 through 4.14. The analysis results are summarized in Table 4.3. The results are not highly consistent, which is an indication that the analysis is not accurately identifying the modes. As discussed previously, the source of this error is likely problems with the model itself, rather than any interaction of the model with the MTDC data Consequently, the effective use of Prony techniques for this type of analysis requires improvements in the overall model representation of the power system.

The main result of this part of the study was successful implementation of the MTDC model in the large-scale planning models. However, problems associated with the eigenanalysis tools accurately calculating the modal interactions (the result of the reduced-order model analysis described in Section 3), combined with problems associated with the planning models themselves (as discussed in Appendix B), prevented a more detailed assessment of the MTDC model and SSSP eigenanalysis tools when applied in the planning models. 


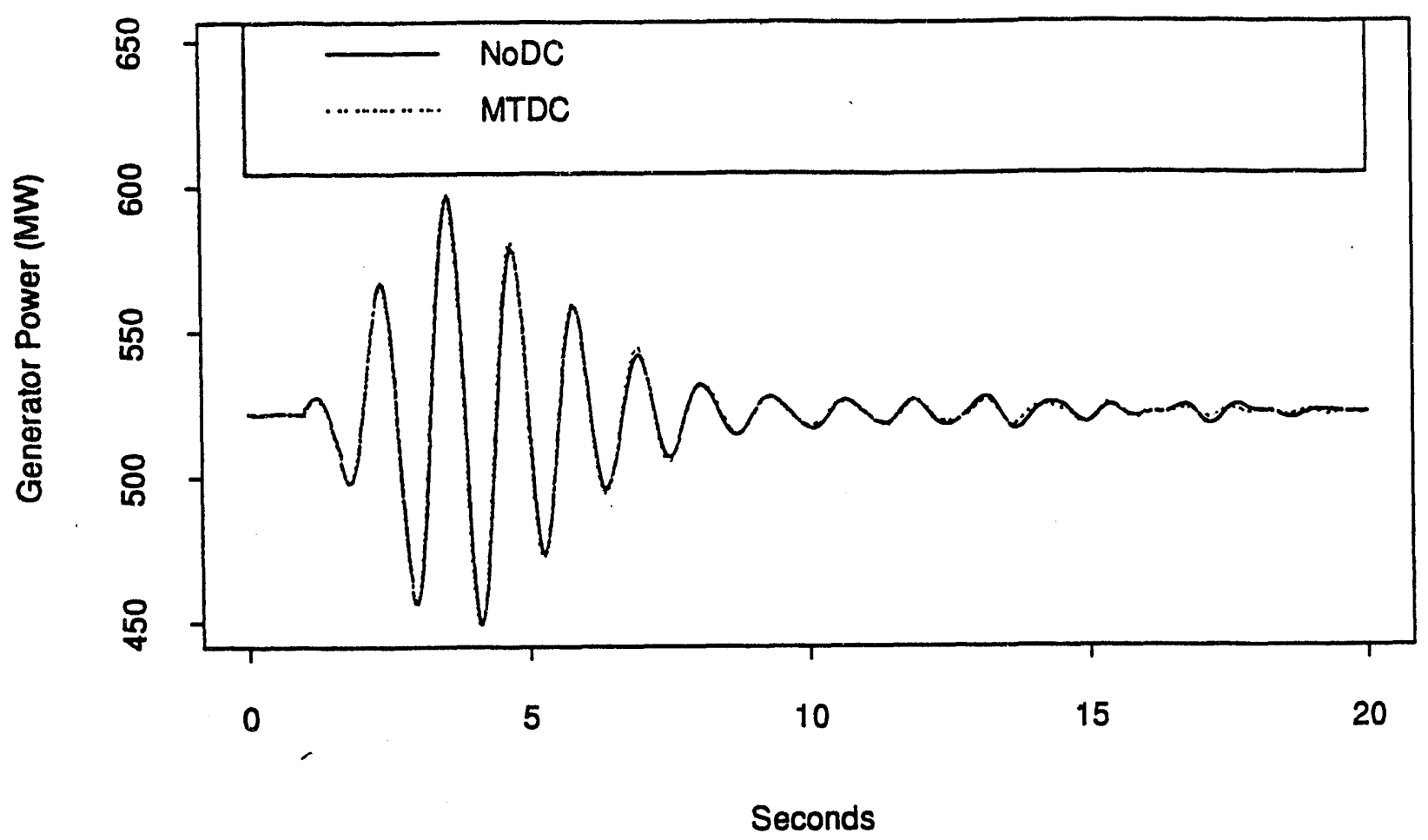

Figure 4.3. Unit GEYSER D Response to Palo Verde - Devers Line Outage

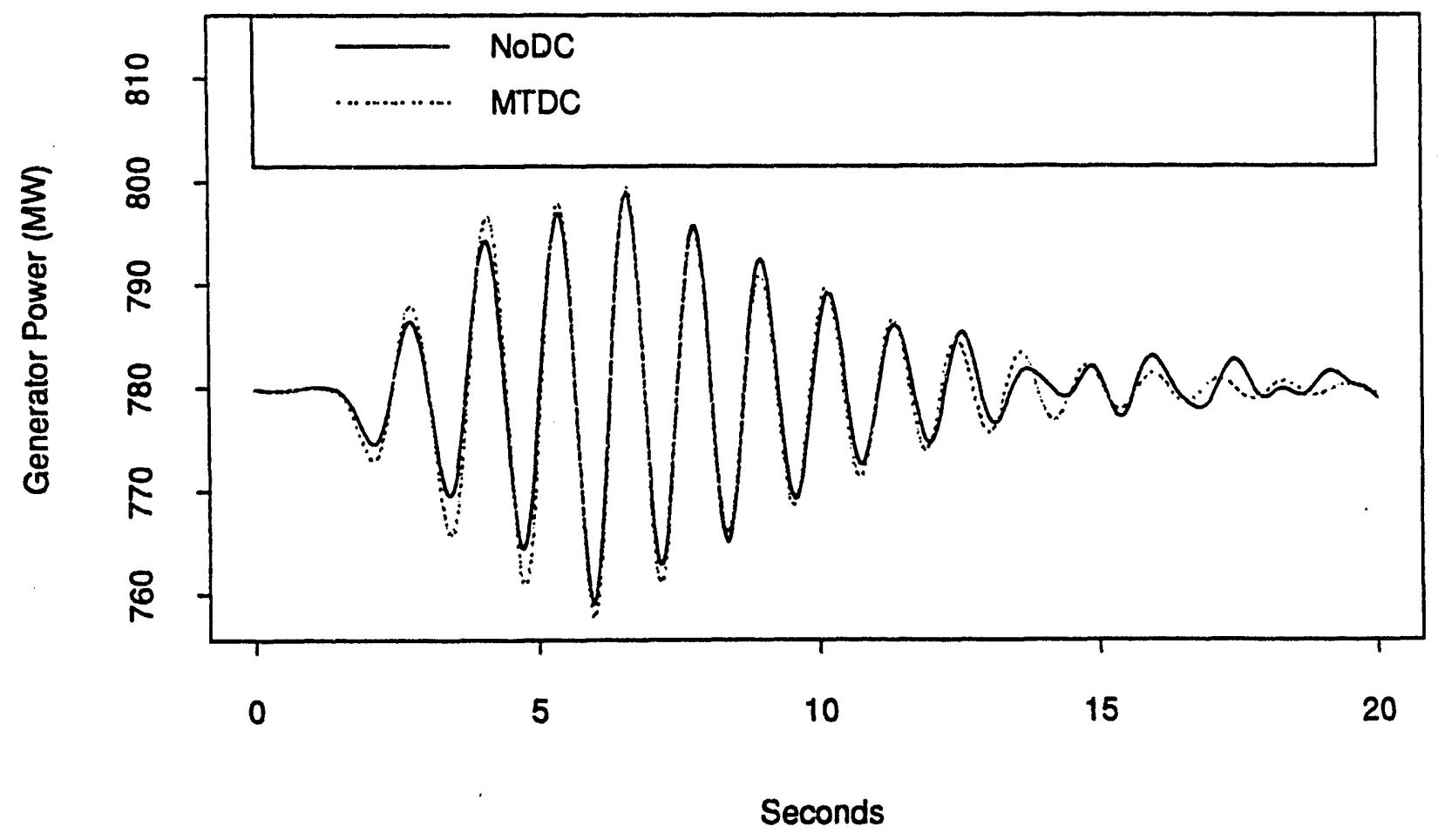

Figure 4.4. Unit COLSTP 4 Response to Palo Verde - Devers Line Outage 


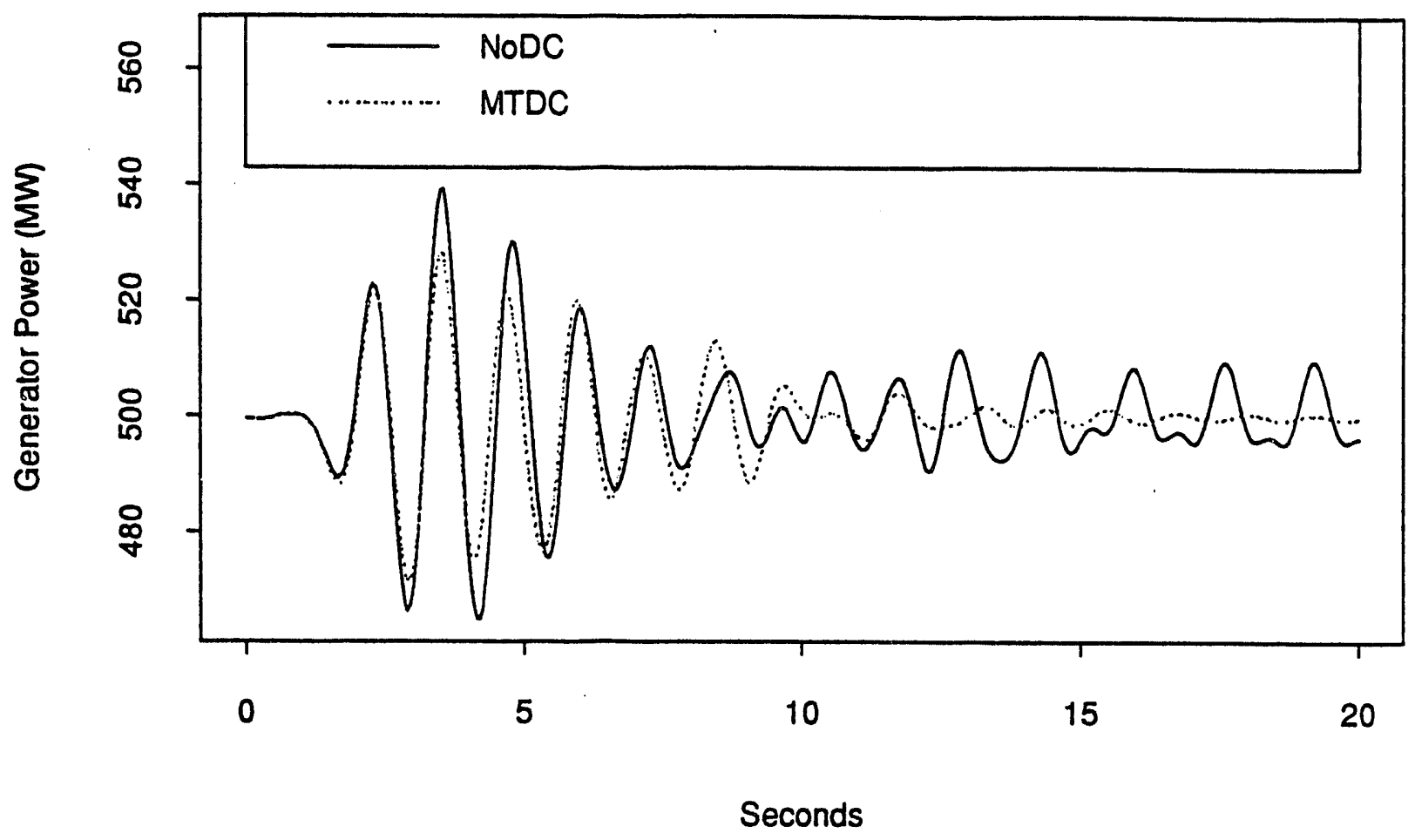

Figure 4.5. Unit COMANCHE Response to Palo Verde - Devers Line Outage

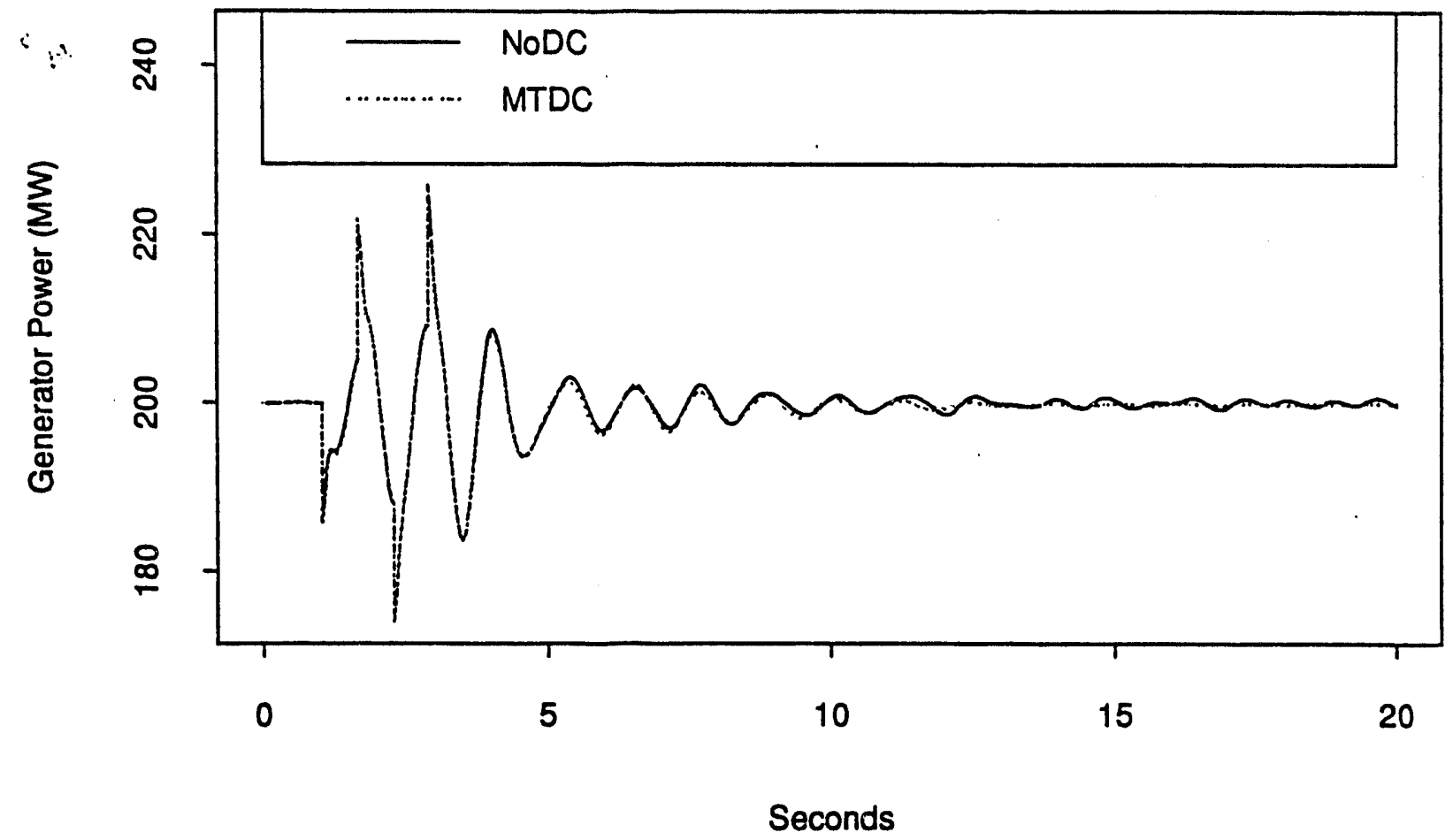

Figure 4.6. Unit CORONAD2 Response to Palo Verde - Devers Line Outage 


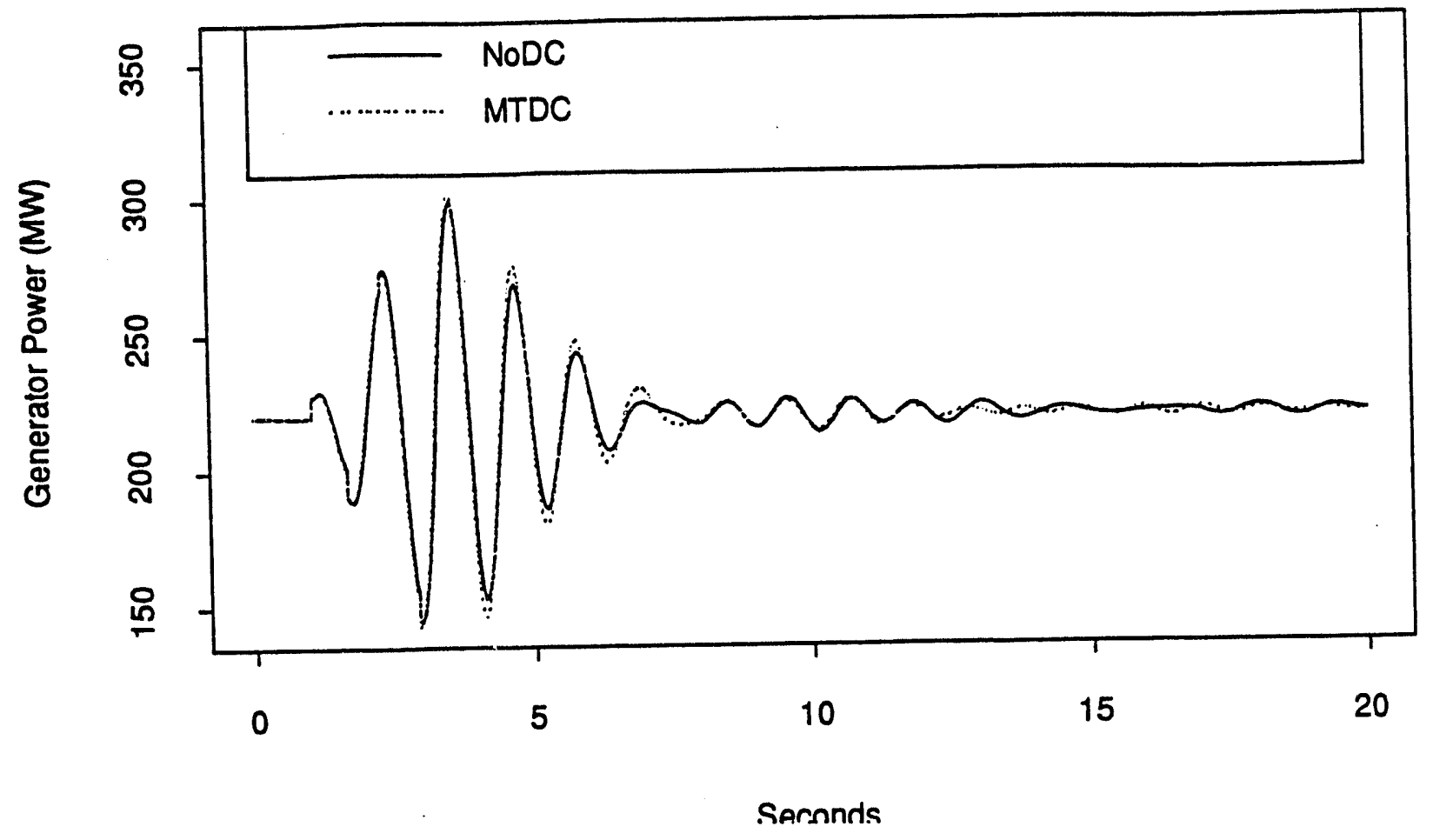

Figure 4.7. Unit OMAR G Response to Palo Verde - Devers Line Outage

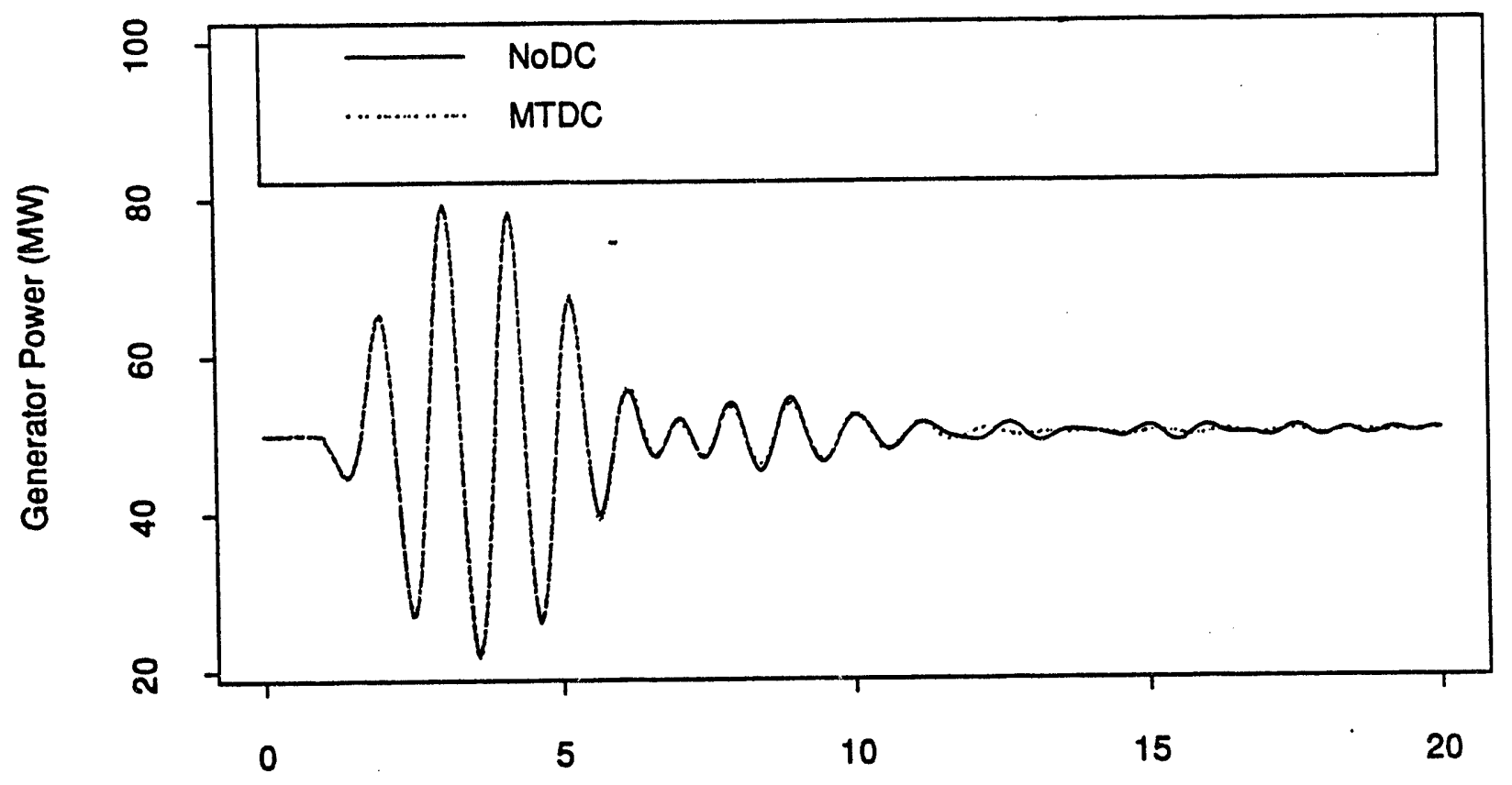

Seconds

Figure 4.8. Unit NEWMN4G1 Response to Palo Verde - Devers Line Outage 


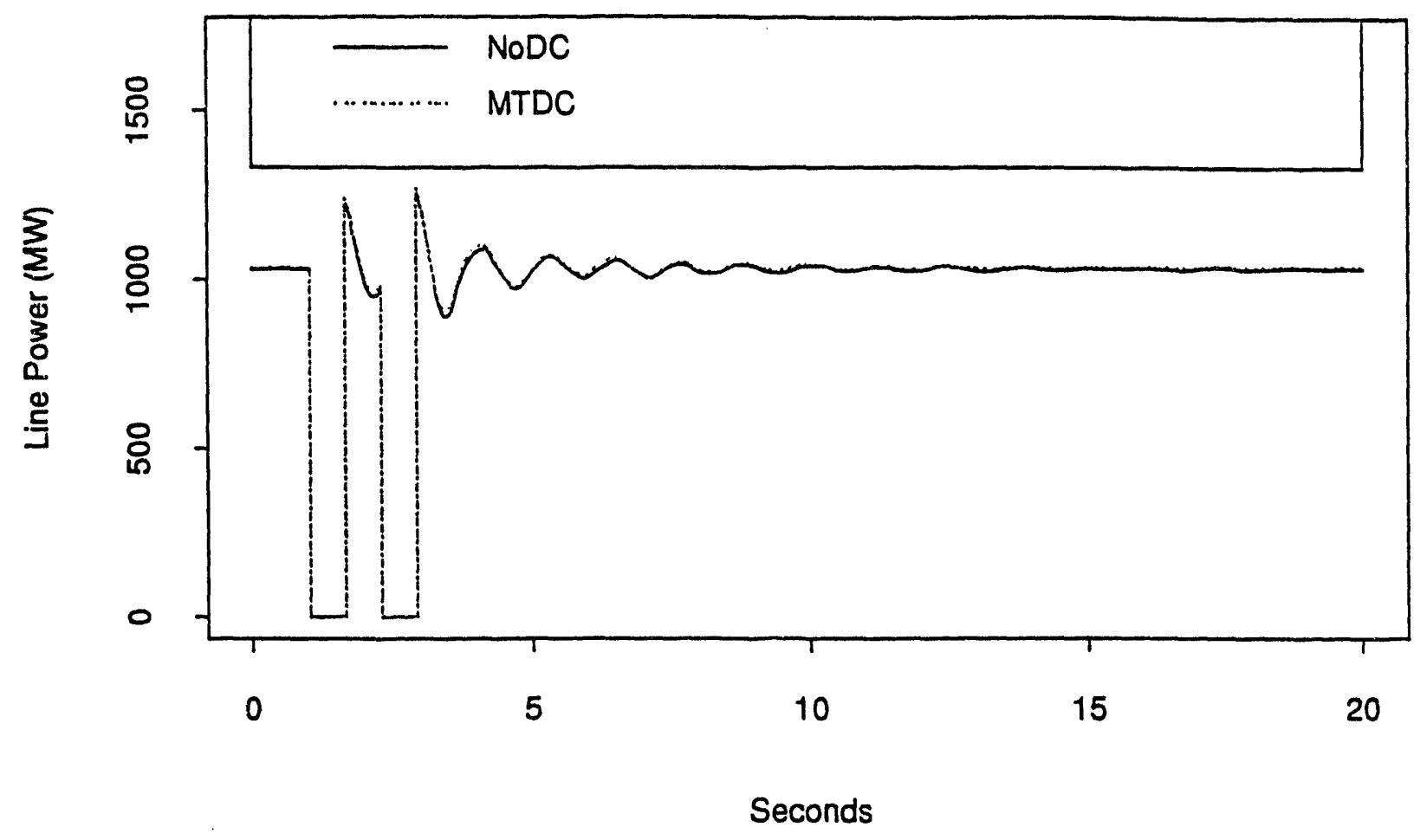

Figure 4.9. Line PALOVRDE - DEVERS Response to Palo Verde - Devers Line Outage

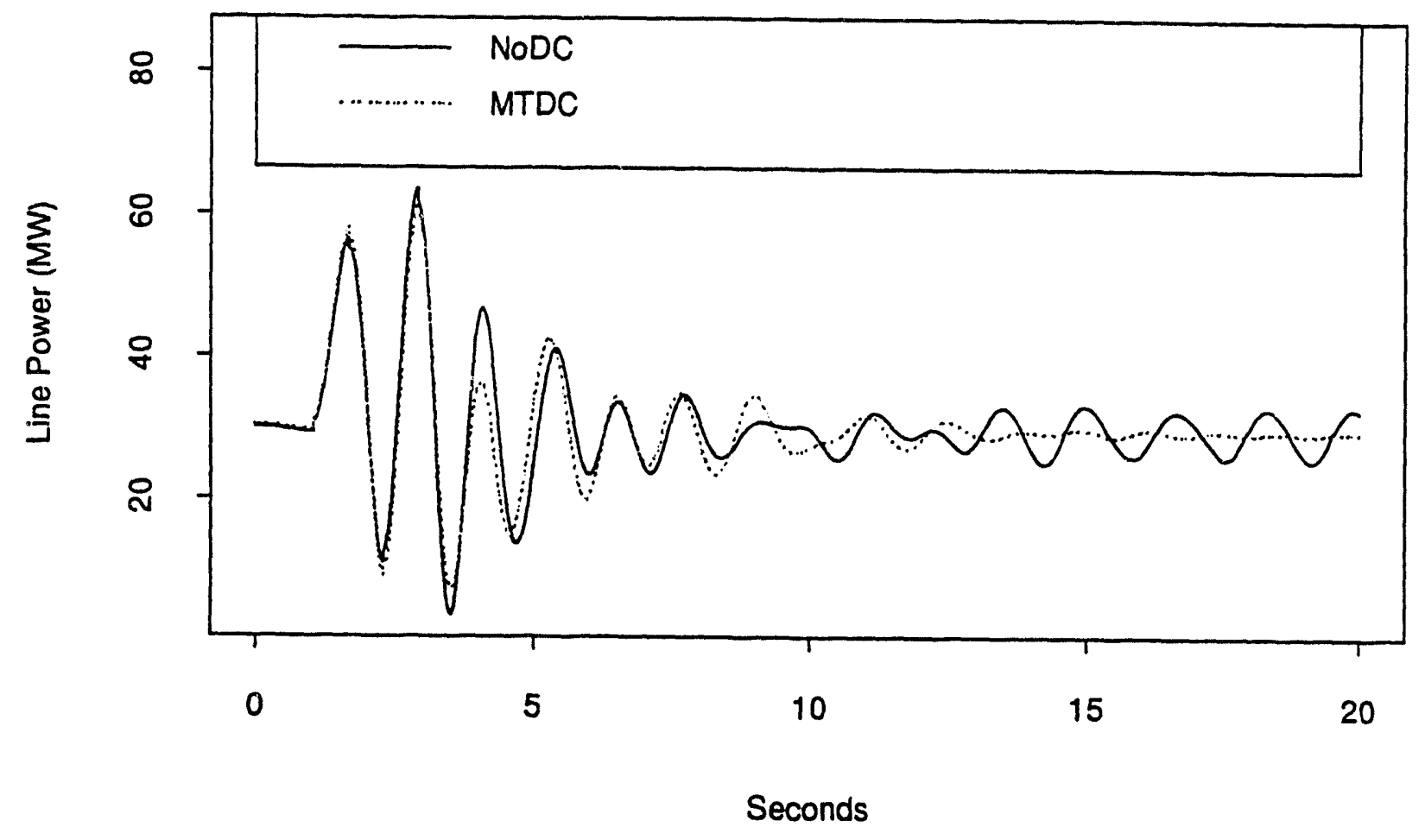

Figure 4.10. Line LOSTCANY - CURECANT Response to Palo Verde - Devers Line Outage 


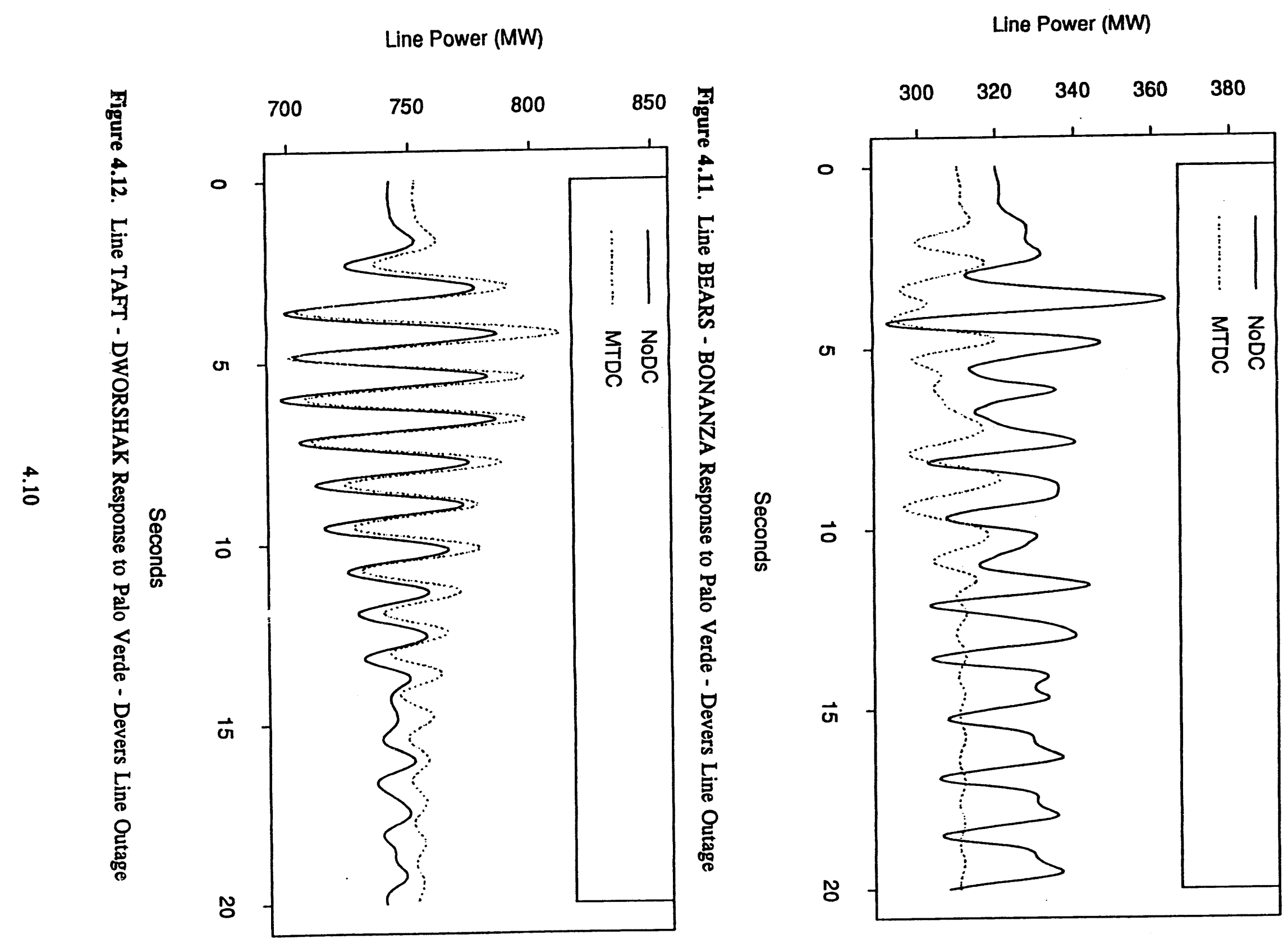




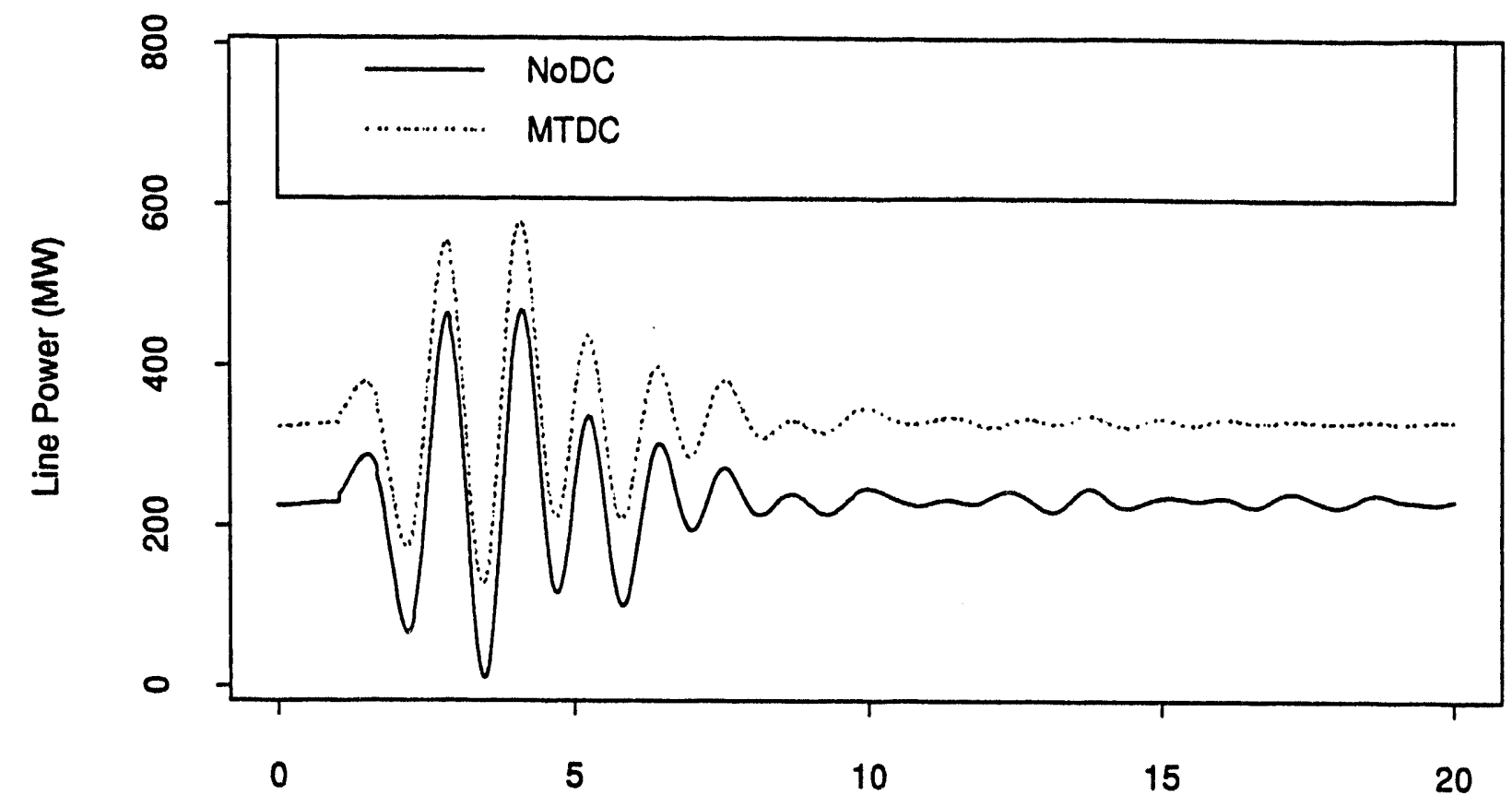

Seconds

Figure 4.13. Line MALIN - ROUND MT Response to Palo Verde - Devers Line Outage

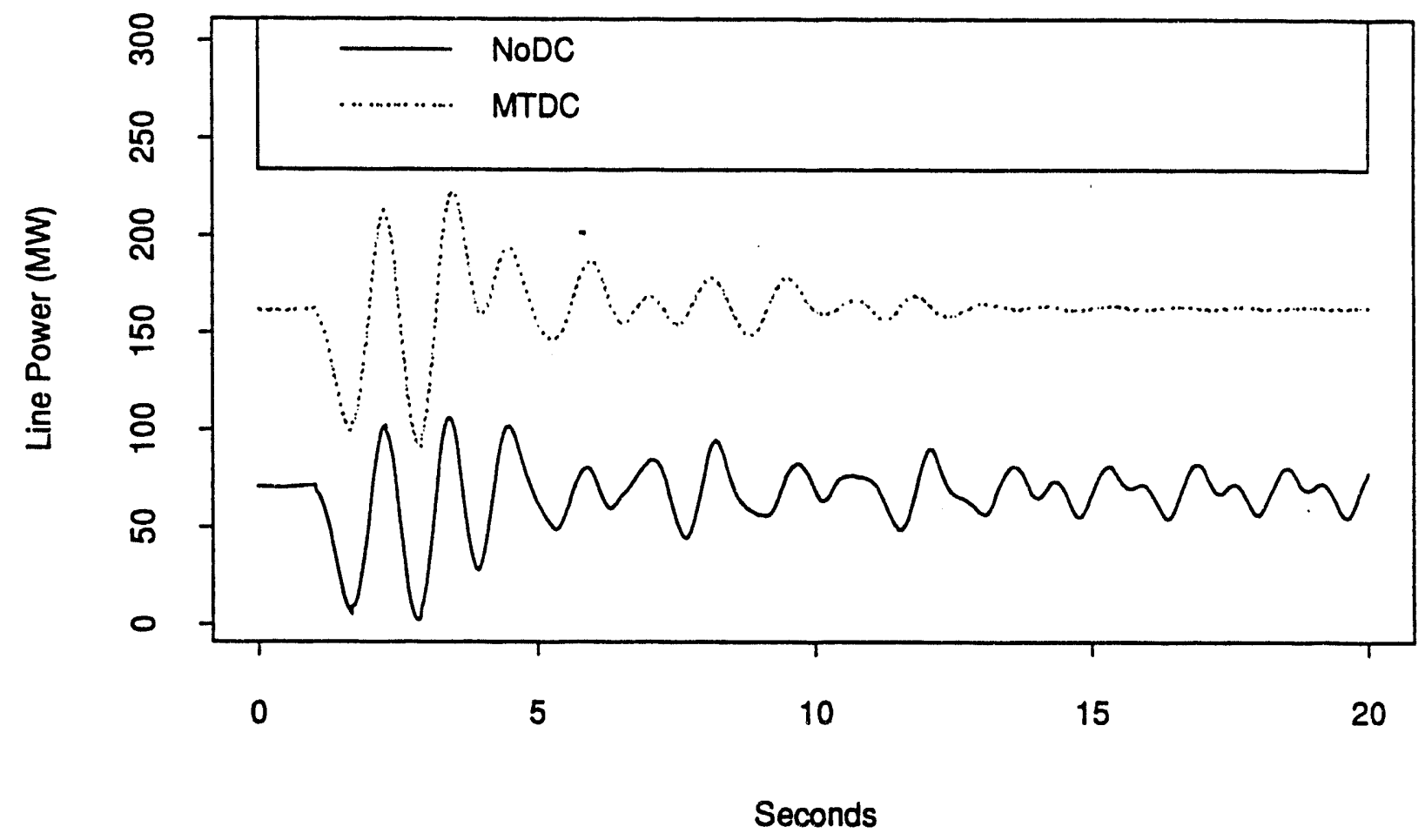

Figure 4.14. Line HUNTNGTN - PINTO Response to Palo Verde - Devers Line Outage 
Table 4.3. Prony Results for 92LW Model

(a) No MTDC

Data

GEYSER D Generator Power COLSTP 4 Generator Power CORONAD2 Generator Power OMAR G Generator Power DEVERS - PALOVRDE Line Power DWORSHAK - TAFT Line Power
Erequency (Hz)

0.8640

0.8138

0.8192

0.8246

0.8353

0.8294
Damping Ratio 0.0859

0.0583

0.0577

0.0158

0.0467

0.0345

(b) MTDC Included

Data

GEYSER D Generator Power COMANCHE Generator Power CORONAD2 Generator Power OMAR G Generator Power NEWMN4G1 Generator Power DEVERS - PALOVRDE Line Power DWORSHAK - TAFT Line Power
Erequency $(\mathrm{Hz})$

0.8445

0.8113

0.8455

0.8285

0.8463

0.8387

0.8259
Damping Ratio

0.0565

0.0455

0.0625

0.0919

0.0620

0.0554

0.0710 


\subsection{Conclusions and Recommendations}

The results of this study indicate that although the SSSP tools appear able to read and process the data contained within the MTDC model, significant inconsistencies raise serious doubts as to the accuracy of these analytic tools. This study found that the SSSP tools were inconsistent between themselves as well as with other modal analysis techniques, such as Prony analysis on ETMSPgenerated time-domain simulation results. Furthermore, some of the tools did not perform well at all, such as the PEALS (Arnoldi) program unable to accurately identify modes below $0.5 \mathrm{~Hz}$ with the MTDC model included, and MASS unable to calculate the right eigenvector entries.

It is very likely that further modification is necessary to the SSSP tools to enable them to process the MTDC data correctly. Particularly important is the FLODA5 module modification, which is crucial for the conversion of the data from BPA POWERFLOW format to the format used by the PSAPAC tools. The modifications to the FLODA5 modules (for MASS and PEALS) were based on changes made to the FLODA5 module in ETMSP, which has since been modified, and the SSSP FLODA5 modules may have unique requirements from the ETMSP FLODA5 module, which have not been addressed.

Therefore, it is recommended that further work be performed to update the SSSP tools accordingly and perform tests to ensure that the MTDC data is being read correctly by the programs. One means by which to test the FLODA5 module would be to create an identical MTDC model in IPFLOW (the PSAPAC power flow program) and compare the results with the MTDC model in the BPA POWERFLOW format.

The results of the study, however, point to the MTDC model as the source of many of the inconsistencies. It is recommended that the model be further modified to reduce much of its associated complexity (while at the same time preserving as much of the dynamics important for eigenanalysis) to determine if modeling problems are present. This approach will allow identification of the model characteristics that are introducing the sources of error. Quantification of these sources is important if the tools are to be increasingly used.

Finally, when the MTDC model was incorporated into the large planning model, significant difficulties were encountered associated with problems with the planning model itself. It is highly recommended that steps be taken to "clean up" this planning model before relying on it for analytic modal analysis techniques. 


\subsection{References}

Hammad, A., R. Minghetti, J. Hasler, P. Eicher, R. Bunch, and D. Goldsworthy. 1993. "Controls Modelling and Verification for the Pacific Intertie HVDC 4-Terminal Scheme," IEEE Transactions on Power Delivery 8(1):367-375.

Martin, D. E., W. K. Wong, D. L. Dickmander, R. L. Lee, and D. J. Melvold. 1992. "Increasing WSCC Power System Performance with Modulation Controls on the Intermountain Power Project HVDC System," IEEE Transactions on Power Delivery 7(3):1634-1642.

Ontario Hydro. 1993. Extended Transient-Midterm Stabllity Program: Version 3.0 - Volume 3: Application Guide. EPRI TR-102004, Electric Power Research Institute, Palo Alto, California.

Smith, J. R., M. K. Donnelly, and C. S. Woods. 1992. HVDC System Models in ETMSP. Control Technologies, Inc., Bozeman, Montana. 
Appendix A

Control Block Diagrams 


\section{Appendix A}

\section{Control Block Diagrams}

This Appendix contains the control block diagrams for the MTDC model. These diagrams were taken directly from the report CTI report (Smith et al. 1992) prepared for BPA, modified slightly to illustrate connectivity between the various blocks.

\section{Reference}

Smith, J. R., M. K. Donnelly, and C. S. Woods. 1992. HVDC System Models in ETMSP. Control Technologies, Inc., Bozeman, Montana. 


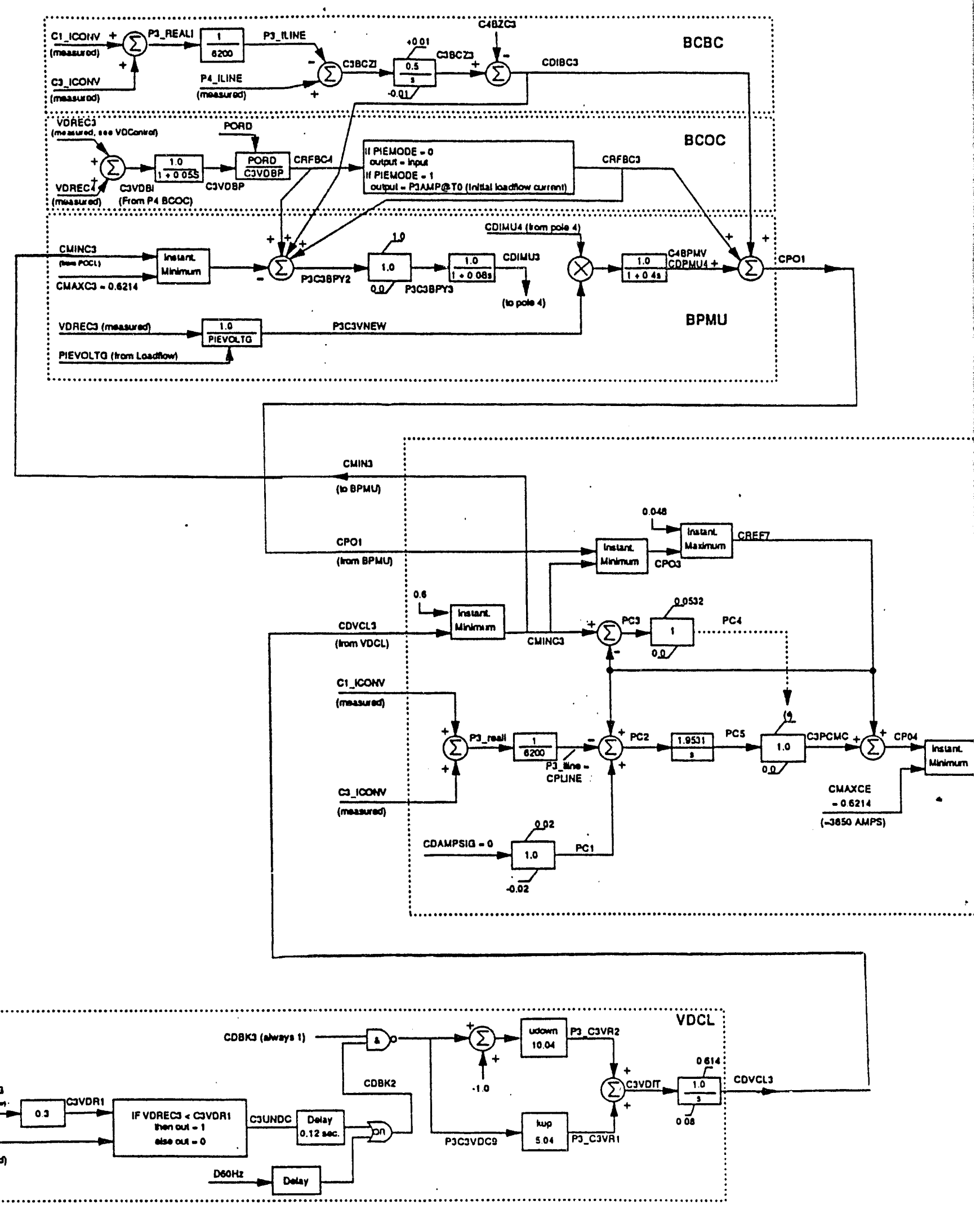

Figure A.1.(a) Celilo Conv 

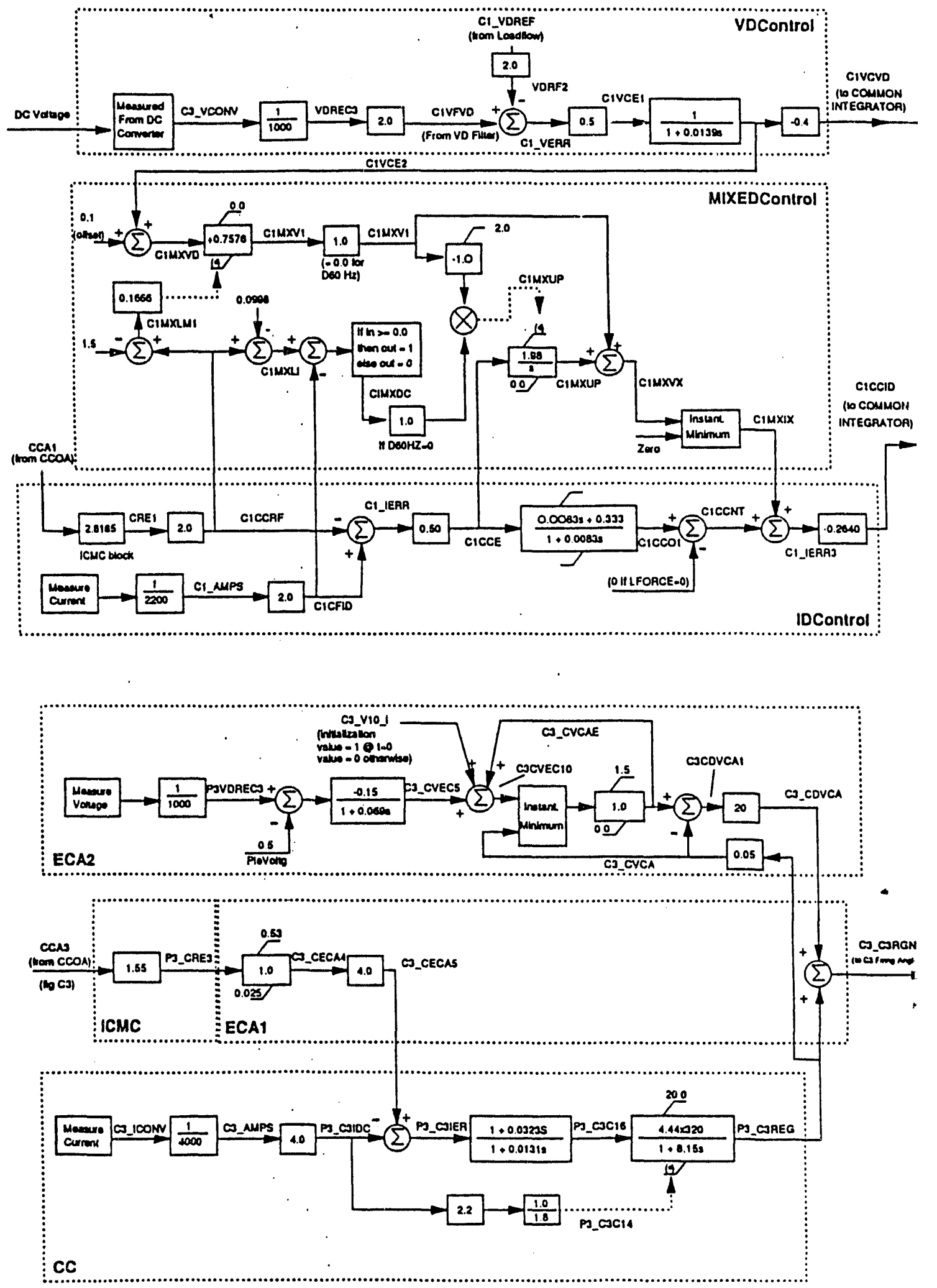

Figure A.1.(b) Celilo Converte 


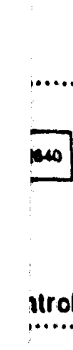

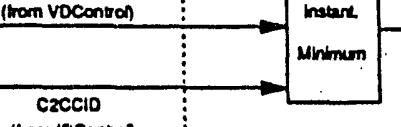

CrCCID
(rom loconted

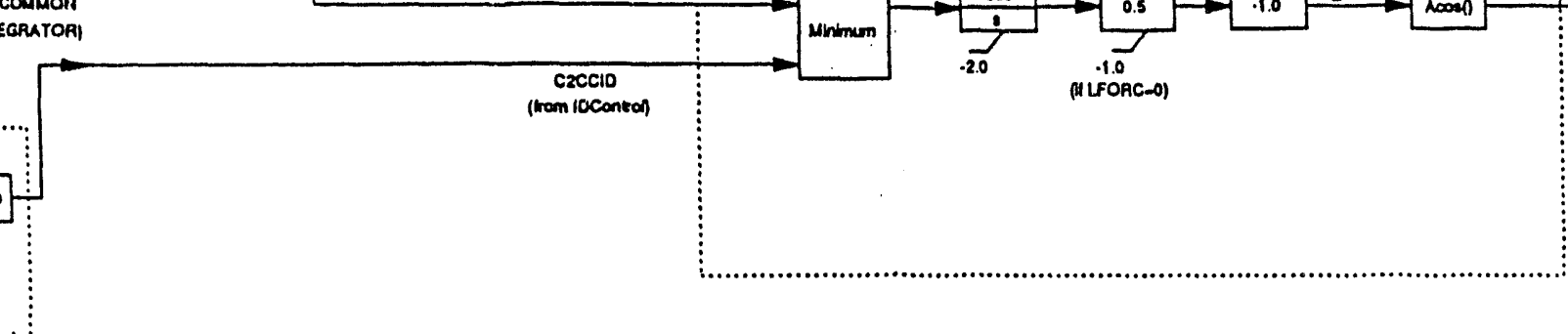

Itrol

0

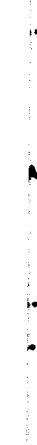



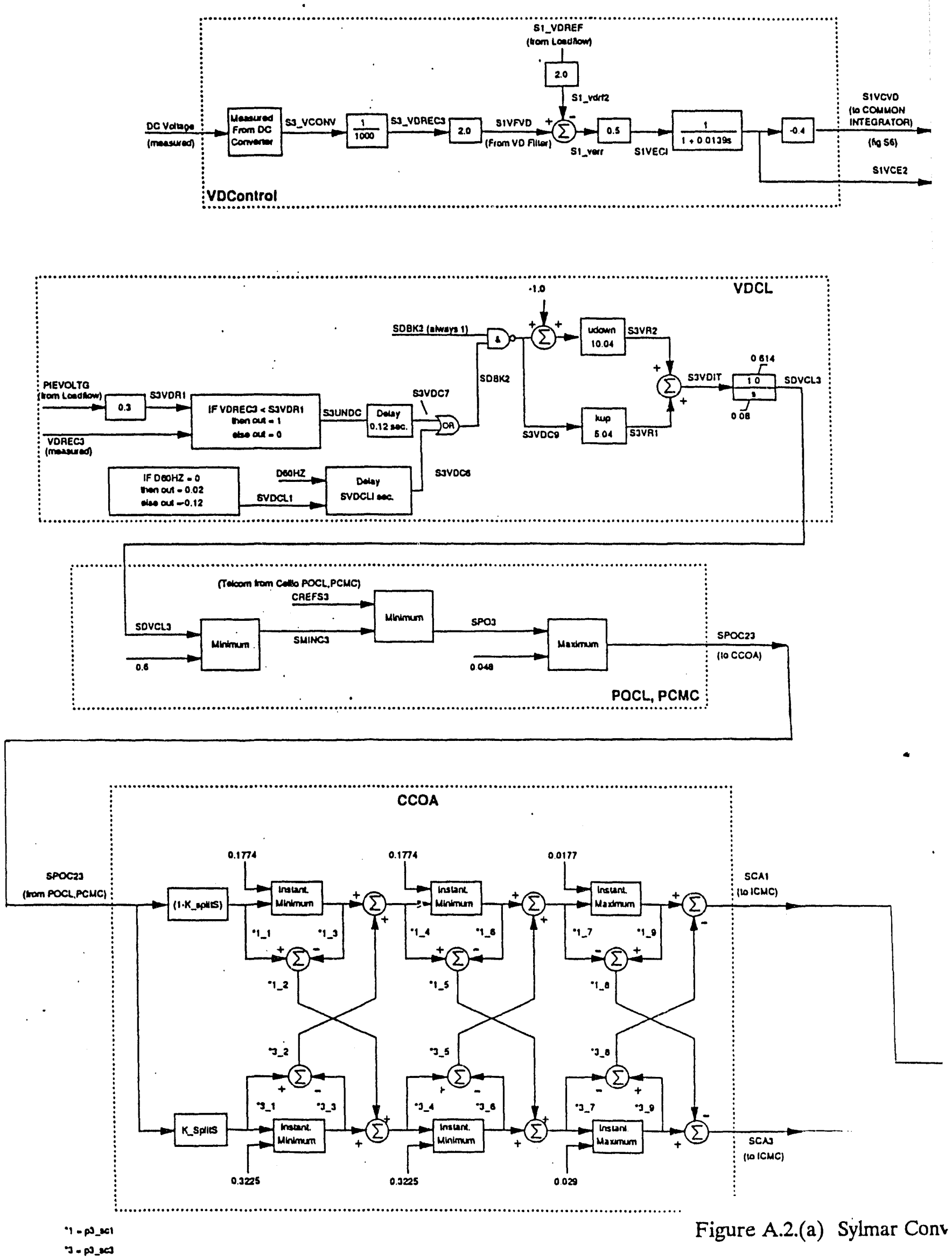


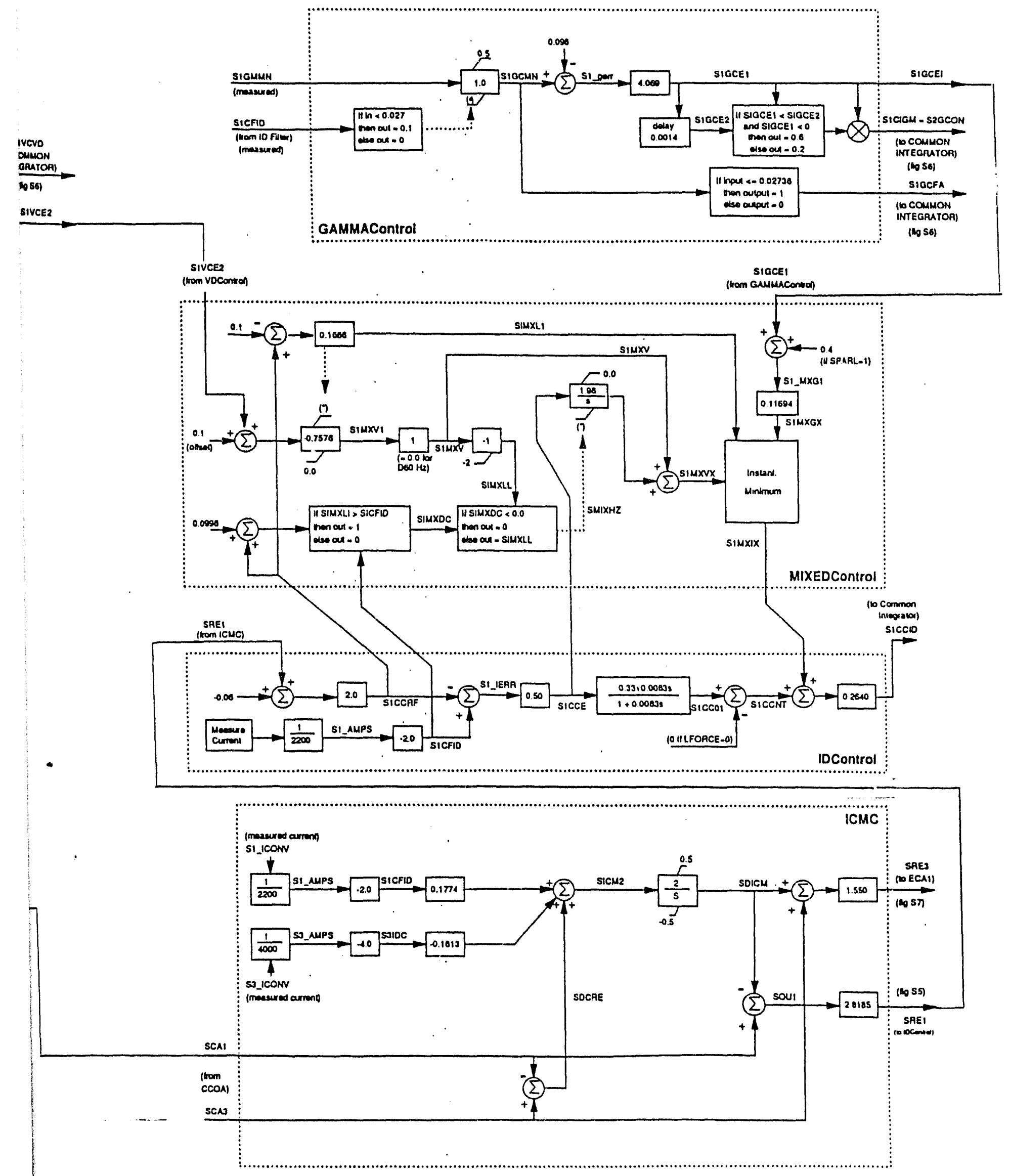



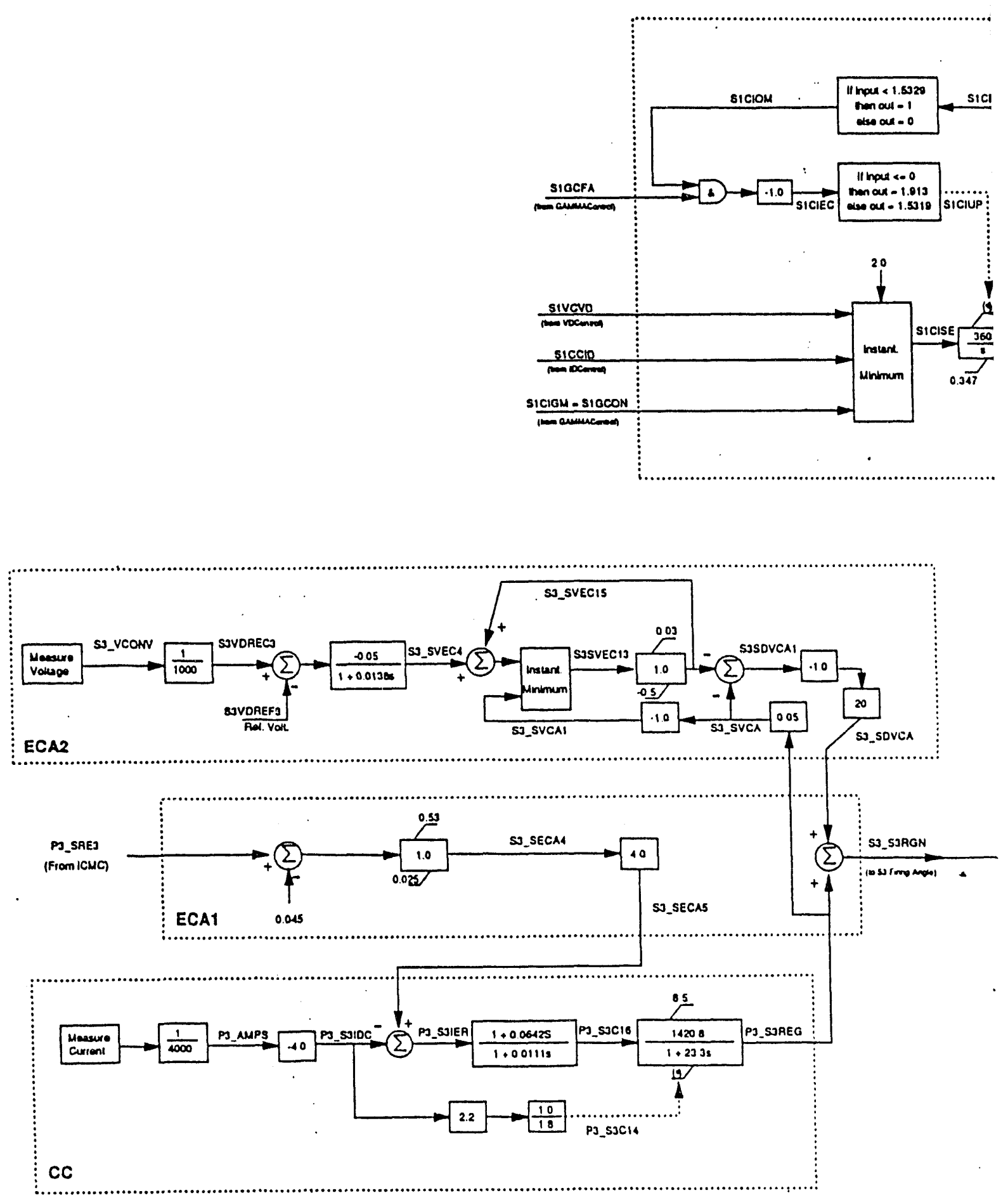

Figure A.2.(b) Sylmar Convertt 


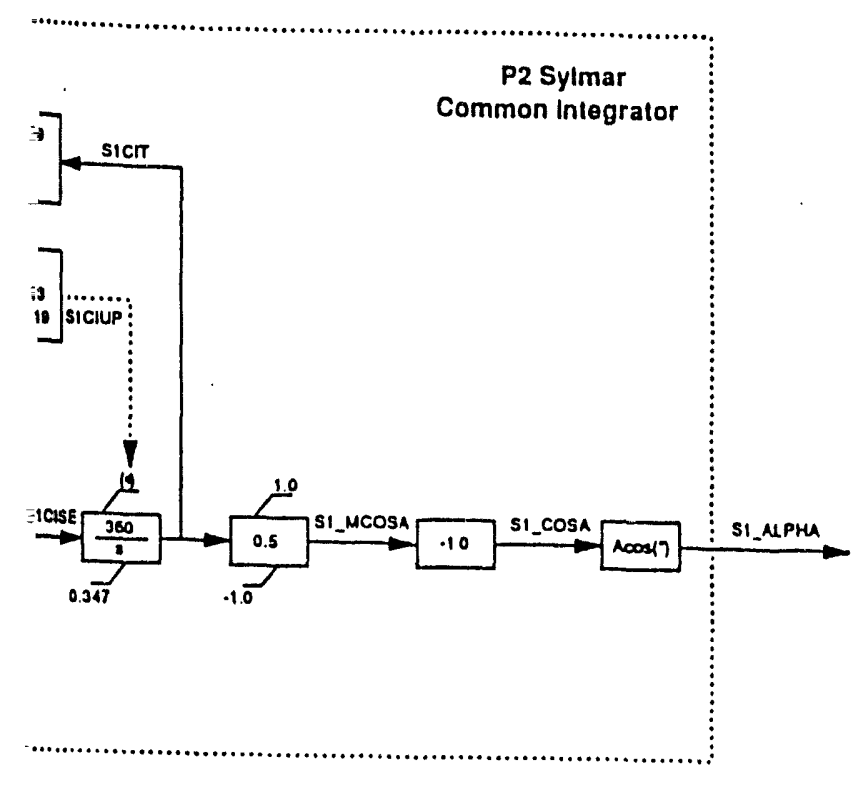

$\cdots$
$\vdots$ 


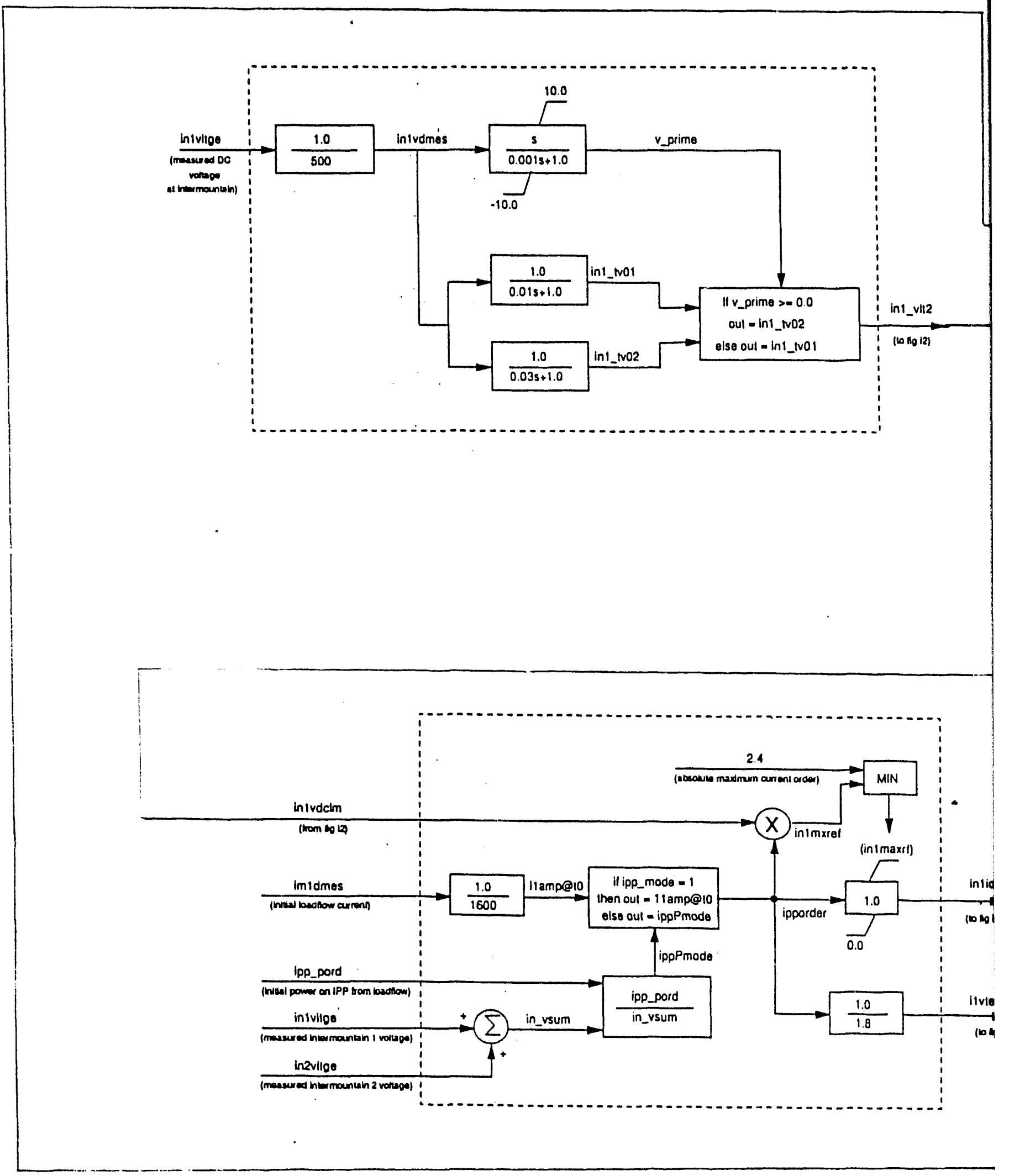

Figure A.3. Intermountain Cc 

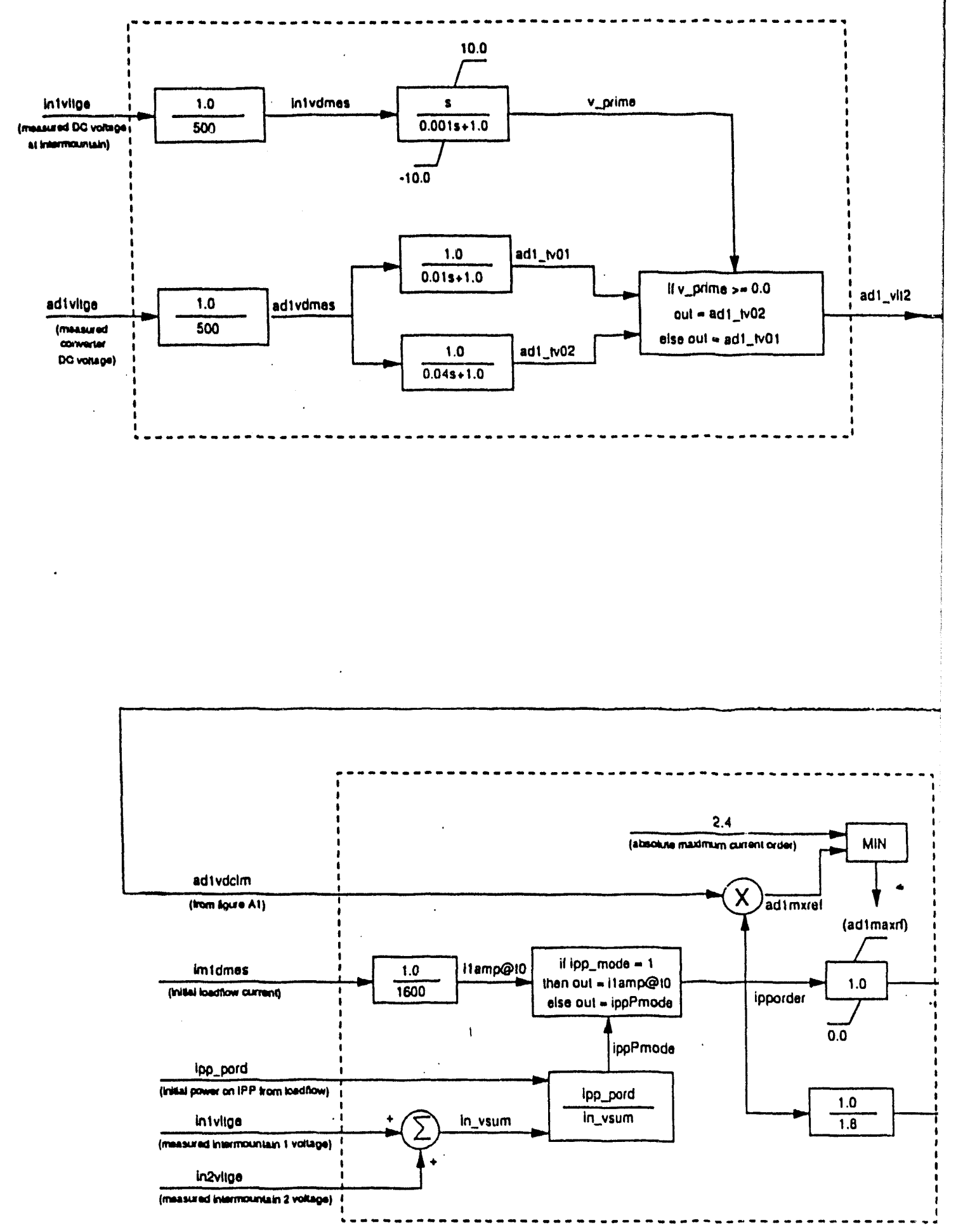

Figure A.4. Adelanto Con 


\title{
Appendix B
}

\author{
Brake Test
}

The model representation of the western United States power system as developed by utility members of the Western Systems Coordinating Council (WSCC) and provided by BPA to perform this analysis was a 1992 light winter case. It consists of 2428 buses, 3673 lines, 990 transformers, 314 detailed machines, and 74 classical machines representing the interconnected power system of the western United States, referred to as the 92LW Model. There is considerable concern over the accuracy of this model. Considerable attention was devoted addressing some of these issues, including integration step-size and type sensitivities, and the identification and a proposed correction for an unstable mode associated with the Alberta system, which are discussed in detail in this appendix.

\section{Brake Test Description}

One of the first activities performed under this contract was to re-create the time-domain transient simulation results and compare these to results obtained by previous BPA analysis of the same data to ensure that the programs were yielding consistent results. The case involved using the 92LW Model, adjusted to approximate the various conditions of the BPA/TransAlta brake tests performed on November 19,1991. Then, simulations of the brake insertion were performed with various sensitivities. J. F. Hauer and G. L. Keenan, BPA, recently indicated substantial uncertainty regarding the accuracy of the simulation results, manifested by the fact that the results can be dramatically different when cross-validating the results between different transient stability programs (there is uncertainty whether the differences are related to the programs themselves, the model data used in the analysis, or both). These uncertainties aside, this case was used to gain familiarity with the simulation packages and the model data, and to ensure that the results obtained by PNL match those simulations performed by BPA (to verify that the programs were consistent on different computer platforms). In addition, some exploratory research was performed to analyze the implications of these differences and attempt to ascertain possible ways to provide a "quick fix" to these discrepancies.

Several cases are part of the brake est analysis, all based on the 92LW Model. The variations include adjusting generation and load in the Northwest to correspond to actual conditions during the brake test, netting out the TransAlta system, the Kemano plant, and the dc line. In all (and with various combinations), there are 10 different cases, of which only two were considered for further investigation as a part of this work. These two cases both have the generator schedules adjusted and the dc lines netted out (both PDCI and IPP). The first case, called 92LW1T010, has both the Kemano plant and TransAlta system netted out. The second case, 92LW1T012, includes the Kemano plant and TransAlta dynamics. 
With both the TransAlta system and Kemano station netted out, the system was well behaved, and generally agreed very well between different simulation packages. With the TransAlta system and the Kemano plant included, the results were not consistent between the various simulation packages, according to BPA staff, nor do they match measured data. Therefore, the model data or the packages themselves are suspected of introducing anomalous response.

Sensitivity analysis was performed on these cases to explore the possibility that numerical error might be contributing to the modeling inconsistencies. This analysis involved experimenting with different integration methods and time steps. The baseline case uses the Trapezoidal method with an integration time step of 1 cycle. The sensitivities performed included both the Trapezoidal and the Fourth-Order Runge-Kutta methods, with time steps varying from one to one-quarter cycle. As a general rule, the Trapezoidal method is less accurate than the Runge-Kutta method. However, the Trapezoidal method can be used with a relatively large integration step regardless of any small time constants in the system, and, as a result, fast solutions can be reached (Kundur et al. 1993). The purpose of this investigation is to see whether significant error is introduced with the utilization of the Trapezoidal integration method with a step size of 1 cycle as compared to the Fourth-Order RungeKutta method or other integration step sizes. Figures B.1 through B.10 compare the Trapezoidal and Runge-Kutta methods for Cases 92LW1T010 and 92LW1T012, and Figures B.11 through B.18 compare the Trapezoidal and Runge-Kutta methods for Case 92LW1T012 only.

The basic difference between Case 92LW1T010 and Case 92LW1T012 is that in the latter case, TransAlta goes out-of-step with the rest of the system (several seconds into the simulation). This causes the results for this case to be dramatically different depending upon the type (and time step) of integration used. These differences are not apparent in the first case, in which there is no instability associated with the TransAlta system. Therefore, it appears that the instability itself is causing the differences observed between the simulation packages rather than any problems or differences between the packages themselves, as illustrated by the differences observed using the same package with different integration methods and time steps.

From the data represented in the figures, the Fourth-Order Runge-Kutta method with about a 0.5 -cycle integration period is desired. This was determined by observing that the results between the 0.5 -cycle and 0.25 -cycle Runge-Kutta are similar, indicating that the 0.5 -cycle case is most likely yielding results that are reasonably accurate, providing a good balance ween performance and accuracy. One option suggested by the ETMSP manual is to use the Runge-Kutta method during periods of the simulations in which there are relatively fast dynamics, switching to the Trapezoidal method for mid-term or long-term simulation effects. All ETMSP simulations (other than those associated with this sensitivity analysis) for this study use the Fourth-Order Runge-Kutta method with a 0.01 -second integration period ( 0.6 cycle). 

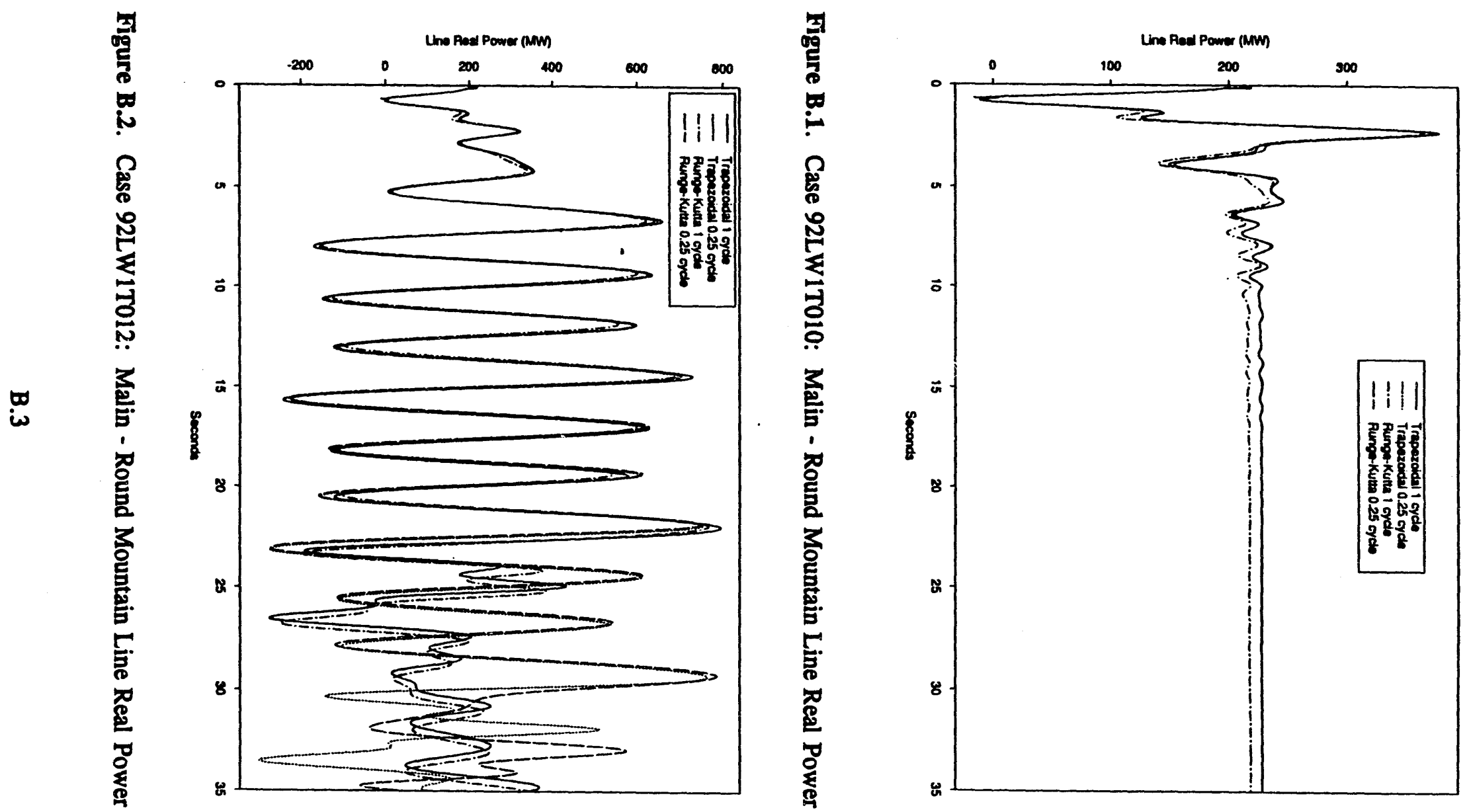


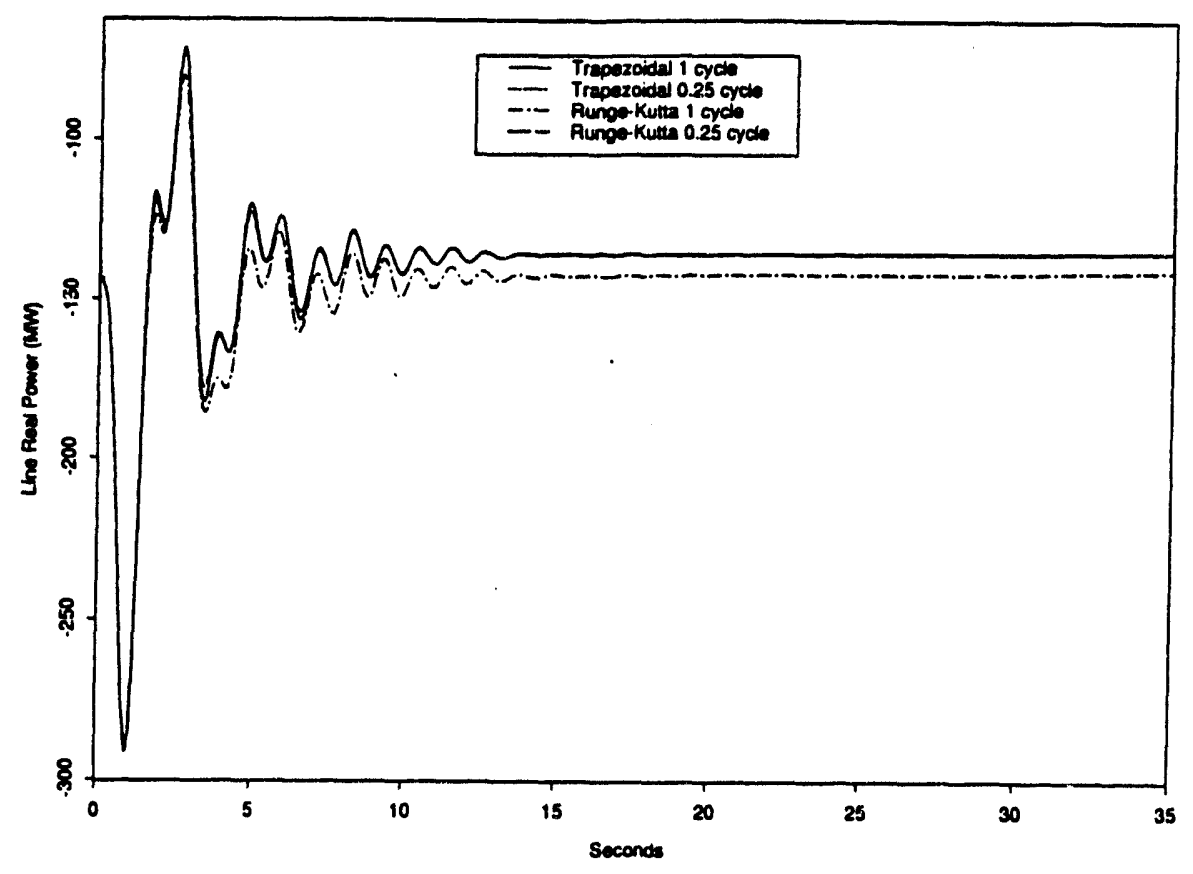

Figure B.3. Case 92LW1T010: Midway - Vincent Line Real Power

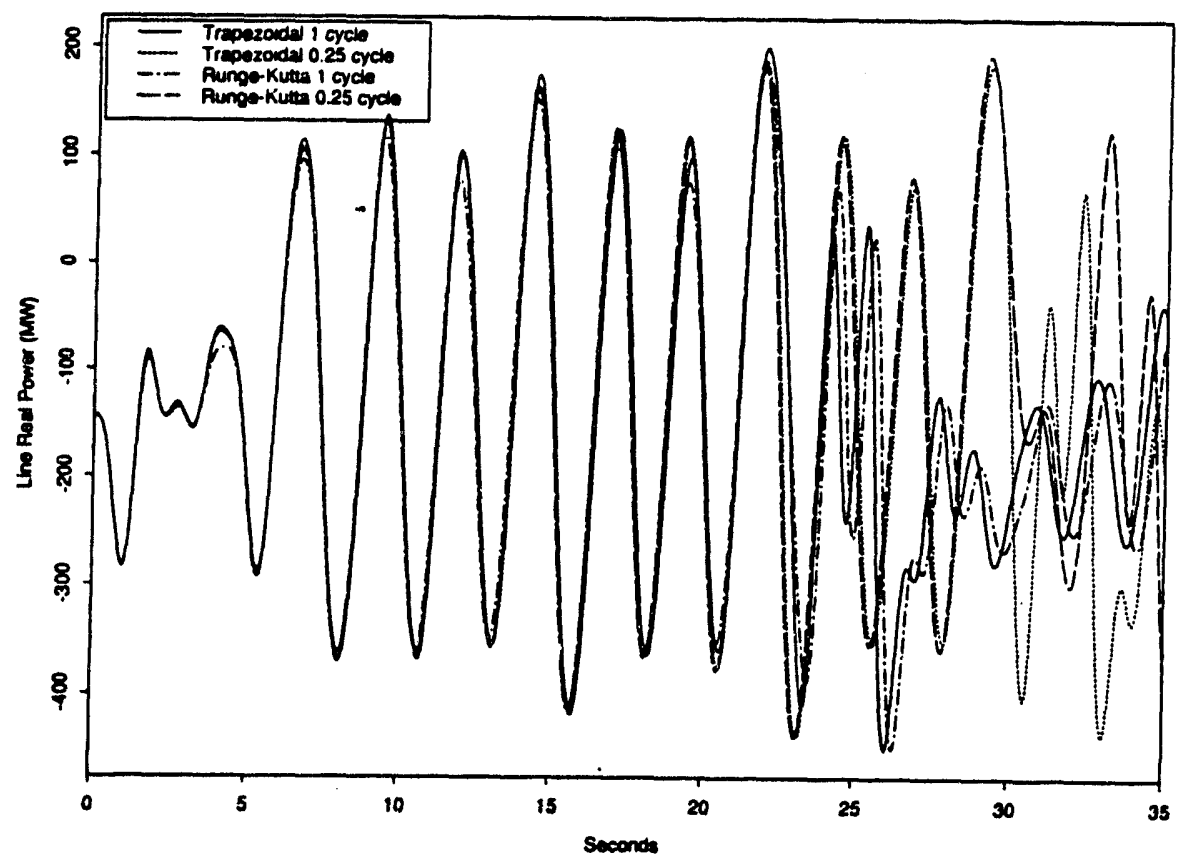

Figure B.4. Case 92LW1T012: Midway - Vincent Line Real Power

\section{B.4}




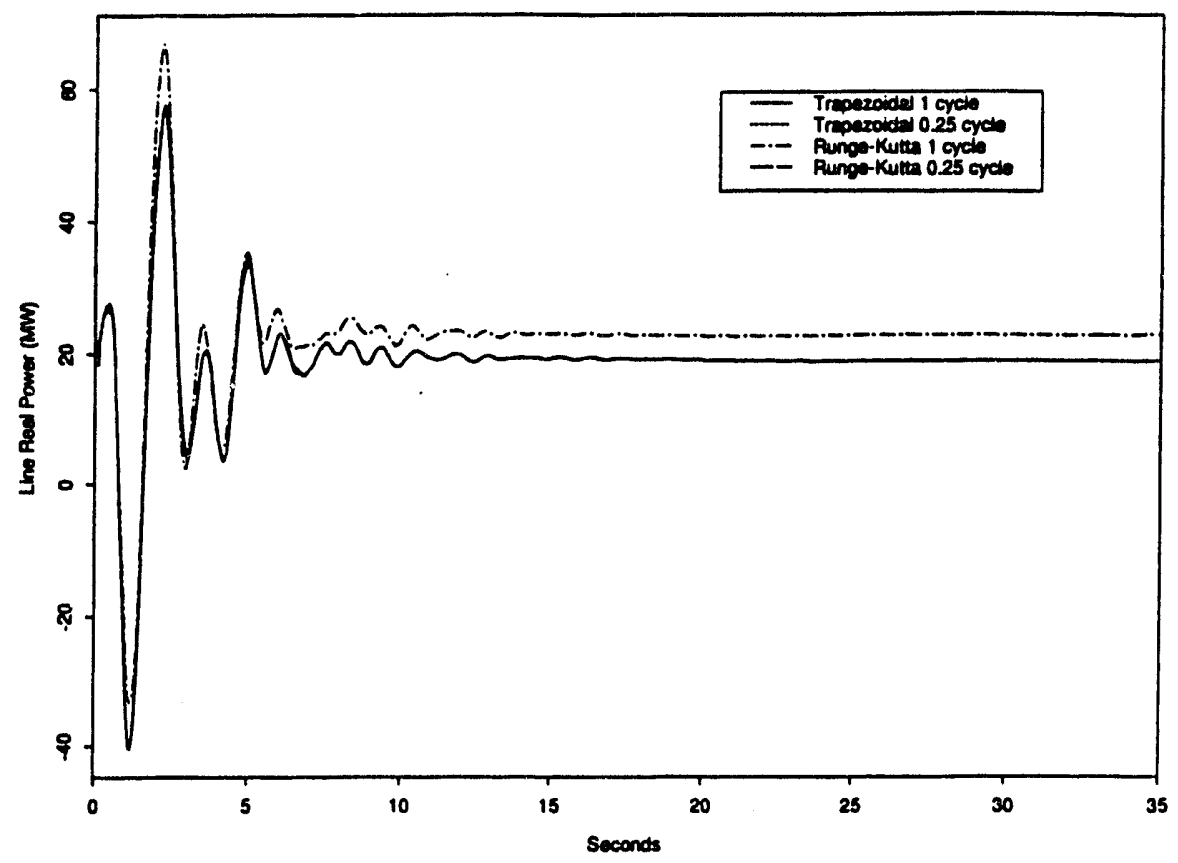

Figure B.5. Case 92LW1T010: Nelway - Boundary Line Real Power

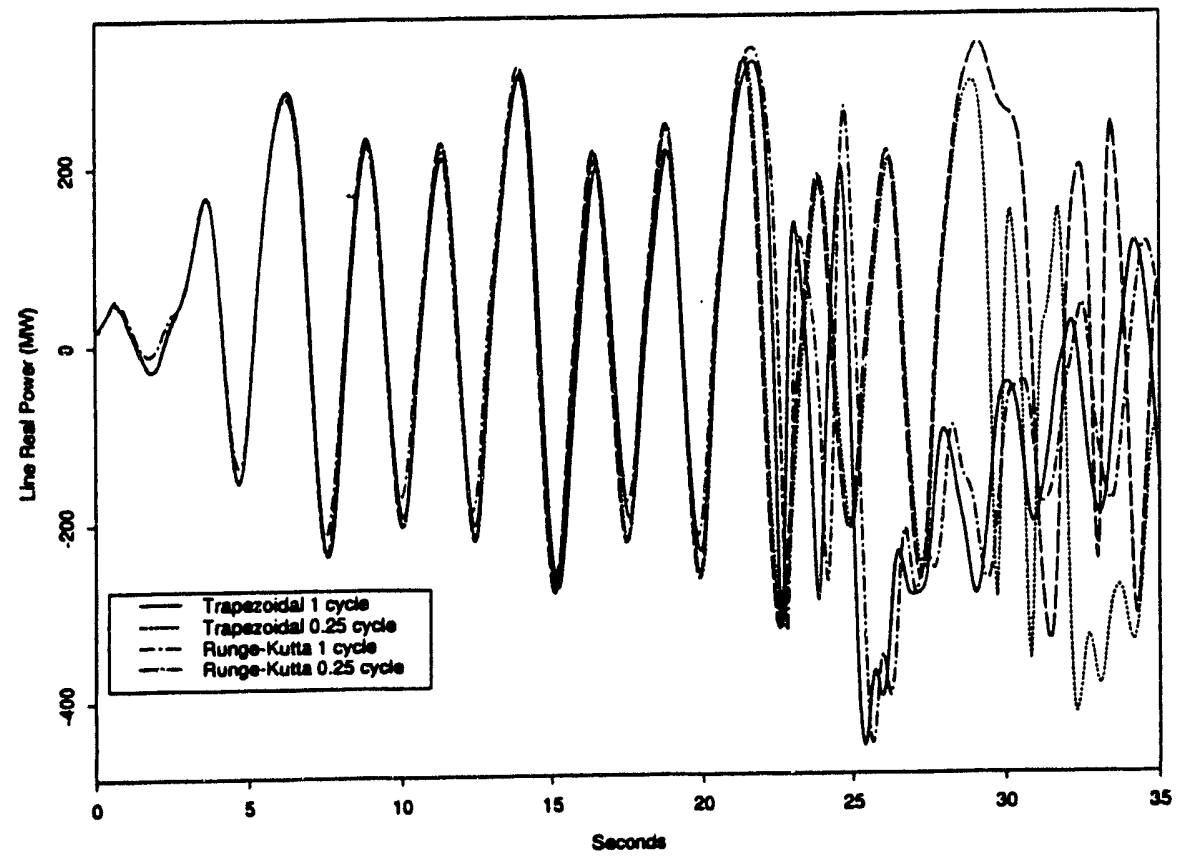

Figure B.6. Case 92LW1T012: Nelway - Boundary Line Real Power 


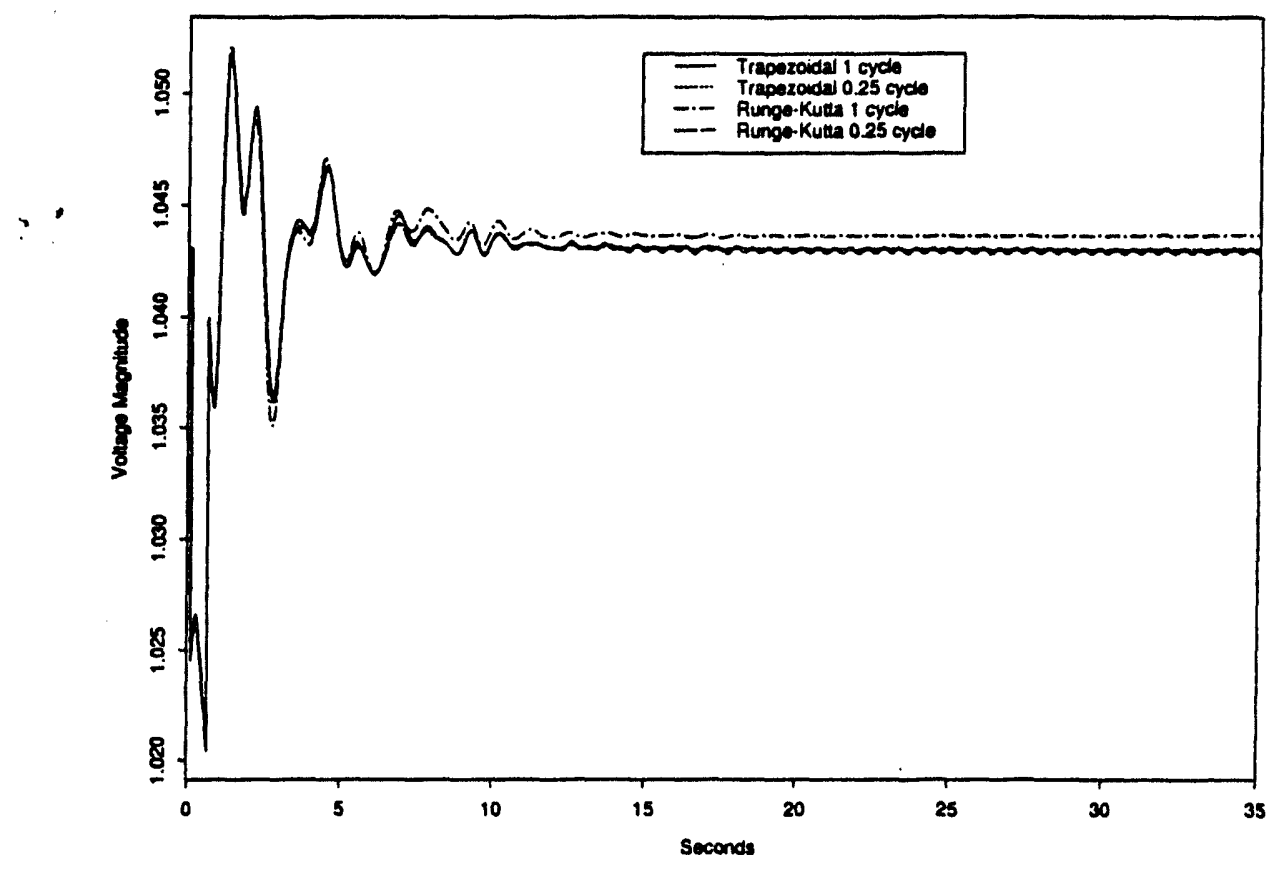

Figure B.7. Case 92LW1T010: Chief Joseph Bus Voltage

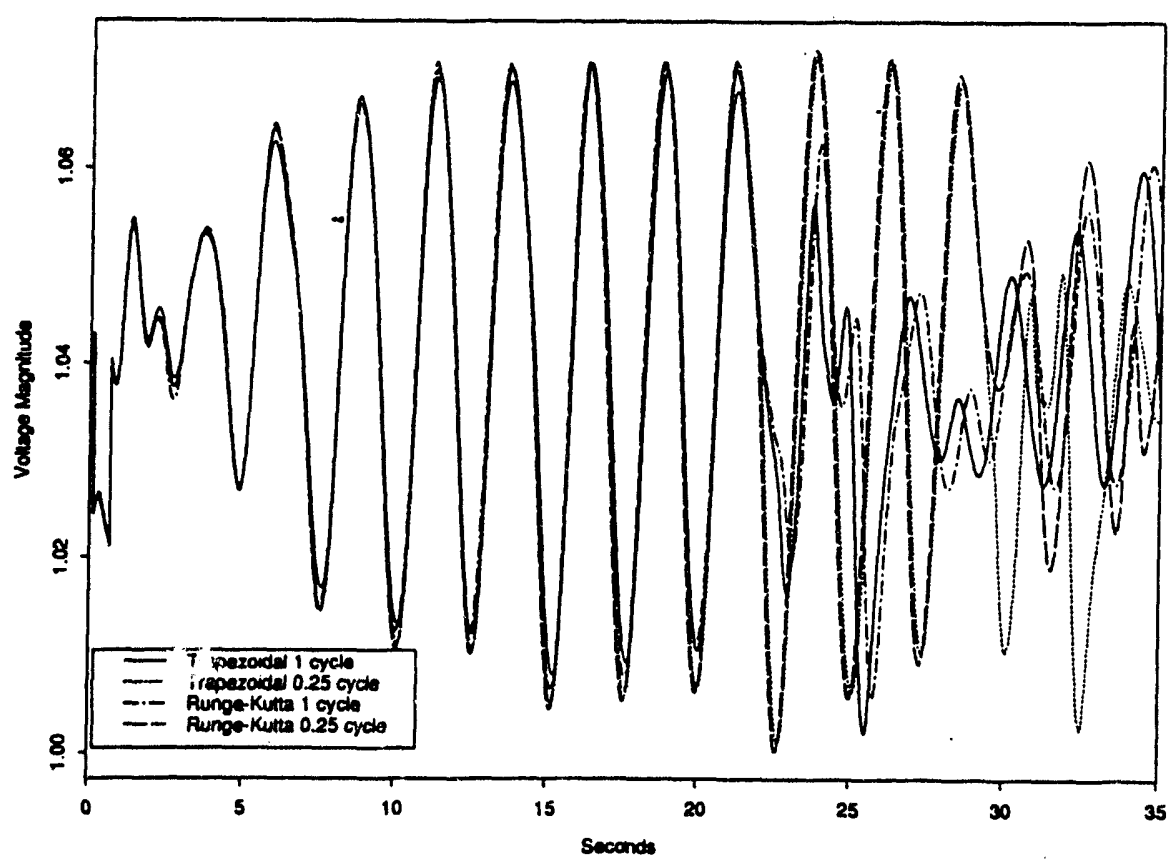

Figure B.8. Case 92LW1T012: Chief Joseph Bus Voltage

B. 6 


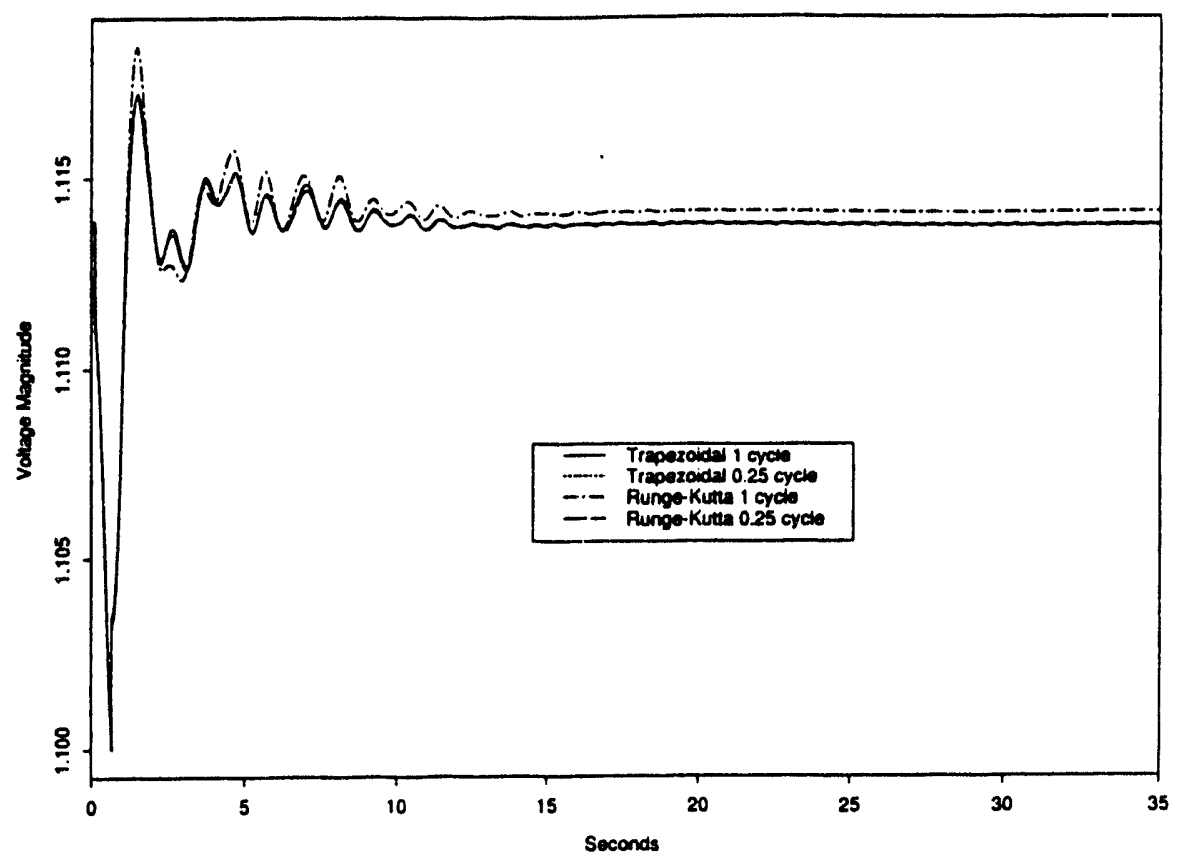

Figure B.9. Case 92LW1T010: Malin Bus Voltage

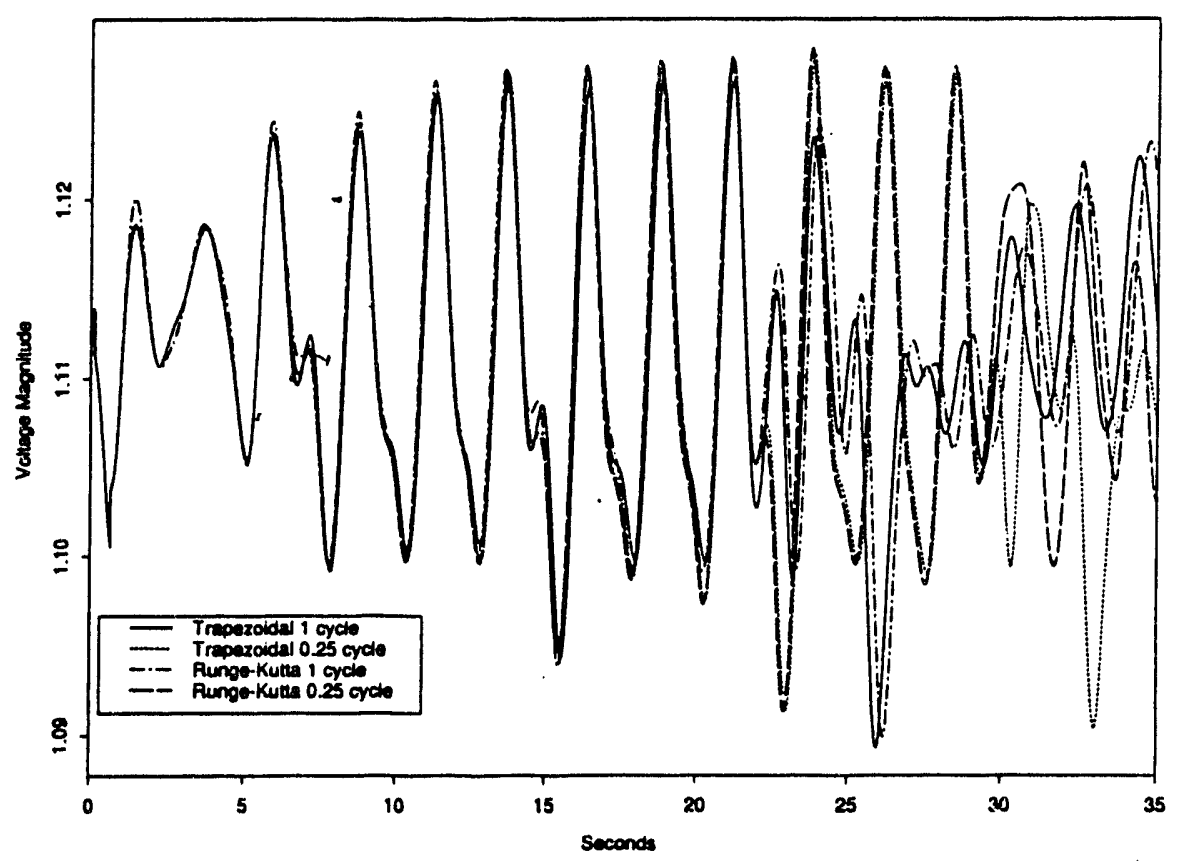

Figure B.10. Case 92LW1T012: Malin Bus Voltage

B. 7 

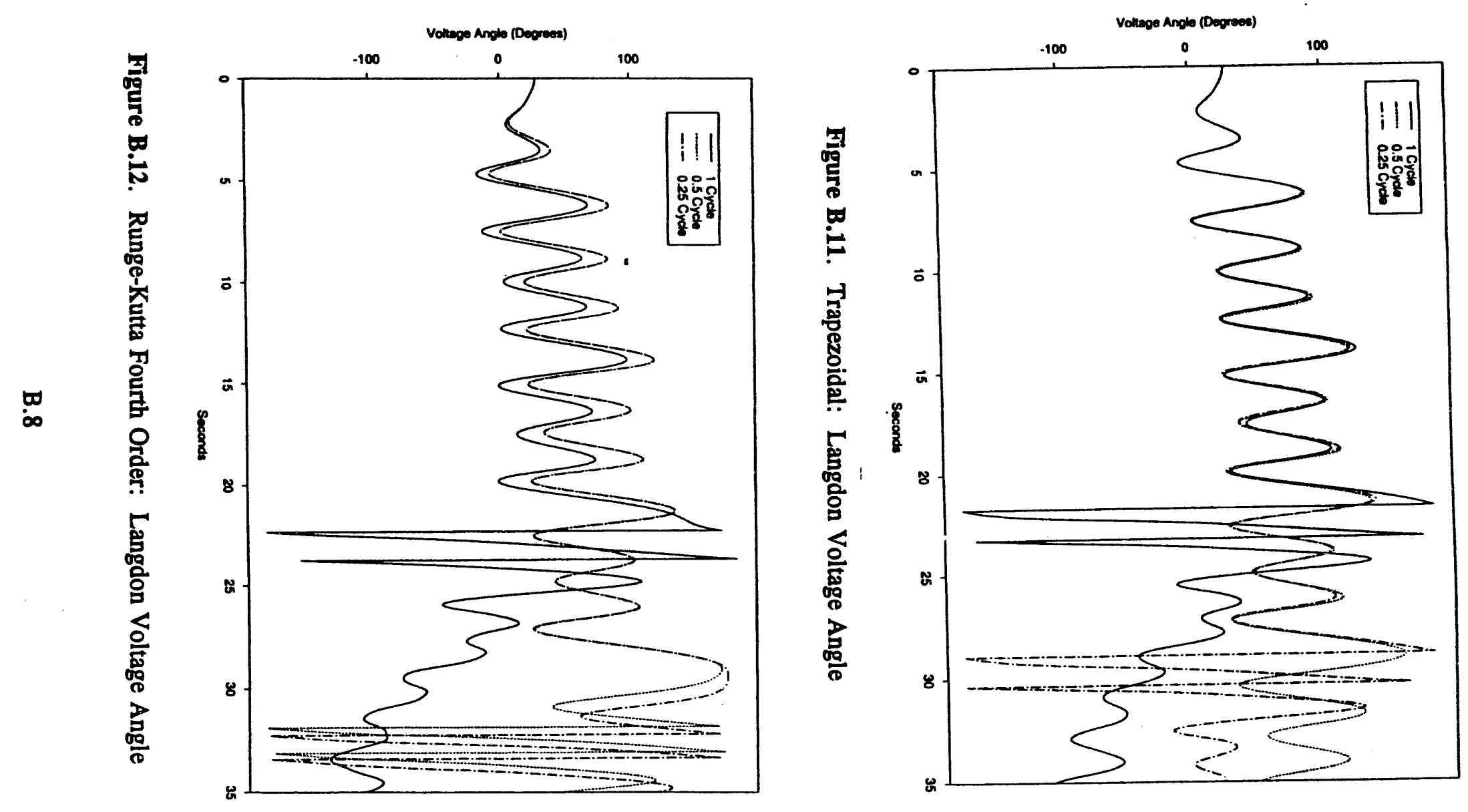

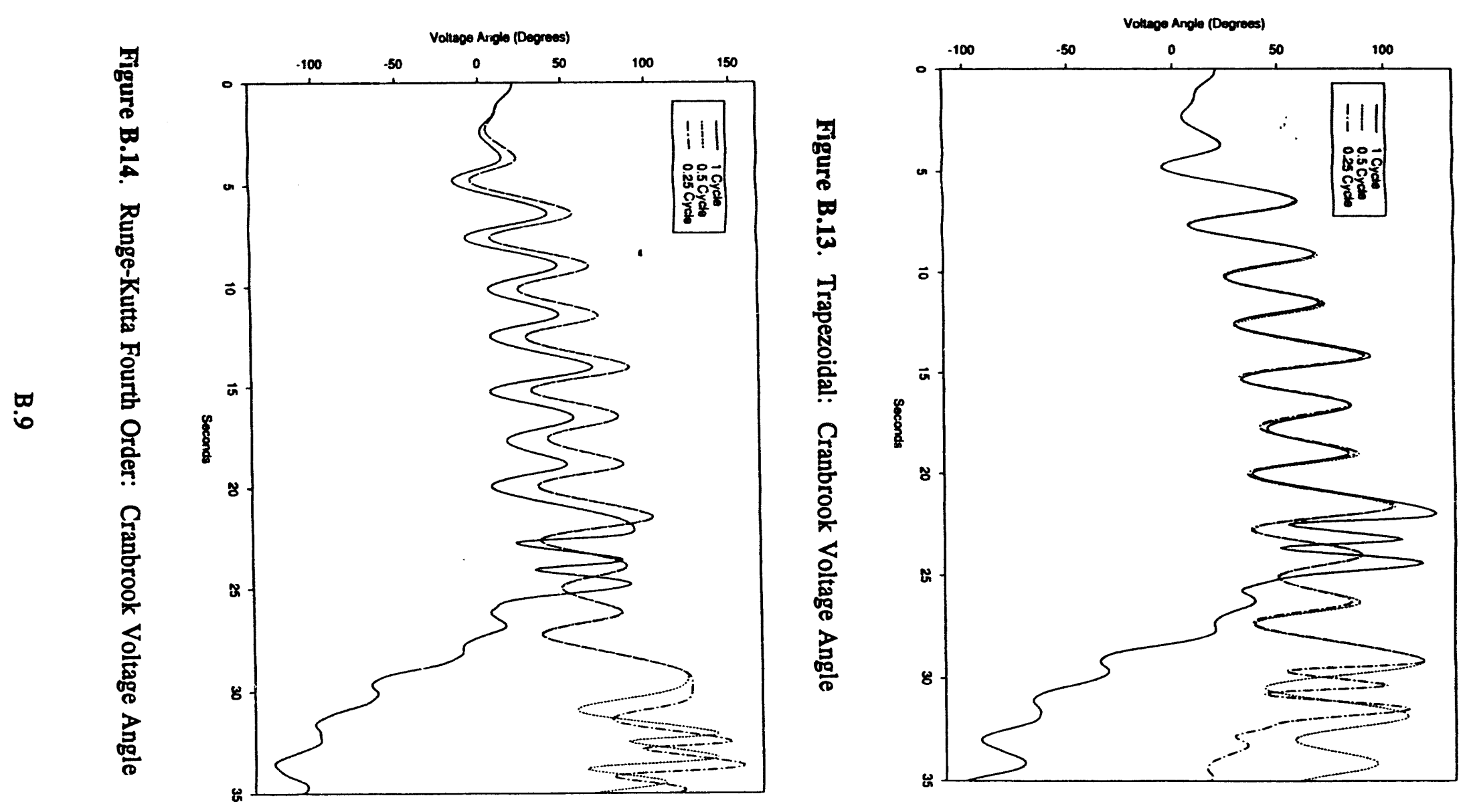


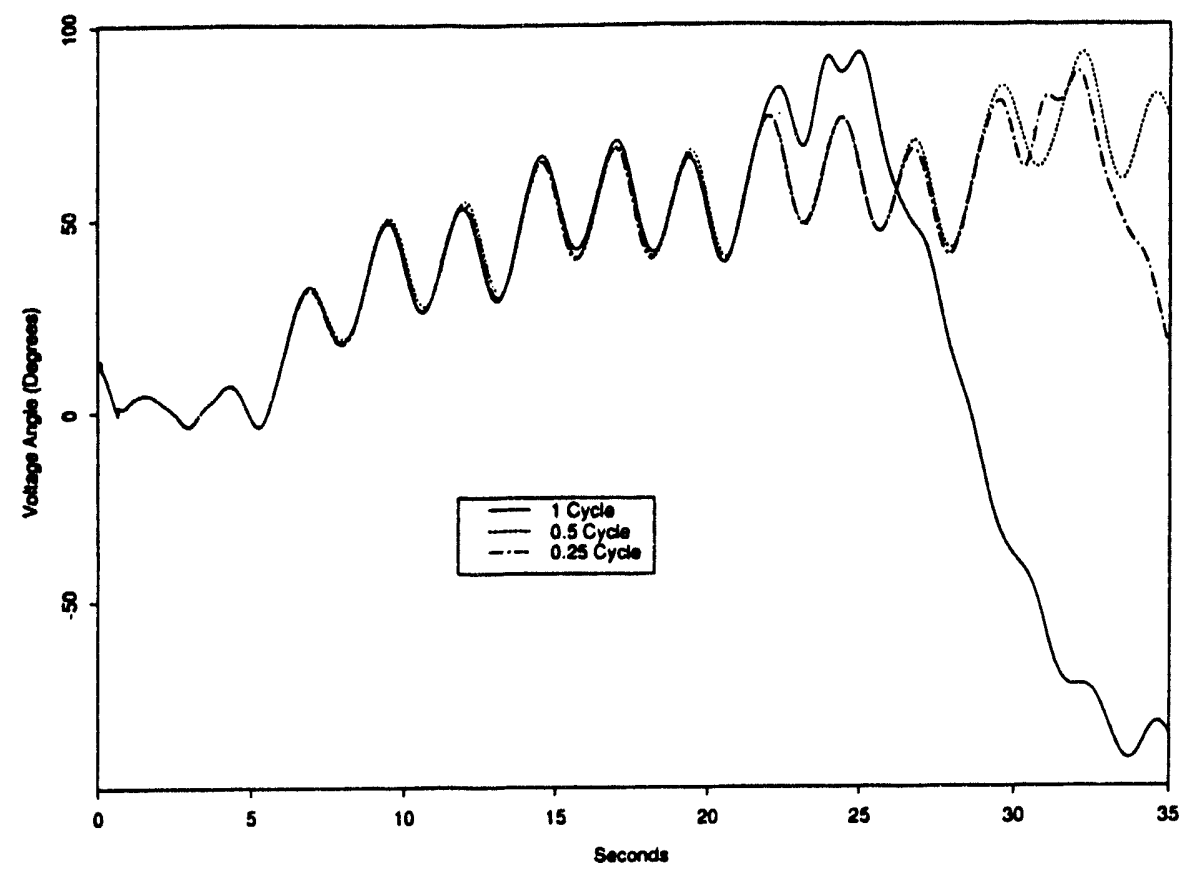

Figure B.15. Trapezoidal: Chief Joseph Voltage Angle

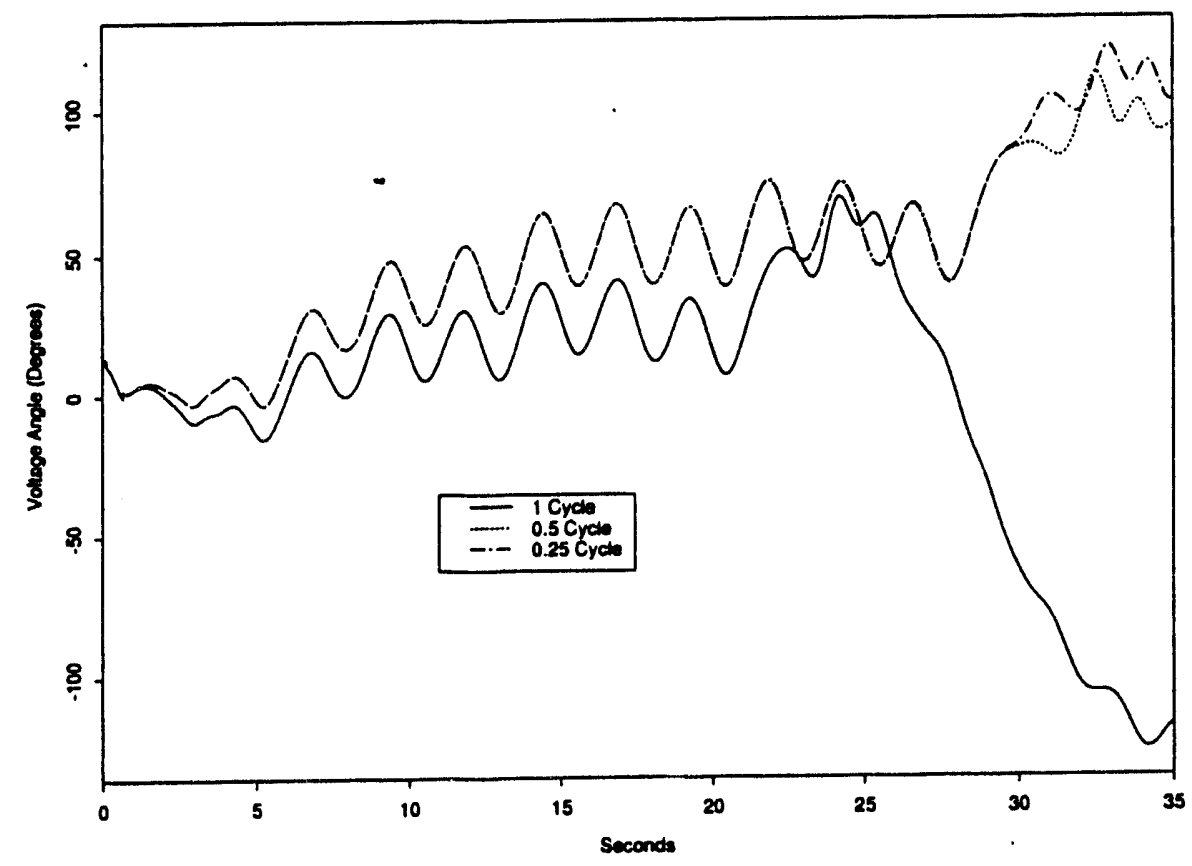

Figure B.16. Runge-Kutta Fourth Order: Chief Joseph Voltage Angle 


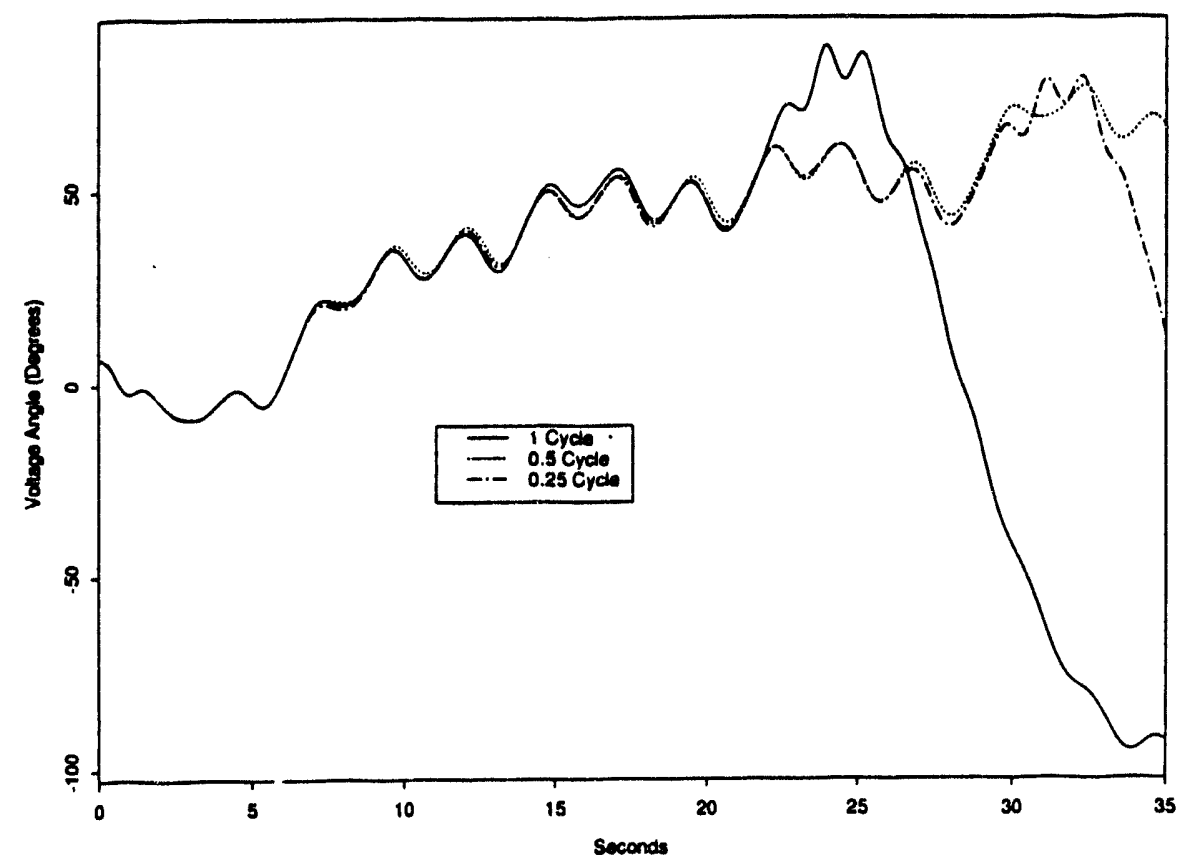

Figure B.17. Trapezoidal: Malin Voltage Angle

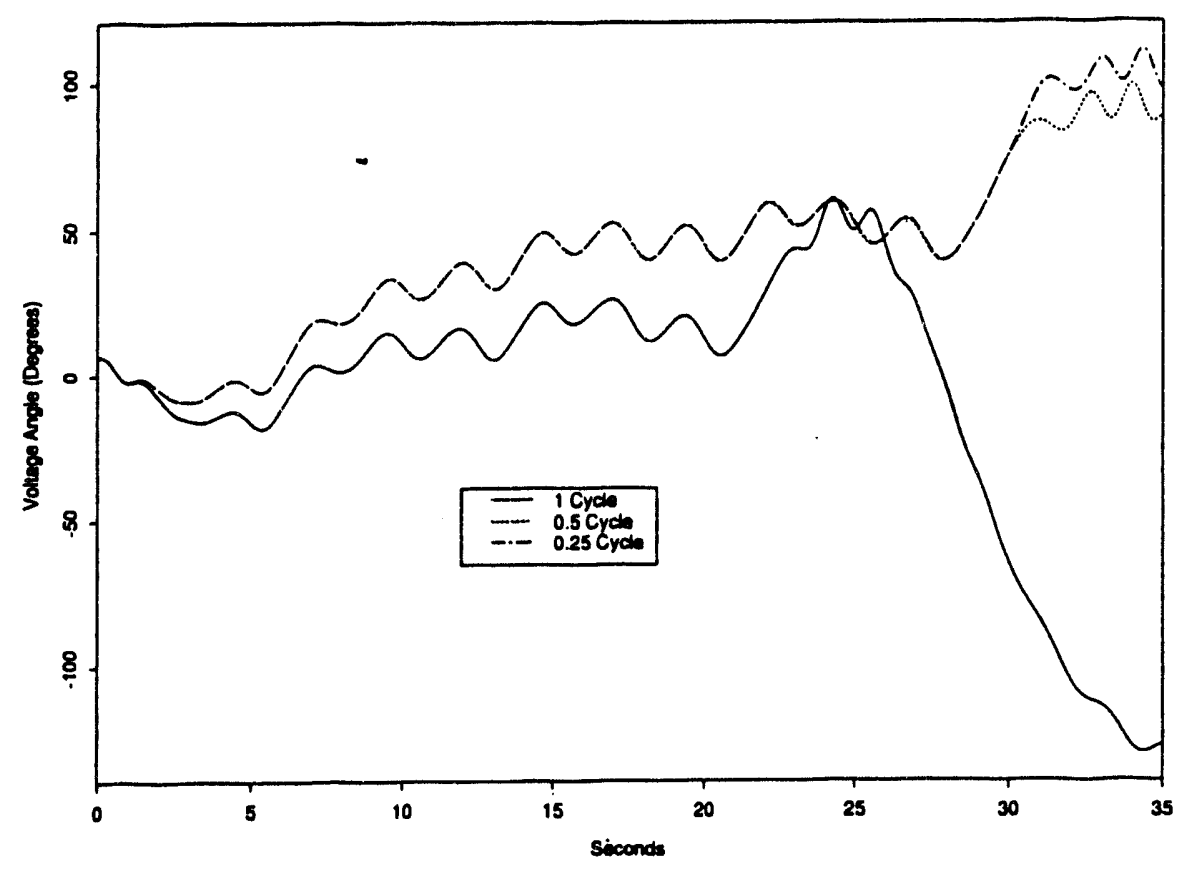

Figure B.18. Runge-Kutta Fourth Order: Malin Voltage Angle

B. 11 
This unstable TransAlta mode was further investigated using SSSP. Table B.1 shows the modes associated with case with Kemano and TransAlta included. There is an unstable mode at $0.4115 \mathrm{~Hz}$ in the model, with the Sundance unit in Alberta having the highest participation factor. An improperly tuned Power System Stabilizer (PSS) unit is most likely causing the problem, as the Sundance PSS frequency response plot is highly suspicious. The frequency response is shown in Figure B.19, which has a peak gain of around $-70 \mathrm{~dB}$; this is essentially zero (this PSS does not respond at all during the simulation).

As a quick-fix (although it would be desired to have a more accurate representation of the system), various PSS units that may have an effect on this unstable mode were removed from the model. Although taking out several of these PSS units simultaneously solves the problem (and causes the mode to become stable), removing only the MICA PSS unit results in the system becoming stable. The MICA PSS transfer function is dominant in the frequencies near this critical oscillation, with the frequency response shown in Figure B.20. Table B.2 shows the modes associated with the system with the Mica PSS removed.

Table B.1. Baseline Eigenvalues $(0.4$ to $1.2 \mathrm{~Hz})$

Eigenvalue No.

1

2

3

4

5

6

7

8

9

10

11

12

13

14

15

16

17

18

19

20

21
Eigenvalues

0.031793

$-0.550600$

$-0.910008$

$-0.735506$

$-0.304851$

$-0.500903$

$-0.334013$

$-0.325354$

$-0.346598$

$-0.447219$

$-0.107359$

$-0.219143$

$-0.229413$

$-0.416842$

$-0.000139$

$-0.392584$

$-0.237827$

$-0.147612$

$-0.207489$

$-0.205037$

$-0.180065$
2.585402

3.546794

3.585068

3.639863

4.061625

4.933099

5.245400

5.535364

5.934849

6.197538

6.288604

6.426512

6.613640

6.677500

6.711123

7.018583

7.036613

7.184696

7.289099

7.331206

7.499180
Frequency $(\mathrm{Hz})$

0.4115

0.5645

0.5706

0.5793

0.6464

0.7851

0.8348

0.8810

0.9446

0.9864

1.0009

1.0228

1.0526

1.0628

1.0681

1.1170

1.1199

1.1435

1.1601

1.1668

1.1935
Damping Ratio

$-0.0123$

0.1534

0.2460

0.1981

0.0748

0.1010

0.0635

0.0587

0.0583

0.0720

0.0171

0.0341

0.0347

0.0623

0.0000

0.0558

0.0338

0.0205

0.0285

0.0280

0.0240 

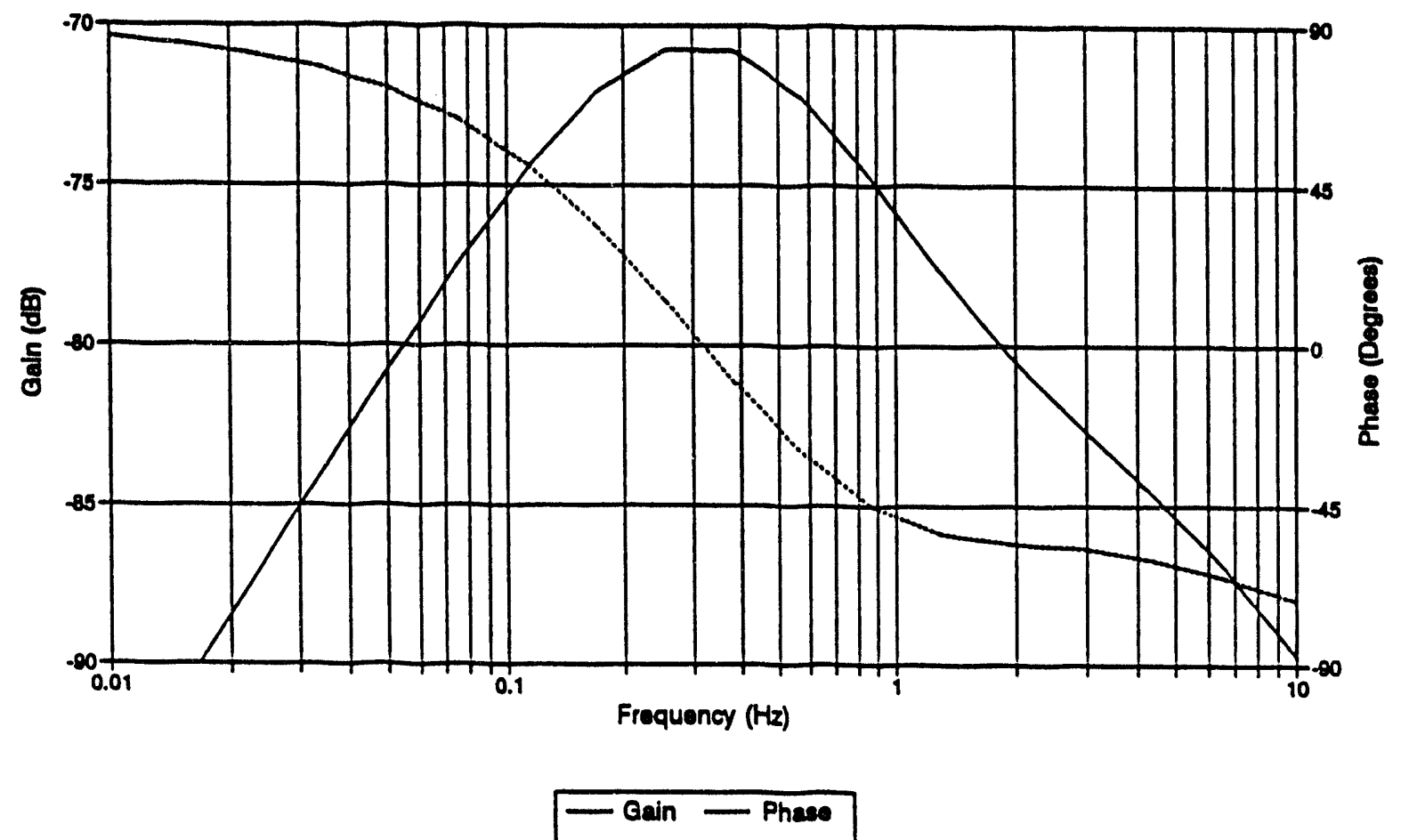

Figure B.19. Frequency Response of Sundance PSS
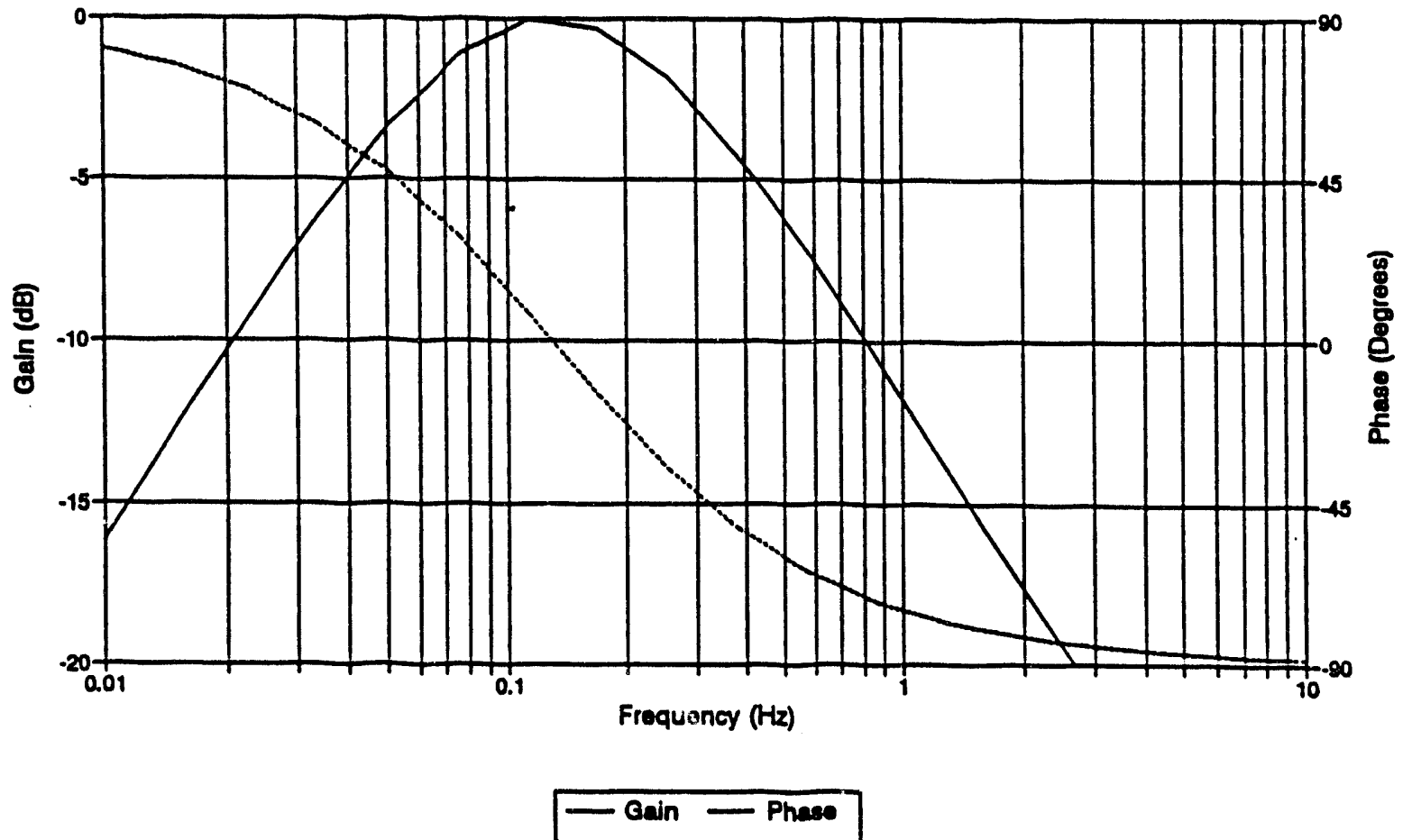

Figire B.20. Frequency Response of Mica PSS

B. 13 
Table B.2. Eigenvalues with MICA PSS Removed $(0.4$ to $1.2 \mathrm{~Hz})$

Eigenvalue No.

Eigenvalues

Erequency (Hz)

Damping Ratio

$\begin{array}{rrrrr}1 & -0.017568 & 2.614276 & 0.4161 & 0.0067 \\ 2 & -0.540424 & 3.544647 & 0.5641 & 0.1507 \\ 3 & -0.906217 & 3.584653 & 0.5705 & 0.2451 \\ 4 & -0.733878 & 3.643082 & 0.5798 & 0.1975 \\ 5 & -0.312305 & 4.054471 & 0.6453 & 0.0768 \\ 6 & -0.268386 & 4.933061 & 0.7851 & 0.0543 \\ 7 & -0.328568 & 5.239899 & 0.8340 & 0.0626 \\ 8 & -0.293081 & 5.554813 & 0.8841 & 0.0527 \\ 9 & -0.344231 & 5.929926 & 0.9438 & 0.0580 \\ 10 & -0.447391 & 6.197650 & 0.9864 & 0.0720 \\ 11 & -0.107363 & 6.288632 & 1.0009 & 0.0171 \\ 12 & -0.215105 & 6.419862 & 1.0218 & 0.0335 \\ 13 & -0.229549 & 6.613502 & 1.0526 & 0.0347 \\ 14 & -0.416835 & 6.677500 & 1.0628 & 0.0623 \\ 15 & -0.000212 & 6.711140 & 1.0681 & 0.0000 \\ 16 & -0.237846 & 7.036592 & 1.1199 & 0.0338 \\ 17 & -0.340315 & 7.137027 & 1.1359 & 0.0476 \\ 18 & -0.146045 & 7.172607 & 1.1416 & 0.0204 \\ 19 & -0.207570 & 7.289266 & 1.1601 & 0.0285 \\ 20 & -0.205670 & 7.330961 & 1.1668 & 0.0280 \\ 21 & -0.180064 & 7.499187 & 1.1935 & 0.0240\end{array}$

The desired approach for cleaning up the large planning model would be to investigate specific items that appear to be inconsistent with the actual system, such as the Sundance PSS unit. Barring this, it would be possible to either remove or change specific items in the model (as in this case with the MICA PSS removed) that are known to cause spurious results, or to design specific work-arounds to adjust the model response to match more closely with actual system responses (designing a new PSS unit for the Sundance unit is an example where known deficiencies could be compensated by taking specific action). Addressing these issues is beyond the scope of this study. All simulations performed with the 92LW Model as described in the body of this report (Section 4) used the 92LW1T010 case, in which the Kemano station and TransAlta system were removed, thus yielding a stable model in which the MTDC model was incorporated.

\section{Summary}

This appendix addressed several aspects of the 92LW Model accuracy. Of chief importance among the analysis is that eigenanalysis results provide an indication of an unstable mode associated with the Alberta system under the conditions simulated by the model. Notwithstanding the highly suspect nature of some of the data that is causing the unstable mode (and if corrected may result in a stable base case), a systematic approach was applied that identified one key change to one PSS that brought the system stable again. Although this change is not recommended (as it is not representative 
of the actual power system), it can be an effective work-around for analyzing this case without the instabilities corrupting the results as a result of a unstable base case.

Another important aspect of the 92LW Model addressed in this appendix is the integration step size sensitivity, which indicates that using the Trapezoidal integration method with step sizes on the order of 1 cycle can lead to significant error under certain conditions. It is recommended that the Runge-Kutta integration method be employed with a step size of no larger than 0.5 cycle to verify any results obtained with a Trapezoidal method (and/or with a larger step size).

\section{Reference}

Kundur, P., D. Y. Wong, G. J. Rogers, L. Wang, and S. Arabi. 1993. Extended Transient-Midterm Stabllity Program: Version 3.0. TR-102004, Electric Power Research Institute, Palo Alto, California. 


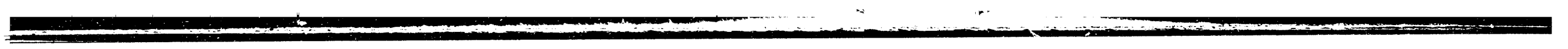




\section{Appendix C}

\section{Software}

1. FLODA5_M.FOR Modified FLODA5 module for MASS version 3.0.

2. FLODA5_P.FOR Modified FLODA5 module for PEALS version 3.0.

3. 17MACHDC.PFI Reduced-order power flow input with MTDC model with changes made to correct equal eigenvalue error associated with PEALS.

4. 17MACHDC.DYN Reduced-order dynamic data file with MTDC model with changes made to correct initialization errors in the model. 


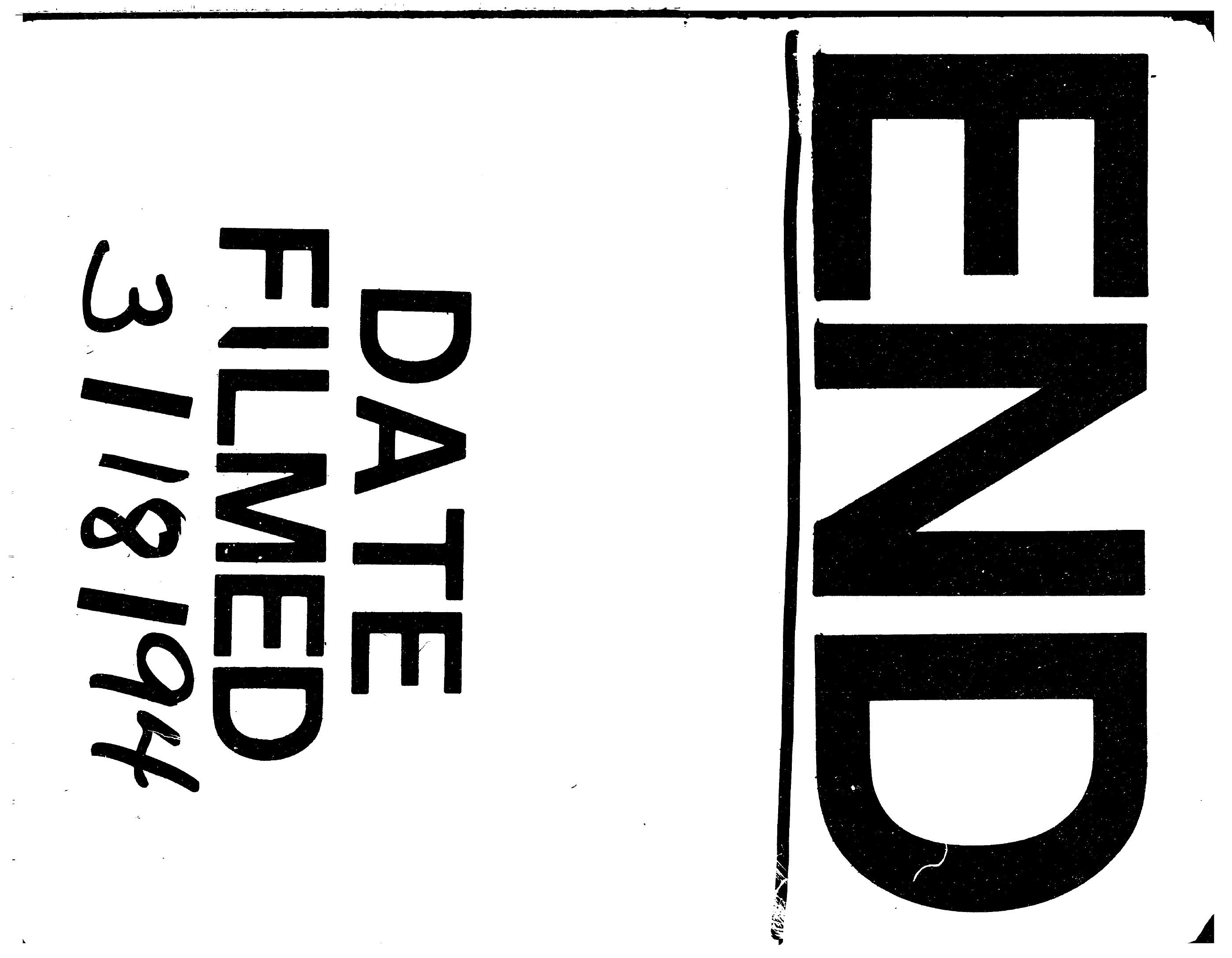


